\author{
Universidade de São Paulo \\ Instituto de Física
}

\title{
Estudo de um sistema bidimensional formado por rede de antipontos para a engenharia de dispositivos em spintrônica
}

\author{
Julio César Bolaños Pomayna
}

Orientador: Prof. Dr. Guennadii Michailovich Gusev

\author{
Dissertação de mestrado apresentada \\ ao Instituto de Física para a obtenção \\ do título de Mestre em Ciências
}

\section{Banca Examinadora:}

Prof. Dr. Guennadii Michailovich Gusev (IFUSP)

Prof. Dr. Luís Gregório Godoy de Vasconcellos Dias da Silva (IUSP)

Prof. Dr. Américo Sheitiro Tabata (UNESP)

São Paulo 
FICHA CATALOGRÁFICA

Preparada pelo Serviço de Biblioteca e Informação do Instituto de Física da Universidade de São Paulo

Bolaños Pomayna, Julio César

Estudo de um sistema bidimensional formado por rede de antipontos para a engenharia de dispositivos em spintrônica. São Paulo, 2013.

Dissertação (Mestrado) - Universidade de São Paulo. Instituto de Física. Depto. de Física dos Materiais e Mecânica

Orientador: Prof. Dr. Guennadii Michailovich Gusev

Área de Concentração: Física

Unitermos: 1. Poços quânticos; 2. Estrutura eletrônica; 3. Campo magnético; 4. Spintrônica; 5 . Rede de antipontos 
Al Dios todopoderoso, a mis padres Demetrio y Regina, a mis hermanos Wilmer, Moises y Miguel y a Jessica. 


\section{Agradecimentos}

Ao prof. Dr. Gennady Gusev por aceitarme como o seu aluno e pela orientação no trabalho realizado nesta dissertação e pelo ensinamento das técnicas experimentais.

Ao prof. Dr. Alexandre Levine pelo ensinamento e o seus conselhos no tratamento dos dados experimentais.

Ao prof. Dr. Nilo Mauricio Sotomayor Choque pelo apoio e amizade na realização deste trabalho.

Ao prof. Dr. Felix pela sua ajuda na correção deste trabalho.

Ao Sr. Francisco de Paula Oliveira "Paulinho"pela sua ajuda com o criostato.

A Tatiana Lacerda Costa, secretaria do LNMS (Laboratório de Novos Materiais Semicondutores) pelo seu apoio com a documentação e informações necessárias para fazer os tramites no CPG.

Agradeço ao meu amigo Niko Churata Mamani pelo seu apoio e amizade na chegada a este Laboratório, e pela ajuda na correção deste trabalho.

Aos meus queridos pais, Demetrio e Regina, pelos seus apoios, conselhos e orações; aos meus irmãos Wilmer, Moises e Miguel pelo seu apoio e amizade ao longo da minha vida; as minhas queridas sobrinhas Isabel, Noemi e Abigail que são a alegria da mi minha casa em Chimbote; as minhas cunhadas Marina e Edith pela sua amizade.

A Jessica pelo seu amor, carinho, apoio e o seu grande compressão em todos estes anos.

Aos meus amigos da sala Edgar Fernando Aliaga Ayllon, Bruno Anghinoni, André Luis dos Santos, Abdur Rahim, Juan Pablo Badilla Orozco, Bruno Silveira de Lima Honda, Dennis Brenes Badilla, Jorge Augusto Leon Erasi, Victor Manotas, Giovanni, Rafael Ribeiro Oliveira pela amizade en todos este anos. 
Agradeço a meus amigos Gerson Pessotto e Victor pela sua ajuda na correção deste trabalho.

Ao Laboratório de Novos Materiais Semicondutores do Instituto de Física da USP, por permitir a conclusão deste trabalho. 


\section{Resumo}

Neste trabalho, apresentamos estudos sobre o magnetotransporte em um sistema de bicamadas com uma rede de antipontos triangulares em campos magnéticos baixos sob a aplicação de campos elétricos externos, que são produzidos por voltagens de porta. A bicamada é feita em poços quânticos largos (wide quantum well) de alta densidade eletrônica, formado em heteroestruturas semicondutoras de $A l_{x} G a_{1-x} A s / G a A s$. Oscilações magneto-inter-sub-banda (MIS) são observadas em poços quânticos largos de alta densidade eletrônica com duas sub-bandas ocupadas. Estas são originadas pelo espalhamento inter-sub-bandas e tem um máximo para campos magnéticos $\mathrm{B}$ que satisfazem a condição de alinhamento entre os leques dos níveis de Landau de cada sub-banda. Oscilações de comensurabilidade são observadas na magnetoresistência que é sensível ao arranjo do potencial dos antipontos. A aplicação de campos elétricos faz diminuir o número de oscilações na magnetoresistência para campos magnéticos compreendidos entre $0,1 T$ e 0,4T, observando-se uma transição das oscilações MIS aos efeitos de comensurabilidade. Aplicando voltagens de porta podemos variar a amplitude do potencial dos antipontos. 


\section{Abstract}

In this work, we present studying about magnetotransport in a bilayer system with triangular antidot lattices in low magnetic fields under the application of external electric field. The bilayer forms inside a wide quantum well of high electron density in semiconductor heterostructures formed by $A l_{x} G a_{1-x} A s / G a A s$. Magneto-inter-subband (MIS) oscillations are observed in a wide quantum wells of high electron density with two subbands occupied, and they are caused by intersubband scattering and have a maximum for a magnetic field $B$ that satisfies the alignment condition between the staircase of Landau level. Commensurability oscillations are observed in magnetoresistance, which is sensitive to the potential of antidot arrangements. The application of electric fields decrease the number of oscillations in the magnetoresistance for magnetic fields between $0,1 T$ and $0.4 T$, showing a transition of MIS oscillations to commensurability oscillations. We varied the amplitude of the potential of the antidots applying different gate voltages. 


\section{Sumário}

Lista de Figuras $\quad$ xiii

Lista de Tabelas $\quad$ xix

Introdução $\quad$ xxi

1 Conceitos fundamentais $\quad 1$

1.1 O Sistema Bidimensional de Elétrons . . . . . . . . . . . . . . . . . 1

1.1.1 Gás Bidimensional de Elétrons . . . . . . . . . . . . . 5

1.1.2 Estructura Eletrônica em Campo Magnético Perpendicular . . . . . 7

1.2 Transporte Semiclássico . . . . . . . . . . . . . . . . . 10

1.2.1 Equação de Bolztmann . . . . . . . . . . . . . . . . . 10

1.2.2 Modelo de Drude . . . . . . . . . . . . . . . . . 10

1.2.3 Escalas de Comprimento Relevantes . . . . . . . . . . . . . 11

1.2 .4 O Efeito Hall Ordinário . . . . . . . . . . . . . . 15

1.3 Transporte Quântico num 2DEG . . . . . . . . . . . . . 17

1.3.1 O Efeito Shubnikov-de Haas . . . . . . . . . . . . . . . 17

1.3 .2 Efeito Hall Quântico Inteiro . . . . . . . . . . . . . . . . . 19

1.3.3 Efeito Hall Quântico Fracionário . . . . . . . . . . . . . . . 25

1.4 Bicamadas . . . . . . . . . . . . . . . . . . 27

1.4.1 Níveis de Energia de uma Bicamada e Cruzamento dos Níveis de Landau em um Campo Magnético Perpendicular . . . . . . . . . . . 30

1.4.2 Espalhamento Magneto-Inter-sub-banda . . . . . . . . . . . . . . 31

1.4.3 Oscilações MIS em um Poço Quântico Duplo . . . . . . . . . . . 35

2 Redes de Antipontos Quânticos $\quad 37$

2.1 Introdução . . . . . . . . . . . . . . . . . . . . 37

2.2 Redes de Antipontos . . . . . . . . . . . . . . . . . 38

2.2.1 Picos de Comensurabilidade . . . . . . . . . . . . . . 40

2.2.2 Focalização Magnética e Órbitas Difusivas . . . . . . . . . . . . 43

2.2.3 Redes de Antipontos Triangulares . . . . . . . . . . . . . . . . 49

2.2.4 Oscilações Altshuler-Aronov-Spivak . . . . . . . . . . . . . . . 51 
3 Métodos Experimentais $\quad 55$

3.1 Descrição do Sistema . . . . . . . . . . . . . . . . . 55

3.2 Processamento das amostras . . . . . . . . . . . . . . . . 57

3.2.1 Deposição da camada fotoresistiva . . . . . . . . . . . . . 57

3.2.2 Gravação do Padrão da Super-rede de Antipontos . . . . . . . . . . 58

3.2 .3 Gravação da Barra Hall . . . . . . . . . . . . . . . . . . 61

3.2.4 Colocação dos Contatos Ôhmicos e da Porta Metálica . . . . . . . . 63

3.3 Equipamento Básico para o Estudo do magnetotransporte a baixas tempe-

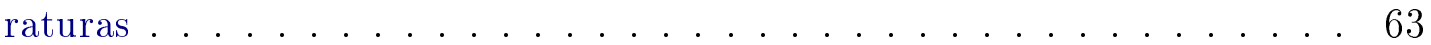

3.3 .1 Criostato de ${ }^{4} \mathrm{He} \ldots \ldots \ldots \ldots$. . . . . . . . . . 63

3.3.2 A Bobina Supercondutora . . . . . . . . . . . . . 67

3.4 Procedimentos Básicos em Medidas de Transporte . . . . . . . . . . . . . 67

3.4.1 Como Fazer as Medidas de Transporte . . . . . . . . . . . . . 67

3.4.2 Parâmetros Básicos de Transporte . . . . . . . . . . . . . 69

4 Resultados Experimentais $\quad 71$

4.1 Amostras empregadas . . . . . . . . . . . . . . . . 71

4.2 Magnetotransporte em Bicamadas com Antipontos . . . . . . . . . . 71

5 Conclusões $\quad 83$

5.1 Sugestões para Pesquisas Futuras . . . . . . . . . . . . . 84

Referências Bibliográficas $\quad 85$ 


\section{Lista de Figuras}

1.1 Tipos de heteroestruturas. (a) Tipo I: os elétrons e buracos estão confinados no mesmo espaço. (b) Tipo II: Os elétrons e buracos estão confinados em diferentes espaços, resultando uma transição indireta no espaço. (c) Tipo III: gap zero. . . . . . . . . . . . . . . . . . .

1.2 Modulação da dopagem nas heteroestruturas. (a) Caso não dopado, onde não existe campo elétrico. Quando a densidade eletrônica é pequena e os buracos são excitados por absorção de fótons, estes ocupam as sub-bandas da banda de condução e da banda de valência, respectivamente, e se recombinam para terminar nos estados inicias. (b) Caso onde as impurezas doadoras dopam uniformemente ambas regiões do poço e da barreira. Os elétrons confinados nas regiões do poço formam estados bidimensionais e estão sujeitos ao espalhamento das impurezas na região do poço, produzindo uma redução na mobilidade dos elétrons a baixas temperaturas. (c) Caso de dopagem por modulação, onde as impurezas doadoras dopam somente as regiões da barreira, e os elétrons confinados nas regiões do poço estão separados das impurezas ionizadas. Portanto, uma alta mobilidade do gás bidimensional de elétrons é obtida. . . . . . . . . . . . .

1.3 Um poço quântico de $A l_{x} G a_{1-x} A s / G a A s / A l_{x} G a_{1-x} A s$ com dopagem por modulação é representado esquemáticamente. Duas sub-bandas são identificadas com energias $E_{z}(1)$ e $E_{z}(2)$. Quando a densidade eletrônica é menor, e se $k_{B} T \ll\left(E_{z}(2)-E_{z}(1)\right)$, somente a última sub-banda será

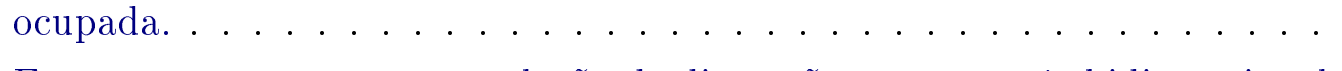

1.4 Esquema que representa a relação de dispersão para um gás bidimensional de elétrons. $k_{\|}$é o vetor de onda no plano $X Y$, e $D(E)$ é a densidade de

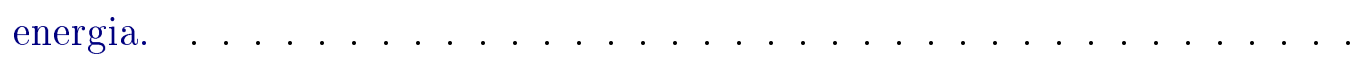


1.5 A densidade de estados de um sistema bidimensional em campo zero (a) e com campo magnético (b)-(d). (b) A densidade de estados são funções delta para valores discretos dos níveis de Landau. (c) A densidade de estados são funções delta com alargamento $\Gamma$ centrado nos níveis de Landau. É mostrada a energia de Fermi $\varepsilon_{F}$ cruzando exatamente no centro do pico do nível de Landau na DOS. (d) Mostra-se o nível de Fermi entre dois picos da DOS. . . . . . . . . . . . . . . . . . . .

1.6 Trajetórias dos elétrons para regimes de transporte difusivo $(l<W, L)$, quase balístico $(W<l<L)$ e balístico $(l>W, L)$ (Galperins, 2009). . . . . 14

1.7 Esquema da configuração de uma medida de magnetotransporte. Uma corrente I é aplicada nos extremos do canal. $R_{x x}$ e $R_{x y}$ servem para identificar os contatos de tensão, onde a magnetoresistência e a resistência de Hall são medidas, respectivamente. Identifica-se por "W"a largura da barra, "T"a espessura e "L"a distância entre contatos longitudinales. . . . . . . . . . . 16

1.8 Oscilações Shubnikov de Haas da resistência $R_{x x}$ de uma heterojunção de GaAs/AlGaAs a temperatura $T=3,8 \mathrm{~K}$. Esta amostra tem uma densidade eletrônica $n_{\text {Hall }}=4.5 \times 10^{11} \mathrm{~cm}^{-2} \ldots \ldots \ldots \ldots \ldots$. . . . . . . 20

1.9 Em campos magnéticos elevados a resistência Hall $R_{x y}$ (curva vermelha) é caracterizada por platôs quantizados $(1 / \nu) h / e^{2}$ para valores inteiros de preenchimento, acompanhado por um desaparecimento longitudinal da magnetoresistência $R_{x x}$ (curva azul) . . . . . . . . . . . . 21

1.10 Energia vs densidade de estados (DOS) de um 2DES. (a) Os LLs representados pelas funções tipo $\delta$. (b) A presença de desordem alarga os níveis. Neste novo espectro de LLs existem os estados localizados e os estados estendidos no centro destes LLs alargados. A localização é essencial para a medição do QHE. . . . . . . . . . . . . . . . .

1.11 Direita: potencial de confinamento para uma amostra de largura W. Esquerda: mapas de contorno do potencial. As áreas vermelhas indicam os estados preenchidos e as áreas brancas os estados vazios. (a) Quando o nível de Fermi, $E_{F}$, cruza a região de estados localizados, os elétrons ocupam apenas vales profundos sem retroespalhamento $\left(R_{x y}\right.$ é quantizada, $R_{x x}=0$ ). (b) Quando $E_{F}$ está no meio de um LL (estados estendidos), o retroespalhamento dos elétrons é a partir de uma borda para a outra $\left(R_{x y}\right.$ não é quantizado, $R_{x} \neq 0$ ). (c) $E_{F}$ cruza a região dos estado localizado de maior energia (acima do estado estendido). A corrente flui sobre os contornos de energia dos topos e dos estados de borda, sem retroespalhamento ( $R_{x y}$ é quantizado, $\left.R_{x x}=0\right)$. 
1.12 Medição do efeito Hall quântico fracionário numa heteroestrutura de GaAs/AlGaAs a temperatura $T=100 \mathrm{mK}$. Os números na figura indicam os fatores de preenchimento (Willett et al., 1987). . . . . . . . . . . . 27

1.13 Perfil da banda de condução de um DQW dopado, que esta constituído por dois poços quânticos e separados por uma barreira de tunelamento de espessura $d_{b}$. Também são indicadas as funções de onda simétrica $\phi_{S} \mathrm{e}$ antisimétrica $\phi_{A S}$, assim como a distância de separação $\Delta Z$ entre as camadas. 29

1.14 Perfil da banda de condução de um WQW, onde um sistema de bicamadas se forma devido à repulsão de Coulomb entre as camadas. Mostra-se as

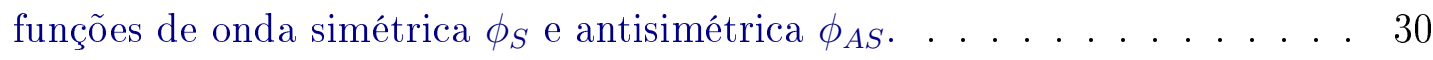

1.15 Representação da formação de dois leques de níveis de Landau, devido à ocupação de duas sub-bandas separadas pela energia $\triangle S A S$. Aumentando o campo magnético os dois leques de níveis penetram-se, originado o cruzamento dos níveis de Landau. Os níveis de Landau são rotulados por três números quânticos: índice da sub-banda, o número quântico orbital e a orientação do spin. . . . . . . . . . . . . . . . . . . . 3

1.16 Representação esquemática das oscilações MIS. Espectro de energias para a primeira e a segunda sub-banda, representados por uma série de níveis de Landau para cada sub-banda ocupada. Quando $\Delta / \hbar \omega_{c}$ é um número inteiro (ou seja, $\delta=0$ ), dois níveis de Landau diferentes são alinhados, resultando um máximo na magnetoresistência. . . . . . . . . . . .

2.1 (a) Uma rede de antipontos. (b)Reflexão elástica de um elétron desde um antiponto. . . . . . . . . . . . . . . . 38

2.2 Diagrama esquemático o efeito de modulação do potencial eletrostático de um arranjo quadrado de antipontos $\operatorname{com} \beta=2$ na equação $2.1 . \quad$. . . . 39

2.3 (Potenciais eletrostáticos num arranjo triangular de antipontos:(a) fraco $\left(\beta=6\right.$ e $\left.U_{0}=1.8 E_{F}\right)$ e (b) forte $\left(\beta=180\right.$ e $\left.U_{0}=80 E_{F}\right)$. As superficies dos potenciais periódicos só são mostrados até o nível de energia de Fermi.

2.4 As resistividades (a) $\rho_{x x}$ e (b) $\rho_{x y}$ para amostras padronizadas com redes de antipontos (linha continua) e para amostras não padronizadas com redes de antipontos (linha pontilhada) em função do campo magnético. Dois picos proeminentes e dois platôs aparecem na resistividade diagonal e de Hall, respectivamente, a campos magnéticos $\sim 0.2 \mathrm{e} \sim 0.6 \mathrm{~T}$ (Weiss et al., 1991).

2.5 Alguns exemplos de órbitas localizadas. $\rho_{x x}$ exibe picos de comensurabilidade a campos magnéticos onde as órbitas do cíclotron clássico rodeiam 1 , 2, 4, 9 e 21 antipontos (Weiss et al., 1991) . . . . . . . . . . 42

2.6 Ilustração esquemática de uma órbita fugitiva que pula regularmente de um antiponto a seu antiponto vizinho na mesma direção (Ando et al., 1997). 43 
2.7 Ilustração esquemática da focalização magnética que conduz ao pico de comensurabilidade fundamental (Ando et al., 1997) . . . . . . . . . . . . . 44

2.8 Alguns exemplos de órbitas ciclotrônicas difusivas que contribuem à migração dos centros guias. Os círculos tracejados correspondem às órbitas localizadas (o número denota a quantidade de antipontos dentro da órbita) (Ando et al., 1997).

2.9 A região (tracejada) do centro das órbitas do cíclotron que passam através de dois antipontos vizinhos muito próximos (Ando et al., 1997). . . . . . . 46

2.10 A área da região onde as órbitas ciclotrônicas passam através de dois antipontos vizinhos. A condutividade diagonal é aproximadamente proporcional ao área (Ando et al., 1997). . . . . . . . . . . . . . . . . . . 47

2.11 Ilustração esquemática de espalhamento de dois antipontos adjacentes. Isto conduz a um aumento de $\left|\sigma_{x x}\right|$ para $2 R_{c}<_{\sim}$ a e uma redução para $2 R_{c}>_{\sim} a$ (Ando et al., 1997). . . . . . . . . . . . . . . . 47

2.12 Alguns exemplos da resistividade e condutividade calculada usando a mecânica clássica para redes de antipontos quadrados (Ishizaka e Ando, 1997a) 48

2.13 Alguns exemplos de órbitas ciclotrônicas difusivas que contribuem à migração dos centros guias numa rede triangular de antipontos. Os círculos tracejados correspondem às órbitas presas (o número denota os antipontos dentro da órbita). A medida das órbitas difusivas tem um dip em torno do campo correspondente a $\left(n_{1}, n_{2}\right)=(2 / 3,2 / 3)$ (Ando et al., 1997). . . . . 49

2.14 Ilustração esquemática das órbitas difusivas que dão origem aos picos de comensurabilidade fundamentais em redes (a) quadradas e (b) triangulares. As órbitas começam a ser perturbadas por outros antipontos para o caso de $d / a$ no caso da rede triangular (Ando et al., 1997) . . . . . . . . . 50

2.15 A região (tracejada) dos centros guias das órbitas ciclotrônicas passam através de dois antipontos vizinhos mais próximos numa rede triangular quando $R_{c}+d / 2 \approx a / \sqrt{3}$ (Ando et al., 1997). . . . . . . . . . . . 50

2.16 Comparação da resistividade de uma rede de antipontos triangular (linha sólida) e quadrada (linha pontilhada) (Nihey et al., 1995) . . . . . . . . . 52

2.17 Condutância de uma rede de antipontos triangular com dimensões $L_{x} \times L_{y}$ como uma função do campo magnético que passa através de uma cela unitária. Fonte: das referências Altshuler et al e Nakanishi e Ando (Altshuler et al. , 1981; Nakanishi e Ando, 1996a) . . . . . . . . . . . . . . 52

2.18 Condutância de uma rede de antipontos triangular na presença de flutuações no diâmetro do antiponto. Fonte: das referências Altshuler et al e Nakanishi e Ando (Altshuler et al., 1981; Nakanishi e Ando, 1996a) . . . . 53 
3.1 Diagrama esquemático de uma heteroestrutura de AlGaA - GaAs mostrando a rede de antipontos triangulares. . . . . . . . . . . . . 56

3.2 Diagrama esquemático mostrando o efeito de modulação do potencial eletrostático devido à presença de uma rede triangular de antipontos. . . . . . 57

3.3 Procedimento empregado para a gravação da barra Hall para as amostras que contém um sistema de bicamadas. . . . . . . . . . . . . . . . 59

3.4 Processo de polimerização da região correspondente ao negativo do padrão da barra Hall. . . . . . . . . . . . . . . . . . . . . . . . . . . . 60

3.5 Desenho da barra Hall para realizar as medidas de voltagens longitudinal e transversal ao fluxo de corrente. $c 1, \ldots, c 6$ indicam as regiões onde vão os contatos elétricos. c1 e c2 são os contatos de corrente; os restantes são contatos de voltagem. O canal de corrente com os contato de voltagem é indicado pela seta vermelha. . . . . . . . . . . . . . . . . .

3.6 Diagrama esquemático do processo de gravação das super-redes de antipontos em amostras contendo uma barra Hall. (1) amostra sem tratamento, (2) gravação do formato da barra, (3) transferência do padrão da barra, obtida por wet etching, (4) gravação da super-rede de antipontos por litografia de feixe eletrônico e dry etching. . . . . . . . . . . . . . . . 6 62

3.7 Passos na colocação de contatos ôhmicos e porta metálica. (a) colocação do contatos ôhmicos de índio, (b) colocação da porta cobrindo a região da barra Hall e finalmente (c) a coloção do contato ôhmico na porta metálica e a fixação dos contatos.

3.8 Criostato usado para realizar medidas de magnetotransporte. O criostato montado com o sistema apropriado para usar um sistema de refrigeração de ${ }^{4} \mathrm{He}$ o qual funciona como um sistema VTI. . . . . . . . . . . . . . 65

3.9 Esquema interno básico do criostato com o sistema de refrigeração baseado no ${ }^{4} \mathrm{He}$

3.10 Esquema do equipamento usado no LNMS para realizar estudos de magnetotransporte. Aqui como um exemplo é mostrado um esquema básico do método de medição da magnetoresistência longitudinal. Parte do sistema é automatizada usando um programa computacional.

3.11 Esquema da barra Hall gravada nas amostras de WQWs para os estudos do transporte são indicados o canal de corrente e os respectivos contatos. São indicadas as dimensões da região de interesse largura do canal $200 \mu \mathrm{m}$ e o comprimento $500 \mu \mathrm{m}$. O fator de forma é dado pela fração do comprimento do canal em relação à largura do canal de corrente, em nossas amostras

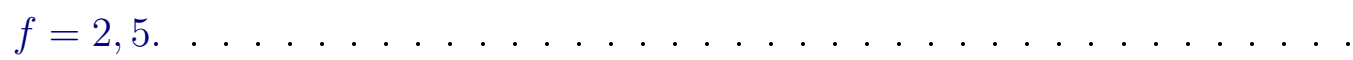


4.1 Magnetoresistência $R_{x x}$ como uma função do campo magnético perpendi-

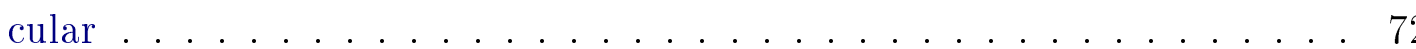

4.2 Magnetoresistência $R_{x x}$ como uma função do campo magnético perpendicular para diferentes voltagens de porta (desde $0 \mathrm{~V}$ até $-4.5 \mathrm{~V}$ ). A magnetoresistência foi medida a baixos campos magnéticos, a temperatura de 1,5K. A magnetoresistência aumenta conforme a magnitude da voltagem de porta aumenta (torna-se mais negativo) e o número de oscilações entre os campos magnéticos de 0,1T até $0,4 T$ diminuem. Dentro da figura mostra-se a forma do poço . . . . . . . . . . . . . . 73

4.3 FFTs das curvas de magnetoresistência onde $f_{1}$ e $f_{2}$ indicam as frequências da primeira e da segunda sub-banda respectivamente, e também mostra-se a frequência MIS $f_{M I S}$ para as diferentes voltagens de porta. . . . . . . . 74

4.4 Densidades eletrônicas da primeira $n_{1}$ e da segunda $n_{2}$ sub-banda. Também mostra-se $n_{M I S}$ que é a freqüência MIS e a diferença entre as densidades das sub-bandas $n_{12}=n_{1}-n_{2} \ldots \ldots \ldots \ldots \ldots \ldots$

4.5 Gráfica 3D onde o eixo $X$ indica o campo magnético, o eixo $Y$ indica a voltagem de porta e o eixo $Z$ indica as medidas da diferença $R_{x x}-R_{x x}(0)$ na magnetoresistência. Se observa que quando a voltagem de porta torna-se mais negativo, as oscilações devido al potencial dos antipontos tornam-se mais importantes. . . . . . . . . . . . . . . . . . . 76

4.6 Oscilações MIS, $k$ indica os picos correspondentes à condição de ressonância. A curva foi obtida para uma voltagem de porta de $V_{g}=0 \mathrm{~V}$ a $\mathrm{T}=1.5 \mathrm{~K} .77$

4.7 Oscilações MIS para voltagens de porta de (a) $-1.0 \mathrm{~V}$ e de (b) $-1.5 \mathrm{~V}$. $k$ indica os picos que correspondem às condições de ressonância. . . . . . . . 78

4.8 Picos de comensurabilidade na magnetoresistência a baixos campos magnéticos e uma voltagens de porta de $-4.5 \mathrm{~V}$ num sistema de bicamadas com uma rede de antipontos triangulares a temperatura $T=1.5 \mathrm{~K}$. Os picos de magnetoresistência + mostrados são $2,3,5$, e 6 e os super-indices indicam se pertencem a primeira o a segunda sub-banda. . . . . . . . . . . . . . 80

4.9 Picos de comensurabilidade da magnetoresistência a baixos campos magnéticos e uma voltagens de porta de (a) $-3,5 \mathrm{~V}$ e (b) -, $0 \mathrm{~V}$ num sistema de bicamadas com uma rede de antipontos triangulares a temperatura $T=1,5 K$. Os picos de magnetoresistência mostrados são 2, 3, 5, e 6 e os super-indices indicam se pertencem a primeira o a segunda sub-banda. . 82 


\section{Lista de Tabelas}

1.1 Algumas escalas de comprimento relevantes. Notar que $1 \mu \mathrm{m}=10^{-6} \mathrm{~m}=$

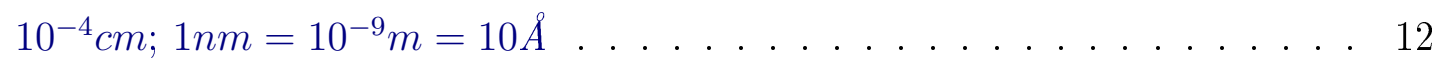

4.1 Razão $R_{c} / a$ para cada uma das sub-bandas para diferentes voltagens de porta. $R_{c}$ é o rádio do cíclotron e " $a$ "é o período da rede de antipontos. . . 81 


\section{Introdução}

O transporte quântico em sistemas bidimensionais de elétrons (2DES, two-dimensional systems) na presença de campos magnéticos altos e baixas temperaturas tem revelado uma ampla variedade de fenômenos na física de matéria condensada. Os efeitos Hall quântico inteiro (IQHE, integer quantum Hall effect) (v. Klitzing et al., 1980) e fracionário (FQHE, fractional quantum Hall effect) (Tsui et al., 1982) são dois importantes descobertas que surgiram a partir de varias décadas de intenso estudo nos 2DES. O efeito Hall quântico inteiro surge na presença de campos magnéticos altos nos 2DES, onde o campo magnético quantiza o movimento dos elétrons no plano em órbitas ciclotrônicas caracterizadas pelos níveis de Landau. Horst L. Störmer e Daniel C. Tsui fizeram estudos mais refinados do efeito Hall quântico (temperaturas mais baixas e campos magnéticos mais fortes), e descobriram um novo salto na resistência Hall que era três vezes maior do que o maior que Klitzing achou. Eles descobriram que estes novos saltos podem ser expressos pela constante $e / \hbar$ multiplicada por um número racional.

O transporte quântico eletrônico foi principalmente desenvolvido em sistemas bidimensionais de elétrons com uma sub-banda ocupada. Nesta dissertação foi estudada o transporte quântico em sistemas de bicamadas com uma rede antipontos triangulares. Uma bicamada consiste de dois sistemas eletrônicos bidimensionais de eletrônicos (2DESs) arranjados tão próximos, que a troca de portadores de carga ocorre em virtude do tunelamento quântico. Isto induz a um desdobramento das energias das sub-bandas e induz uma escala de energia adicional. Os sistemas de bicamadas tem sido intensamente estudados teórica e experimentalmente nas últimas décadas. Fenômenos físicos adicionais podem ocorrer devido a esta nova escala de energia dependendo da sua magnitude comparada com outras escalas de diversos sistemas. Fenômenos relacionados ao tunelamento quando dois 2DES estão muito próximos tem um papel muito importante e podem dar origem a novos efeitos quânticos. Existem dois métodos diferentes para realizar uma bicamada. O primeiro método é usar um poço quântico duplo (DQW, double quantum well), que consiste de dois poços quânticos separados por uma barreira potencial estreita. Os DQWs são vistos como duas camadas eletrônicas bidimensionais acopladas por tunelamento. Este acoplamento induz um novo grau de liberdade que leva a uma variedade de fenômenos que não podem ser observados em sistemas de uma única camada. O segundo método para produzir 
uma bicamada é o uso de um poço quântico largo (WQW, wide quantum well). O campo elétrico resultante da presença da dopagem, divide o poço em duas camadas eletrônicas separadas no espaço na direção de crescimento, criando efetivamente uma estrutura de bicamadas, com uma barreira potencial pequena.

Uma rede de antipontos é um sistema bidimensional de elétrons impresso com um arranjo regular de ilhas isolantes. Muitos tipos de redes de antipontos que tem sido estudadas, por exemplo: quadradas (Weiss et al., 1991), hexagonal (Yamashiro et al., 1991), retangular (Schuster et al., 1993), quase-periódicas (Gusev et al., 1993), e desordenadas (Gusev et al., 1992b). Os sistemas de antipontos têm sido estudados teórica e experimentalmente para compreender a ampla faixa de propriedades eletrônicas dos 2DES em campos magnéticos: espalhamento eletrônico balístico (movimento semi-clássico e caótico), efeitos localizados, efeitos de interferência quântica, efeitos de interação de muitos corpos, etc. O magnetotransporte a baixos campos dominado por efeitos geométricos também é observado na forma de máximos na magnetoresistência. O campo magnético destes picos correspondem a movimentos ciclotrônicos rodeando um número finito de antipontos. Estas oscilações são chamadas oscilações de comensurabilidade, porque o radio do cíclotron é comparável ao período da rede de antipontos.

Esta tese esta organizada nos seguintes capítulos:

O primeiro capítulo descreve as propriedades dos gases bidimensionais de elétrons na presença, de um campo magnético perpendicular. A seguir é descrita as propriedades de transporte semi-clássico dos sistemas eletrônicos que estão submetidos, ou não, à ação de campos magnéticos. Obtém-se diversos fenômenos que são de grande utilidade no análise do comportamento dos gases de elétrons nos sistemas periódicos de antipontos em baixas temperaturas. Também é apresentado o transporte quântico, descrevendo as oscilações Shubnikov-de Haas na magnetoresistência e os efeitos Hall quântico inteiro e fracionário. Na última seção deste capítulo, as bicamadas e as oscilações MIS em WQW e DQW são brevemente descritas.

O segundo capítulo descreve os conceitos fundamentais da rede de antipontos num 2DES, resumindo brevemente conceitos acerca de picos de comensurabilidade, a focalização magnética, as órbitas difusivas. Também são relatadas as redes de antipontos triangulares e as oscilações Altshuler-Aronov-Spivak.

O terceiro capítulo apresenta a parte experimental. Primeiro é exposta o sistema de redes de antipontos, e logo é apresentado o processamento das amostras, fabricação da barra Hall, gravação da rede antipontos e a deposição da porta de metálica na superfície 
de amostra. Também é descrito o equipamento empregado e o procedimento básico para realizar a caracterização experimental do magnetotransporte.

O quarto capítulo é acerca dos resultados experimentais obtidos no estudo do magnetotransporte a baixos campos magnético numa rede triangular de antipontos num sistema de bicamadas, indicando as características das oscilações MIS num WQW e dos picos de comensurabilidade, considerando a aplicação de campos eletrostáticos externos (voltagem de porta) que controla aqueles efeitos.

O quinto capítulo apresentamos as conclusões dos resultados experimentais. 


\section{Capítulo 1}

\section{Conceitos fundamentais}

\subsection{O Sistema Bidimensional de Elétrons}

Desde os anos 1980, as frases "estruturas quânticas"ou "dispositivos de efeito quântico"foram citadas muitas vezes. Na década dos anos 1960, foram iniciados os primeiros trabalhos acerca da quantização dos elétrons, quando os elétrons na camada de inversão de um MOSFET (Metal-Oxide-Semiconductor Field Effect Transistor) foram encontrados quantizados na interface, exibindo propriedades bidimensionais. Em 1960, Esaki e Tsui começaram uma nova tentativa para fabricar estruturas quânticas, levando a aplicações mais importantes da física de semicondutores e dispositivos. Eles introduziram a tecnologia de epitaxia por feixe molecular (MBE) para crescer estruturas em camadas, com o nome de super-redes, e conseguiram observar oscilações de Bloch. Desde então, a técnica de crescimento do MBE têm sido usada por muitas pessoas para adaptar vários tipos de estruturas quânticas; foram observadas o efeito da quantização do transporte eletrônico e as propriedades óticas. No ano 1980, o efeito Hall Quântico foi descoberto por van Klitzing et al, usando um MOSFET de Si, depois disso, as propriedades de transporte do gás bidimensional de elétrons receberam uma grande atenção.

Quando materiais diferentes $A$ e $B$ são crescidos sobre um mesmo substrato, a estrutura resultante é chamada heteroestrutura, e as características destas dependem fortemente das propriedades físicas e químicas de ambos materiais. A fim de obter uma boa estrutura, é essencial que as constantes de rede de ambos materiais sejam iguais, ou que os dois materiais sejam redes correspondentes. Sob a condição de redes correspondentes, o crescimento controlado do cristal, fornece o crescimento do cristal de rede correspondente (crescimento pseudomórfico). O descasamento da rede do cristal $A$ com constante de rede $a_{A}$, e do cristal $B$ com constante de rede $a_{B}$ é definido por $\eta=2\left|a_{A}-a_{B}\right| /\left(a_{A}-a_{B}\right)$. Para uma heteroestrutura com um pequeno descasamento de rede, o crescimento pseudomórfico é alcançado, enquanto que para heteroestruturas com uma maior incompatibilidade de rede, os defeitos da rede (deslocação do desajuste) são introduzidos a fim de relaxar a tensão 
devido ao descasamento da rede. A fim de evitar defeitos, as super-redes de camadas finas são crescidas alternadamente, limitando o número destas, com a condição que sejam menores que a espessura da camada crítica. Tais super-redes crescidas sem relaxamento de tensão são chamadas super-redes de camadas tensas. A partir de estas considerações, o crescimento das super-redes e das estruturas quânticas sem efeitos de tensão é conseguido através da escolha de materiais com um pequeno descasamento de rede.

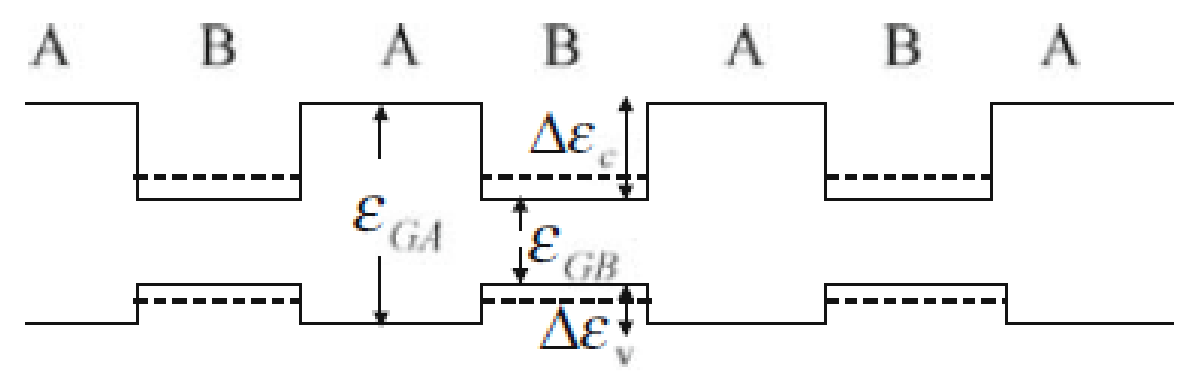

(a) Tipo I

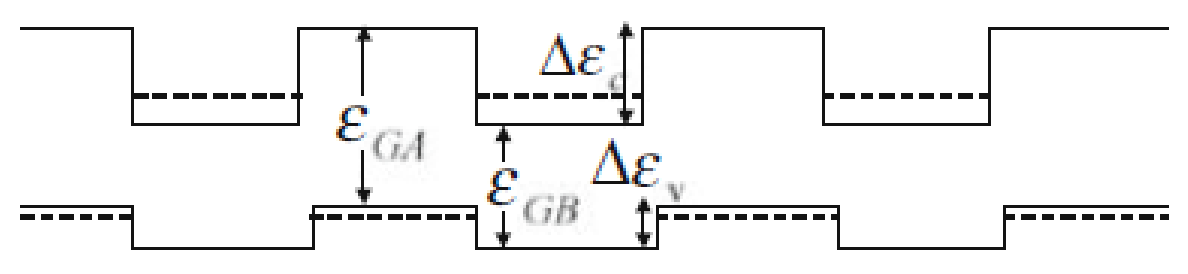

(b) Tipo II

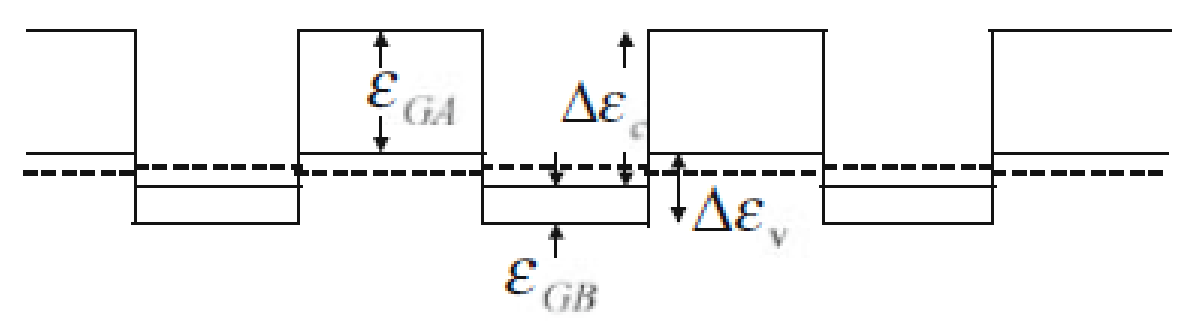

(c) Tipo III

Figura 1.1: Tipos de heteroestruturas. (a) Tipo I: os elétrons e buracos estão confinados no mesmo espaço. (b) Tipo II: Os elétrons e buracos estão confinados em diferentes espaços, resultando uma transição indireta no espaço. (c) Tipo III: gap zero.

O diagrama de bandas de energia das heteroestruturas com correspondência de rede são classificados em três casos, como mostra-se na figura 1.1, eles são do tipo I, II e III após a notação de Esaki et al (Esaki e Tsu, 1970). No tipo I, a banda de condução do semicondutor $B$, com o gap mais pequeno, torna-se num mínimo e a banda de valência 
num máximo, e portanto os elétrons e os buracos são excitados nesta região. No tipo II, o mínimo da banda de condução do semicondutor $A$ e o máximo da banda de valência do semicondutor $B$ são diferentes no espaço, resultando um gap indireto no espaço. No tipo III, as heteroestruturas se comportam como um material de gap zero (semimetal) ou como um material de gap estreito. Destes três tipos, as heteroestruturas do tipo I têm sido amplamente pesquisadas.

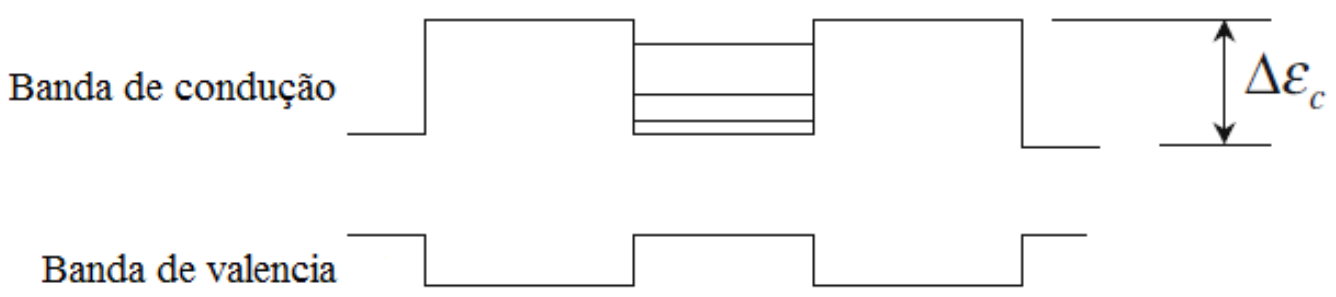

(a) Não dopada

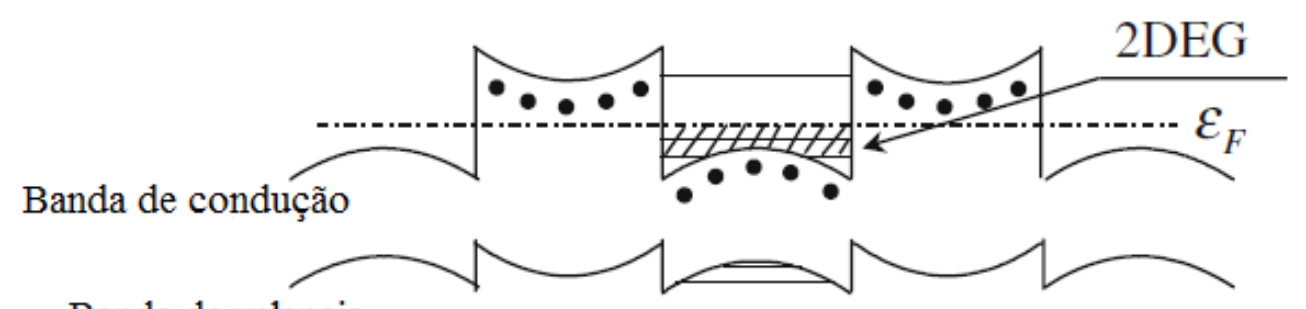

Banda de valencia

(b) Dopada uniformemente

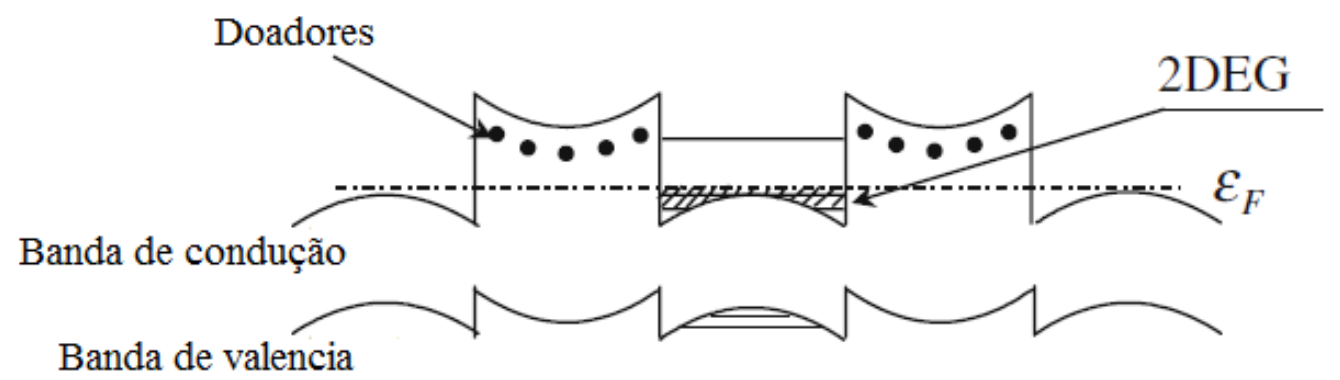

(c) Dopada por modulação

Figura 1.2: Modulação da dopagem nas heteroestruturas. (a) Caso não dopado, onde não existe campo elétrico. Quando a densidade eletrônica é pequena e os buracos são excitados por absorção de fótons, estes ocupam as sub-bandas da banda de condução e da banda de valência, respectivamente, e se recombinam para terminar nos estados inicias. (b) Caso onde as impurezas doadoras dopam uniformemente ambas regiões do poço e da barreira. Os elétrons confinados nas regiões do poço formam estados bidimensionais e estão sujeitos ao espalhamento das impurezas na região do poço, produzindo uma redução na mobilidade dos elétrons a baixas temperaturas. (c) Caso de dopagem por modulação, onde as impurezas doadoras dopam somente as regiões da barreira, e os elétrons confinados nas regiões do poço estão separados das impurezas ionizadas. Portanto, uma alta mobilidade do gás bidimensional de elétrons é obtida.

As heteroestruturas do tipo I são usadas para fabricar os poços quânticos. As regiões do máximo e mínimo da banda de condução são chamadas barreira e poço, respectivamente. 
Quando a barreira é larga, os elétrons não são capazes de penetrar e são confinados na região do poço quântico, sendo o movimento dos elétrons, quantizado e perpendicular à heterointerface, formando uma estrutura de sub-bandas. Desde que os elétrons são capazes de mover-se num plano paralelo à heterointerface, os elétron mostram características bidimensionais. Estas características são mostradas na figura 1.2. A figura 1.2.a é o caso para uma heteroestrutura não dopada e tanto as regiões do poço e da barreira são eletricamente neutras, originando um campo elétrico zero.

A figura 1.2.b é o caso uniformemente dopado, onde os doadores e os elétrons excitados estão confinados na região do poço, originando a formação de um gás bidimensional de elétrons. A mobilidade dos elétrons em tal estrutura é afetada pelo espalhamento das impurezas ionizadas devido aos doadores na região do poço e é reduzida a baixas temperaturas. Para evitar a diminuição na mobilidade, uma nova ideia foi proposta, o que é mostrado na figura 1.2.c, onde os elétrons das regiões do poço são capturados dos doadores das regiões da barreira e confinados nas regiões do poço, produzindo uma redução no espalhamento das impurezas e um aumento na mobilidade a baixas temperaturas. Se observa que o potencial das impurezas é uma força de longo alcance e assim os elétrons são afetados pelos doadores ionizados na região da barreira. A redução mais drástica da dispersão das impurezas é conseguida colocando uma região espaçadora não dopada perto da região do poço. Este método é chamado modulação de dopagem (Hamaguchi, 2010).

Entre os materiais mais utilizados no estudo de transporte em sistemas bidimensionais de elétrons estão o GaAs e o AlGaAs. O perfil das bandas de energia de uma estrutura AlGaAs/GaAs é mostrado na figura 1.3. Para esta estrutura confinar elétrons na banda de condução, a estrutura básica deste sistema pode ser uma camada de $A l G a A s$ com dopagem tipo $\mathbf{n}$ seguida de outra camada de $A l G a A s$ sem dopagem e finalmente a camada de GaAs para formar a interface. Assim, a banda de condução tem elétrons livres fornecidos pela camada dopada. Uma vez que o potencial da banda de condução na região do GaAs é menor que na região do $A l G a A s$, os elétrons na região dopada de AlGaAs migram para a banda de condução do GaAs. Aparece então, uma carga positiva na região das impurezas doadoras, devido à ionização delas, a qual atrai os elétrons para a interface, criando uma curvatura na banda de condução. A transferência de elétrons desde a camada dopada de $A l G a A s$ até a camada de GaAs continua até que a descontinuidade do potencial permita ter o mesmo nível de Fermi na camada de AlGaAs e na camada de GaAs. Os elétrons na banda de condução abaixo do nível de Fermi permanecem confinados em estados quantizados. No caso mostrado na figura 1.3, só existe dois estados quantizados ocupados na região da interface. Assim, este sistema constitui um sistema com duas sub-bandas ocupadas. 


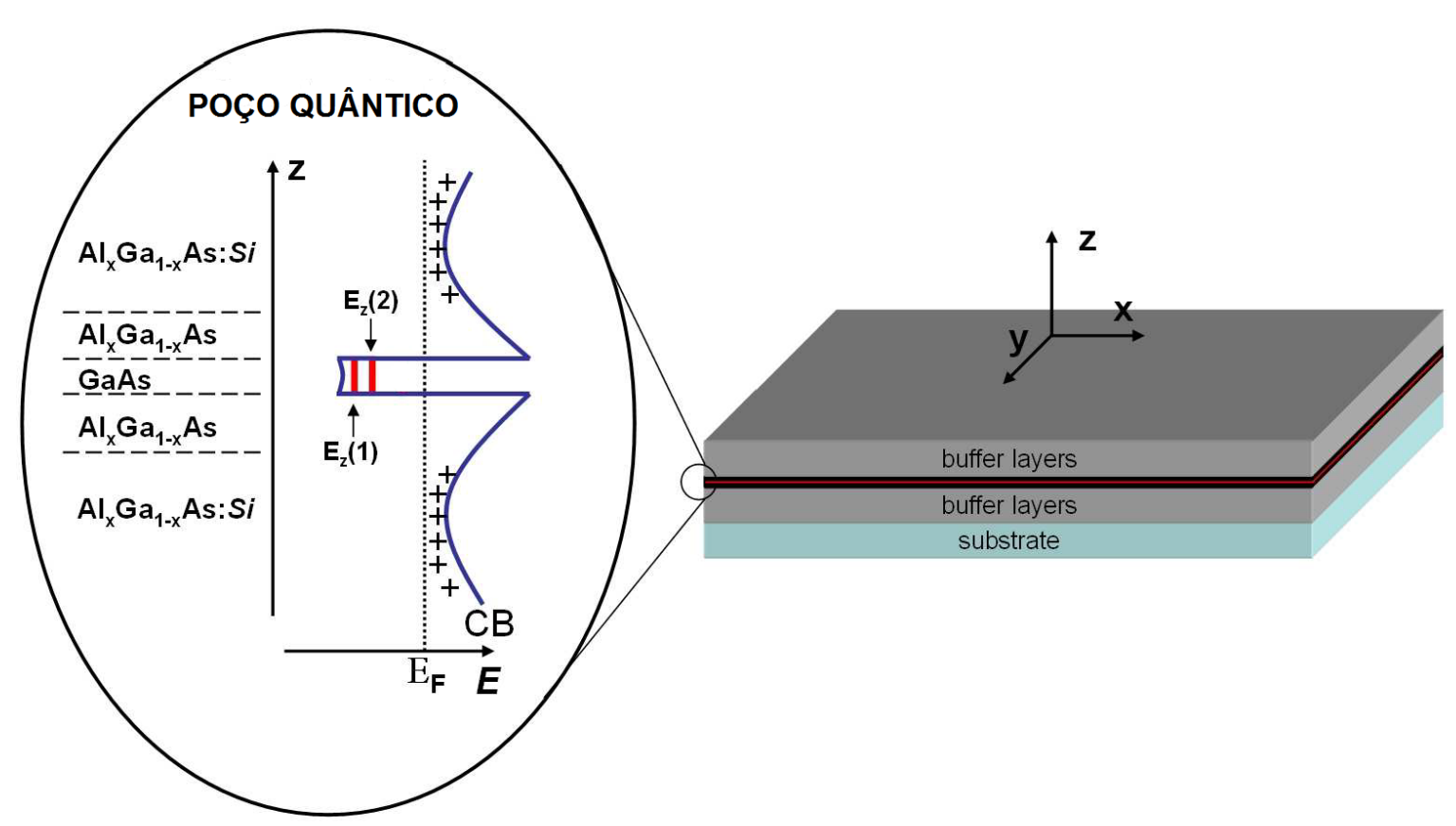

Figura 1.3: Um poço quântico de $A l_{x} G a_{1-x} A s / G a A s / A l_{x} G a_{1-x} A s$ com dopagem por modulação é representado esquemáticamente. Duas sub-bandas são identificadas com energias $E_{z}(1)$ e $E_{z}(2)$ - Quando a densidade eletrônica é menor, e se $k_{B} T \ll\left(E_{z}(2)-E_{z}(1)\right)$, somente a última subbanda será ocupada.

Através da regra de Anderson, se pode calcular o gap de energia na interface entre estes materiais, em que o gap da banda de condução é igual à diferença entre as afinidades eletrônicas destes materiais; por exemplo para uma interface de GaAs-AlGaAs, $\Delta E_{c}=$ $\chi_{A l G a A s}-\chi_{G a A s}$, onde $\chi$ é a afinidade eletrônica. O termo $\Delta E_{g}=\Delta_{g, A l G a A s}-\Delta_{g, G a A s}$ é a diferença entre os gaps de energia do $A l G a A s$ e do GaAs. O gap da banda de valência é calculado de $\Delta E_{v}=\Delta E_{g}-\Delta E_{c}$. Embora a regra de Anderson seja uma regra geral para calcular os gaps de energia, estudos em sistemas de GaAs - AlGaAs mostraram que esta forma de calcular o gap da banda de condução superestima o valor de dito gap para estes materiais. Assim, o gap da banda de condução mais utilizado é $\Delta E_{c}=$ $0,6 \Delta E_{g}$, e que normalmente é conhecido como a regra $60: 40$ aplicada particularmente a sistemas de $A l G a A s-G a A s$. O gap de $A l_{x} G a_{1-x} A s$ foi amplamente estudado como função da concentração $x$ de $A l$, e estes mostram diferenças no cálculo do gap como função da concentração $x$ de $A l$ (Adachi, 1985; Bosio et al., 1988; Debbar e et al., 1989; Dingle et al., 1974; Kroemer et al., 1980).

\subsubsection{Gás Bidimensional de Elétrons}

Um gás bidimensional de elétrons tem um movimento restringido em somente duas dimensões $(X$ e $Y)$ com um confinamento completo na direção perpendicular $(Z)$ ao plano de crescimento, é dizer, não tem liberdade de movimento nesta direção. Considerando 
um potencial de confinamento arbitrário $V(z)$, a equação de Schrödinger que descreve o movimento dos elétrons é dada por:

$$
\left(-\frac{\hbar^{2}}{2 m^{*}} \nabla^{2}+V(z)\right) \Psi(x, y, z)=E \Psi(x, y, z)
$$

onde $m^{*}$ é a massa efetiva do elétron. Como os elétrons tem um movimento livre no plano $X Y$ devido ao potencial de confinamento $V(z)$, independente das coordenadas $x$ e $y$, usamos como função de onda tentativa a função:

$$
\Psi(x, y, z)=\frac{1}{\sqrt{S}} \phi_{n}(z) \exp \left(i k_{x} x\right) \exp \left(i k_{y} y\right)
$$

onde $k_{x}$ e $k_{y}$ são as componentes do vetor de onda e $S$ é a área da amostra, isto é $S=L_{x} L_{y}$, onde $L_{x}$ e $L_{y}$ são as dimensões da amostra. Substituindo a equação 1.2 na equação 1.1, a relação de dispersão é obtida:

$$
E_{\vec{k}, i}=E_{n}+\frac{\hbar^{2}}{2 m^{*}}\left(k_{x}^{2}+k_{y}^{2}\right)
$$
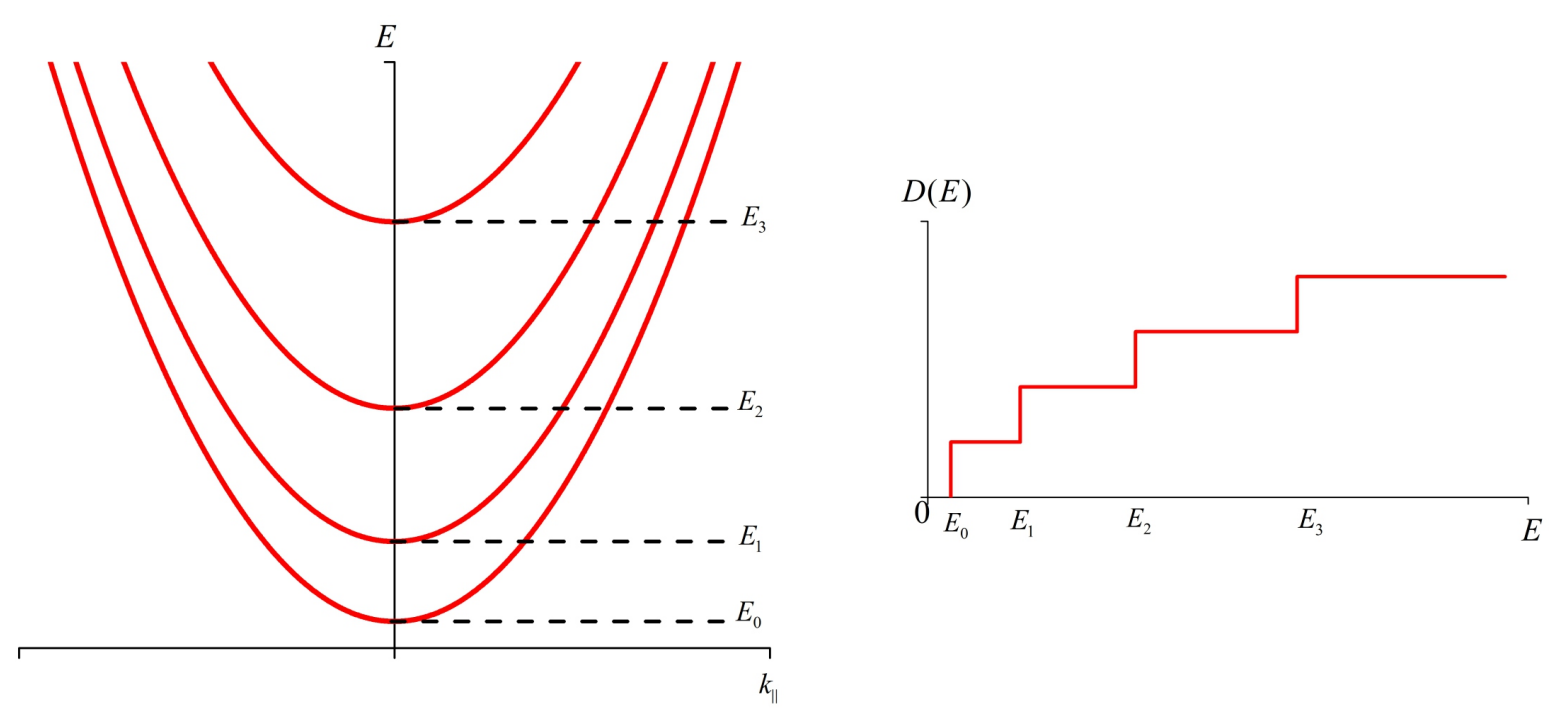

Figura 1.4: Esquema que representa a relação de dispersão para um gás bidimensional de elétrons. $k_{\|}$é o vetor de onda no plano $X Y$, e $D(E)$ é a densidade de energia.

onde $E_{i}$ corresponde as auto-energias devido ao potencial de confinamento na direção de crescimento $(z)$ e $i$ denota o índice de cada sub-banda ocupada, considerando que as massas efetivas nos eixos $X$ e $Y$ são iguais $m^{*}=m_{x}^{*}=m_{y}^{*}$. A densidade de estados de cada sub-banda é constante, e é dada por: 


$$
\rho\left(E_{i}\right)=\frac{m^{*}}{\pi \hbar^{2}}
$$

Quando o sistema tem somente uma sub-banda ocupada, o sistema é considerado um sistema perfeitamente bidimensional, e quando o sistema tem duas ou mais sub-bandas ocupadas, é chamado quase-bidimensional (Ferry e Goodnick, 1997).

\subsubsection{Estructura Eletrônica em Campo Magnético Perpendicular}

Quando aplicamos um campo magnético, $B_{z}$, perpendicular ao plano do 2DEG, a força sempre é perpendicular à direção de movimento dos elétrons, e seu movimento na ausência de outras forças é circular, com frequência angular dada pela frequência do cíclotron

$$
\omega_{c}=\frac{e B}{m^{*}}
$$

onde $B$ é a magnitude do campo magnético, e $m^{*}$ é a massa efetiva do elétron. Na descrição da mecânica quântica, as órbitas circulares associadas com a força de Lorentz devem ser quantizadas em analogia ao que ocorre com respeito a um potencial central. Desde que os elétrons efetuam um movimento harmônico, se espera que a energia associada com o movimento no plano perpendicular ao campo magnético seja quantizada, é dizer, o movimento dos elétrons no plano $X-Y$ é livre, e no eixo $Z$ é quantizado em órbitas com níveis de energia discretos chamados níveis de Landau (Ferry e Goodnick, 1997).

Considerando um campo magnético aplicado na direção $Z, \vec{B}=(0,0, B)$, sobre uma estrutura bidimensional com potencial de confinamento $V(z)$, a equação de Schrödinger que descreve este caso é dada por:

$$
\left(\frac{1}{2 m^{*}}(i \hbar \nabla+e \vec{A})^{2}+V(z)\right) \Psi(x, y, z)=E \Psi(x, y, z)
$$

onde $\vec{A}$ é o potencial vetor ou também chamado gauge de Landau. Assumindo que o "gauge" $\vec{A}=(0, B x, 0)$, satisfazendo $\vec{B}=\nabla \times \vec{A}$, com o qual teremos ao campo magnético na direção $Z, \vec{B}=(0,0, B)$. A solução da equação 1.6 é separável como $\Psi(x, y, z)=$ $\varphi(z) \chi(x, y)$, onde a solução para a coordenada $z$ é a mesma indicada na seção anterior, porque o potencial vetor não depende da coordenada $Z$. Então $\chi(x, y)$ satisfaz:

$$
\left(-\frac{\hbar^{2}}{2 m^{*}} \frac{\partial^{2}}{\partial x^{2}}-\frac{\hbar^{2}}{2 m^{*}}\left(\frac{\partial}{\partial y}-\frac{i}{\hbar} e B x\right)^{2}\right) \chi(x, y)=E^{\prime} \chi(x, y)
$$


A última equação só depende de $x$, então a função de onda $\chi(x, y)$ pode ser escrita como um produto de uma onda plana em $Y$ e uma função não conhecida $u(x)$ :

$$
\chi(x, y)=e^{i k_{y} y} u(x)
$$

Assim, a equação de Schrödinger em termos da coordenada $X$ é dada por:

$$
\left(-\frac{\hbar^{2}}{2 m^{*}} \frac{\partial^{2}}{\partial x^{2}}+\frac{m^{*} \omega_{c}^{2}}{2}\left(x-x_{0}\right)^{2}\right) u(x)=E^{\prime} u(x)
$$

onde $x_{0}=\frac{\hbar k_{y}}{e B}$ é o centro de coordenadas. A equação 1.9 é a equação do oscilador harmônico para $X$, com auto-funções e auto-energias dadas por:

$$
\begin{aligned}
u_{n}(x) & =\frac{1}{\sqrt{2^{n} n ! \sqrt{\pi} l_{m}}} \exp \left(-\frac{\left(x-x_{0}\right)^{2}}{2 l_{m}^{2}}\right) H_{n}\left(\frac{x-x_{0}}{l_{m}}\right) \\
E^{\prime} & =\left(n+\frac{1}{2}\right) \hbar \omega_{c}
\end{aligned}
$$

onde $H_{n}$ é o polinômio de Hermite de ordem $n$, e $l_{m}=\sqrt{\frac{\hbar}{e B}}$ é o comprimento magnético. A quantização orbital dos níveis de energia pode ser expressa como:

$$
E=E_{i}+\left(n+\frac{1}{2}\right) \hbar \omega_{c}
$$

onde os $E_{i}$ são as auto-energias associadas com o potencial de confinamento perpendicular.

Como a energia $E^{\prime}$ não depende de $k_{y}$, o sistema tem degenerescência em $Y$, assim a degenerescência de cada nível de Landau é igual à quantidade de elétrons que podem ocupar num nível de Landau. A degenerescência pode ser achada considerando as dimensões da amostra com área $A=L_{x} L_{y}$ e também considerando que cada órbita ciclotrônica ocupa um área $\pi l_{m}^{2}$, portanto a área $A$ contém $A / \pi l_{m}^{2}$ órbitas e $A / 2 \pi l_{m}^{2}$ estados por nível de Landau (incluindo a degenerescência de spin). Então, a degenerescência de cada nível de Landau é dada por:

$$
N=\frac{L_{x} L_{y}}{2 \pi l_{m}^{2}}
$$

A densidade de elétrons num nível de Landau é dado pela quantidade de estados por nível de Landau por unidade de superfície. Portanto, a densidade de elétrons num nível de Landau é expressa por: 


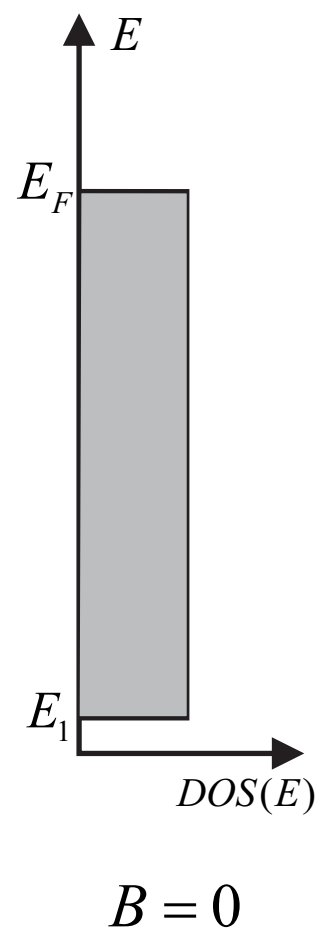

(a)

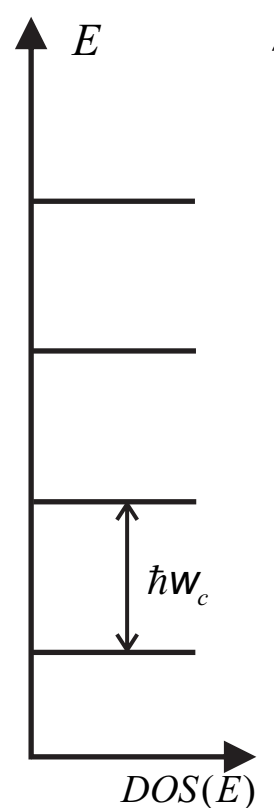

$B \neq 0$
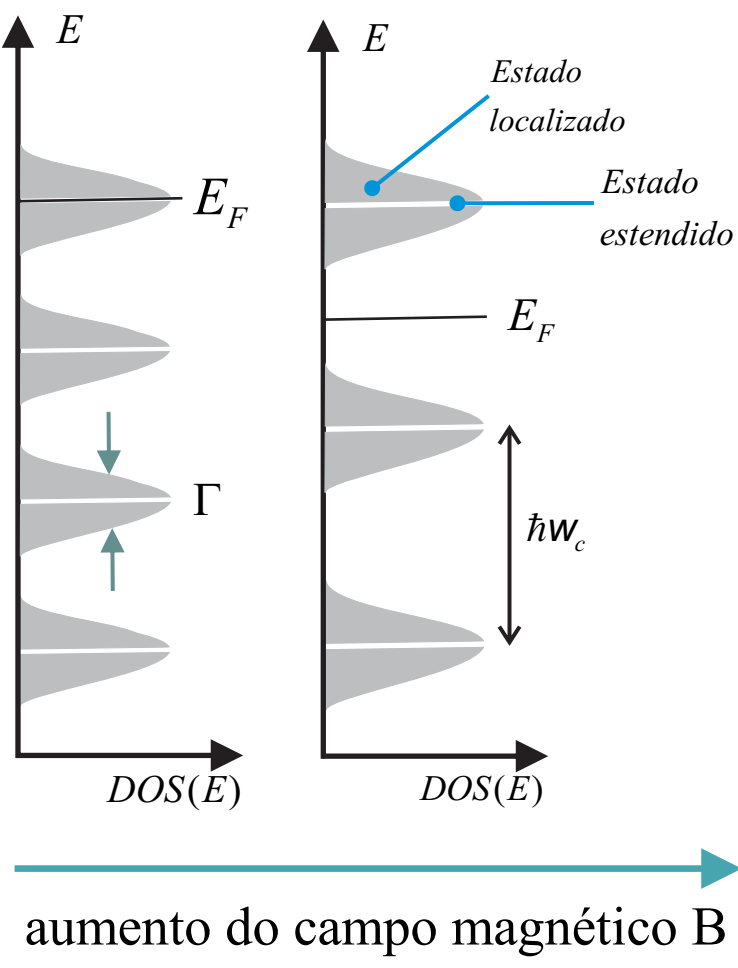

(b) (c)

(d)

Figura 1.5: A densidade de estados de um sistema bidimensional em campo zero (a) e com campo magnético (b)-(d). (b) A densidade de estados são funçôes delta para valores discretos dos niveis de Landau. (c) A densidade de estados são funçôes delta com alargamento $\Gamma$ centrado nos niveis de Landau. É mostrada a energia de Fermi $\varepsilon_{F}$ cruzando exatamente no centro do pico do nível de Landau na DOS. (d) Mostra-se o nivel de Fermi entre dois picos da DOS.

$$
n_{B}=\frac{N}{L_{x} L_{y}}=\frac{1}{2 \pi l_{m}^{2}}=\frac{e B}{h}
$$

O último resultado indica a quantidade máxima de elétrons que podem ser colocadas num nível de Landau.

A densidade de estados para uma sub-banda com degenerescência $n_{B}$, é dada pela expressão:

$$
D(E)=n_{s} n_{v} n_{B} \sum_{n} \delta\left(E-\left(n+\frac{1}{2}\right) \hbar \omega_{c}\right)
$$

onde $n_{s}$ é a degenerescência de spin e $n_{v}$ é a degenerescência de vale. 


\subsection{Transporte Semiclássico}

\subsubsection{Equação de Bolztmann}

Dentro do contexto semiclássico, os elétrons de condução são tratados como partículas clássicas que obedecem à estatística de Fermi-Dirac. Ao ser partículas clássicas seu comprimento de onda associada é muito menor que os tamanhos característicos das estruturas cristalinas e que as distâncias típicas da variação dos campos aplicados. Portanto, a equação de Boltzmann dá conta dos mecanismos que podem afetar à função de Distribuição de Fermi-Dirac, $f_{F D}$, em equilíbrio. Estes mecanismos podem ser de difusão, de campo externo ou de dispersão.

Uma função de distribuição de portadores de carga $f(\vec{k})$ pode ser definida como a probabilidade do estado de uma banda com energia $E_{k}$ ser ocupada por esse portador à temperatura $T$ do portador.

A equação de Boltzmann governa a variação da função $f(\vec{k})$ na presença de perturbações externas, e é expressa como (Hamaguchi, 2010; Lundstrom, 2000)

$$
\frac{d f(\vec{k})}{d t}=\frac{\partial f}{\partial t}+\frac{\partial f}{\partial \vec{r}} \frac{d \vec{r}}{d t}+\frac{\partial f}{\partial \vec{k}} \frac{d \vec{k}}{d t}+I_{c o l}
$$

Em particular, se o transporte ocorre no estado estacionário, ou seja, $d f(\vec{k}) / d t=0$, temos:

$$
\frac{\partial f}{\partial t}-\vec{v}(\vec{k}) \cdot \frac{\partial f}{\partial \vec{r}}+\frac{\vec{F}}{\hbar} \frac{\partial f}{\partial \vec{k}}+I_{c o l}=0
$$

onde $\vec{F}=-e(\vec{E}+\vec{v}(\vec{k}) \times \vec{H})$ é a força que atua sobre os elétrons, $\vec{v}(\vec{k})$ é a velocidade de grupo dos elétrons, e $I_{c o l}$ é o operador colisão, que expressa as mudanças no estado devido às colisões e pode ser expresso através da probabilidade de transição $W_{\text {if }}$ entre o estado inicial $i$ e o estado final $f$.

Uma vez obtida $f(\vec{k})$, estamos en condições de calcular a densidade de corrente como função de distribuição de não equilíbrio, a qual é dada por:

$$
\vec{J}=e \int d \vec{k} \vec{v}(\vec{k}) f(\vec{k})
$$

\subsubsection{Modelo de Drude}

Em 1900, P. Drude propôs o primeiro modelo para dar conta das propriedades do transporte eletrônico nos sólidos. O modelo consiste em supor que os portadores de carga 
(elétrons) interagem com os defeitos e as vibrações da rede, de modo que, na media realizam uma colisão cada certo intervalo de tempo ao que se chama "tempo de relaxação". Aplicando um campo elétrico $\vec{E}$, os elétrons são acelerados por uma força $\vec{F}_{e}=-e \vec{E}$, a dinâmica das partículas é descrita pela relação:

$$
m \frac{d \vec{v}}{d t}=-e \vec{E}
$$

Portanto, a velocidade eletrônica média ou velocidade de arraste $\vec{v}$, é dada por:

$$
\vec{v}(t)=\vec{v}_{0}-\frac{e t}{m} \vec{E}
$$

O modelo de Drude não esta interessado no comportamento individual dos elétrons, mas, num maior número de elétrons, é por isso que é de interesse a media da velocidade. Considerando um elétron típico em tempo zero, com $t$ sendo o tempo transcorrido desde a última colisão, a velocidade do elétron no tempo zero será $\vec{v}(0)$ imediatamente após a última colisão mais a velocidade adicional $-e t \vec{E} / m$, que posteriormente alcançou. Ao definir que o elétron emerge de uma colisão em uma direção aleatória, não existe contribuição de $\vec{v}_{0}$ à velocidade eletrônica média, a qual estará dada inteiramente por $-e t \vec{E} / m$. Mas, o valor médio de $t$ é o tempo de relaxação $\tau$. Portanto temos:

$$
\vec{v}=-\frac{e \tau}{m} \vec{E}
$$

O deslocamento dos elétrons no material condutor produz uma corrente devido à velocidade de arrastamento e, portanto, dá uma densidade de corrente $\vec{J}$ igual a:

$$
\vec{J}=-e n \vec{v}
$$

Comparando com a expressão geral da lei de Ohm, a partir das equações 1.21 e 1.22, podemos obter uma simples relação para a condutividade elétrica:

$$
\sigma=\frac{n e^{2} \tau}{m}
$$

\subsubsection{Escalas de Comprimento Relevantes}

Pode-se distinguir entre diversas escalas de comprimento importantes em sistemas de baixa dimensionalidade. Elas são mostradas na seguinte tabela 1.1 (Galperins, 2009): 


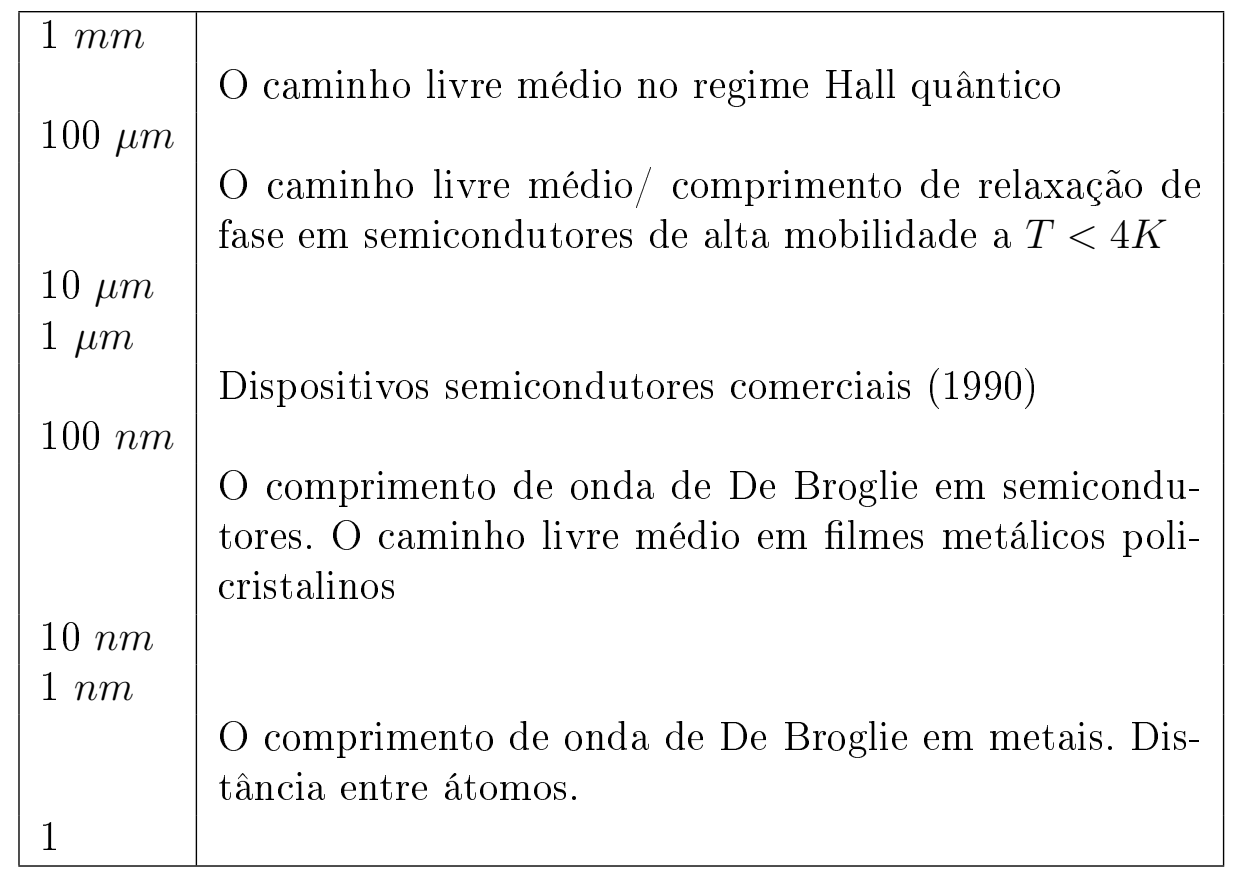

Tabela 1.1: Algumas escalas de comprimento relevantes. Notar que $1 \mu \mathrm{m}=10^{-6} \mathrm{~m}=10^{-4} \mathrm{~cm}$; $1 n m=10^{-9} m=10 \AA$

As escalas acima mencionadas têm o seguinte significado físico:

\section{O Comprimento de Onda de De Broglie, $\lambda$}

O comprimento de onda de De Broglie é definido como:

$$
\lambda=\frac{2 \pi \hbar}{p}=\frac{2 \pi}{k}
$$

onde $p(k)$ é o momento do elétron (vetor de onda). Para um gás de Fermi, o momento característico é o momento de Fermi. Para o caso de uma única sub-banda ocupada num gás bidimensional de elétrons temos:

$$
\lambda=\frac{2 \pi}{k_{F}}=\sqrt{\frac{2 \pi}{N_{s}}}
$$

onde $N_{s}$ é a densidade bidimensional de elétrons. Para o gás de Boltzmann, $p \approx \sqrt{2 m k T}$, é

$$
\lambda=\frac{2 \pi \hbar}{\sqrt{2 m k T}}
$$




\section{O Caminho Livre Médio, $l$}

Este é um comprimento característico entre as colisões dos elétrons com as impurezas ou fônons. Ela é definida como:

$$
l=v \tau_{t r}
$$

onde $v$ é a velocidade típica e $\tau_{t r}$ é o tempo de relaxação do transporte. Ela é definida como

$$
\frac{1}{\tau_{t r}} \propto \int d \theta \sin \theta W(\theta)(1-\cos \theta)
$$

onde $\theta$ é o ângulo de espalhamento e $W(\theta)$ é a probabilidade de espalhamento. Usualmente o transporte de elétrons é caracterizado pela mobilidade

$$
\mu_{e}=\frac{e \tau_{t r}}{m}
$$

O significado físico da mobilidade é que a velocidade de arraste alcançada pelo elétron num campo elétrico externo $\vec{E}$ é dada pela relação

$$
v_{d}=\mu_{e} E
$$

\section{Comprimento de Relaxação de Fase, $L_{\varphi}$}

Este é especialmente um comprimento de relaxação da mecânica quântica o qual não tem análogo na física clássica. Isto é, o movimento clássico pode ser descrito como a evolução da probabilidade para achar uma partícula num ponto e tempo dado. No entanto, na mecânica quântica o estado é caracterizado pela função de onda a qual tem a fase. A fase é importante nos fenômenos de interferência, onde as funções de onda dos elétrons tendo diferentes historias, são convergidas num mesmo ponto. Se as fases das ondas não são destruídas, um fenômeno de interferência quântico específico poderá ser observado. O tempo de relaxação de fase, $\tau_{\varphi}$, describe a relaxação de memoria da fase. É claro que o espalhamento sobre qualquer potencial independente do spin estático não pode levar para o tempo de relaxação. Certamente, em qualquer potencial estacionário as equações de movimento possuem reversão-temporal. Somente os processos de espalhamento responsáveis pela relaxação da fase são aqueles que produzem a quebra da simetria de reversão-temporal. Dentro destes estão os espalhamentos inelásticos por fônons, colisões elétron-elétron, etc. Uma característica importante desses processos é que os elétrons sofrem muitas colisões elásticas durante o tempo $\tau_{\varphi}$. Para o movimento difusivo pode ser estimado o valor relevante de $L_{\varphi}$ através da relação: 


$$
L_{\varphi}=\sqrt{D \tau_{\varphi}},
$$

onde $D=(1 / d) v l$ é a constante de difusão ( $d$ é a dimensionalidade do gás de elétrons).

\section{Comprimento de Defasagem Térmico, $L_{T}$}

O processo de relaxação anteriormente mencionado é relevante para a interferência das funções de onda pertencentes a um estado uni-eletrônico. Porém, a interferência pode ser importante para a interação de dois elétrons com energias próximas. Certamente, se a diferença de energias entre os elétrons é $\approx k T$, eles viajam quase coerentemente no decorrer do tempo $\hbar / k T$. Assim, o comprimento característico de propagação é estimado como:

$$
L_{T}=\sqrt{\frac{\hbar D}{k T}}
$$

a)

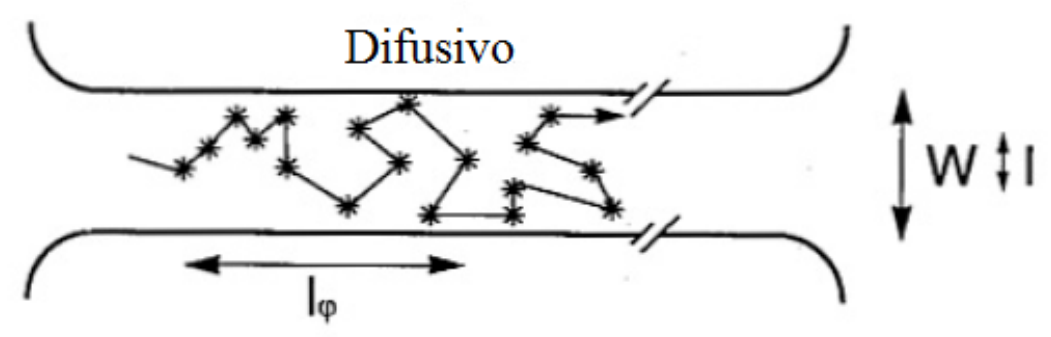

b)

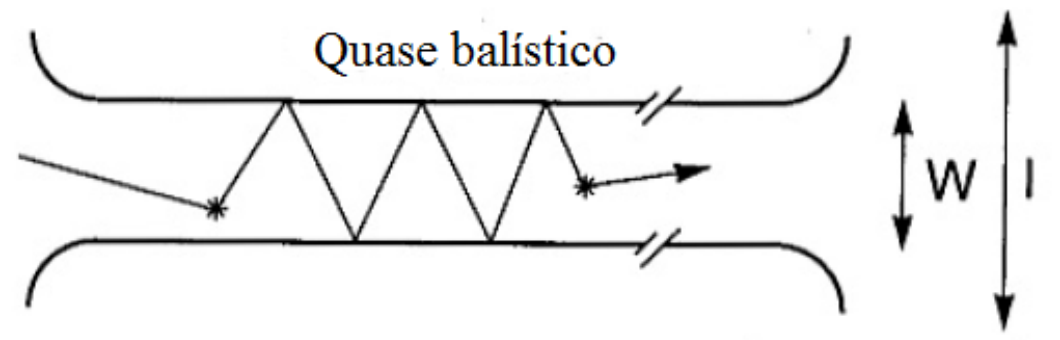

c)

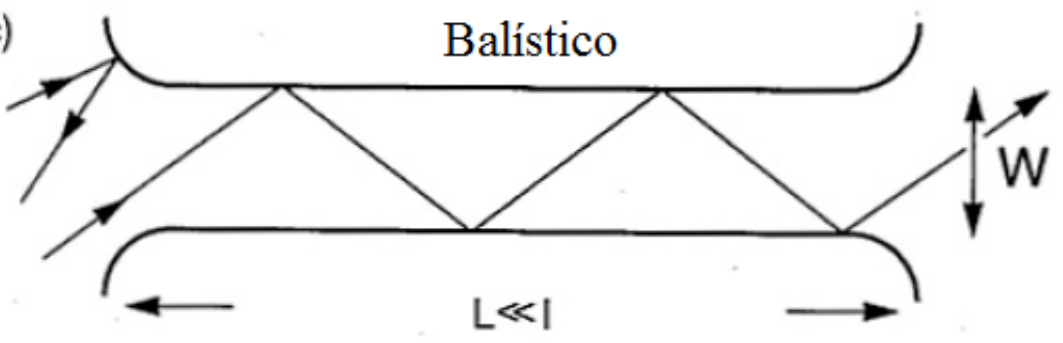

Figura 1.6: Trajetórias dos elétrons para regimes de transporte difusivo $(l<W, L)$, quase balístico $(W<l<L)$ e balístico $(l>W, L)$ (Galperins, 2009). 
Comparando o caminho livre médio $l$ com as dimensões características do sistema $L$, se pode discriminar entre o transporte difusivo $l \ll L$, e o transporte balístico $l \gg L, W$. Tal classificação aparece incompleta na situação onde as diferentes dimensões da amostra são substancialmente diferentes. A situação é ilustrada na figura 1.6, para o caso onde o comprimento $L$ da amostra é muito maior que a sua largura $W$. Se a coerência de fase é levada em conta, as escalas $L_{\phi}$ e $L_{T}$ tornam-se importantes, e a situação é mais interessante.

\subsubsection{O Efeito Hall Ordinário}

O estudo de efeitos do campo magnético nas propriedades de transporte dos metais e semicondutores tornou-se uma ferramenta bem estabelecida e inestimável. Em particular as medidas de Hall, destinadas a determinação da concentração e sinal da carga, são usadas rotineiramente para a caracterização de materiais. Também as medidas de magnetoresistividade, as quais determinam a resistividade dos materiais na presença de campos magnéticos, oferecem uma ampla gama de efeitos. Para o estudo dos fenômenos de magnetotransporte, ou seja, de como a condução elétrica na presença de campo magnético é efetuada, a experiência básica consiste na aplicação de corrente elétrica de baixa intensidade ao longo do 2DES, que sofre a influência de um campo magnético, orientado perpendicularmente ao longo do gás de elétrons (Grosso e Parravicini, 2003).

A equação clássica do movimento de um elétron, num médio dissipativo, na presença de um campo elétrico $\vec{E}$ e um campo magnético $\vec{B}$ é:

$$
\vec{F}=-e \vec{E}-e \vec{v} \times \vec{B}-\frac{m}{\tau} \vec{v}
$$

Onde $m^{*}$ é a massa efetiva do elétron, e o termo de amortecimento com o tempo de relaxamento constante $\tau$ foi incluído devido a dispersão. Em condições estacionarias $\vec{F}=0$, com o qual temos:

$$
\vec{v}=-\frac{e \tau}{m} \vec{E}-\frac{e \tau}{m} \vec{v} \times \vec{B}
$$

Consideremos o movimento dos elétrons no plano $X Y$ e um campo magnético $\vec{B}$ na direção $Z$ e o campo elétrico no plano $X Y$, temos:

$$
\begin{aligned}
& v_{x}=-\frac{e \tau}{m} E_{x}-\omega_{c} \tau v_{y} \\
& v_{y}=-\frac{e \tau}{m} E_{y}+\omega_{c} \tau v_{x}
\end{aligned}
$$


Onde $\omega_{c}$ é a frequência do cíclotron. A densidade de corrente é dada por:

$$
\vec{J}=-n e \vec{v}
$$

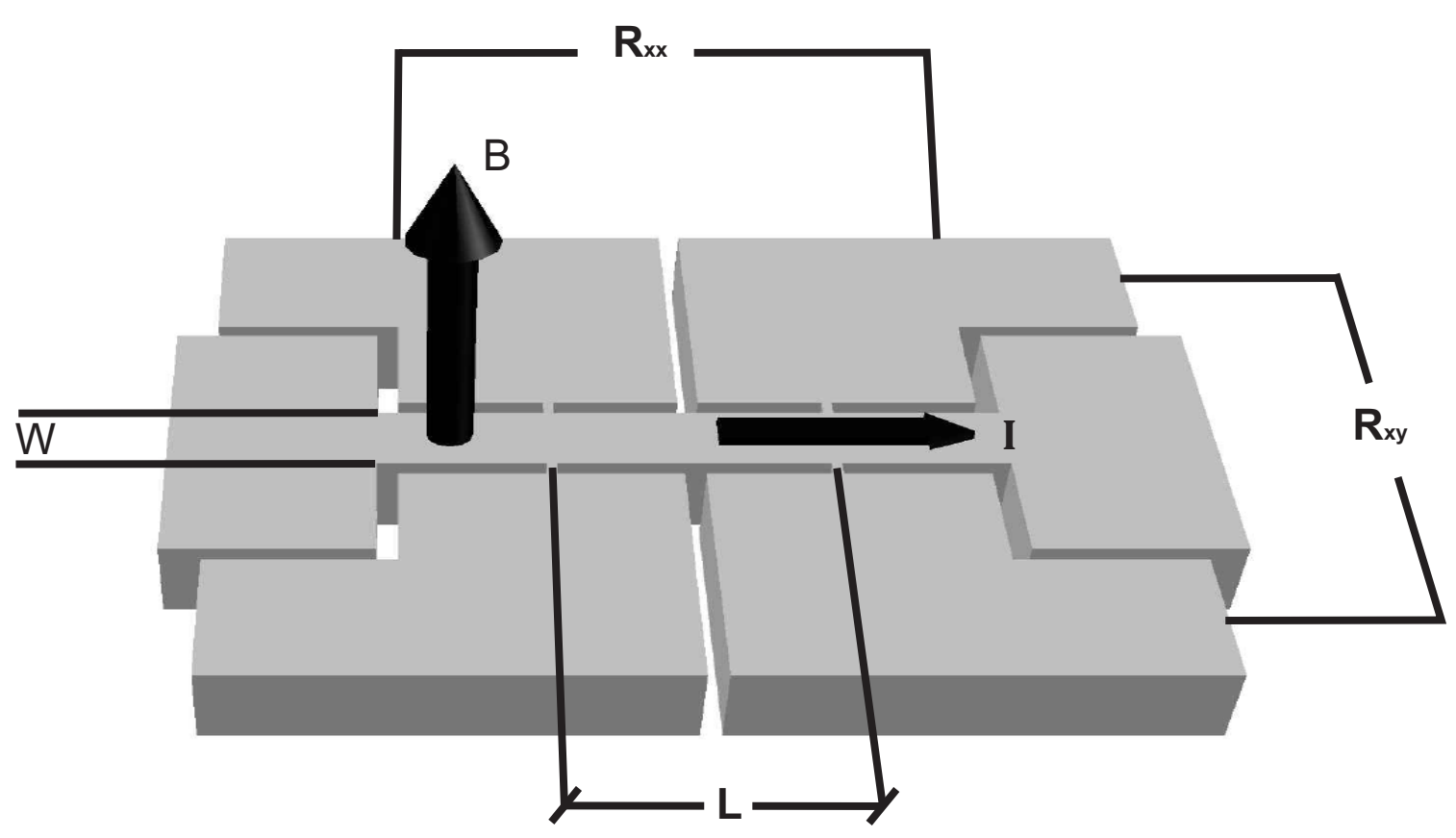

Figura 1.7: Esquema da configuração de uma medida de magnetotransporte. Uma corrente I é aplicada nos extremos do canal. $R_{x x}$ e $R_{x y}$ servem para identificar os contatos de tensão, onde a magnetoresistência e a resistência de Hall são medidas, respectivamente. Identifica-se por " $W$ " a largura da barra, "T"a espessura e "L"a distância entre contatos longitudinales.

onde $n$ é a densidade de elétrons (número de elétrons por unidade de volume). O tensor de magnetocondutividade é dado por:

$$
\sigma=\frac{\sigma_{0}}{1+\omega_{c}^{2} \tau^{2}}\left(\begin{array}{cc}
1 & -\omega_{c} \tau \\
\omega_{c} \tau & 1
\end{array}\right)
$$

Onde $\sigma_{0}=n e^{2} \tau / m$ é a condutividade. Da lei de Ohm, conhecemos a relação $\vec{J}=\sigma \vec{E}$. Então a densidade de corrente é dada por (Patterson e Bailey, 2007)

$$
\left(\begin{array}{l}
J_{x} \\
J_{y}
\end{array}\right)=\frac{\sigma_{0}}{1+\omega_{c}^{2} \tau^{2}}\left(\begin{array}{cc}
1 & -\omega_{c} \tau \\
\omega_{c} \tau & 1
\end{array}\right)\left(\begin{array}{c}
E_{x} \\
E_{y}
\end{array}\right)
$$


Usando a geometria, como se mostra na figura 1.7 , em condições estacionarias $J_{y}=$ $0\left(v_{y}=0\right)$, temos o campo de Hall em função da densidade de corrente $J_{x}$ :

$$
E_{y}=-\frac{J_{x}}{e n} B
$$

A resistência de Hall é definida como:

$$
R_{x y}=\frac{V_{x y}}{I_{x}}=\frac{E_{y} W}{J_{x} L T}=\frac{B}{e n T}
$$

A resistência longitudinal $R_{x x}$, também chamada magnetoresistência é o quociente da voltagem longitudinal $\left(V_{x x}=E_{x} L\right)$ e a corrente $I_{x}=J_{x} W T$, então temos:

$$
R_{x x}=\frac{V_{x x}}{I_{x}}=\frac{E_{x} L}{J_{x} W T}=\rho_{x x} \frac{L}{W T}
$$

A resistividade longitudinal é expressa por:

$$
\rho_{x x}=\frac{W T}{L} \frac{V_{x x}}{I_{x}}
$$

A mobilidade de Hall $\mu_{H}$ é obtida da relação

$$
\mu_{H}=\frac{R_{H}}{\rho_{x x}}
$$

Nas medidas de magneto transporte em heteroestruturas semicondutoras, a voltagem longitudinal na região de campo fraco é quase constante, no entanto, a voltagem de Hall cresce linearmente conforme com o modelo semiclássico de Drude. Porém, para valores de campo magnéticos altos, a resistividade longitudinal mostra um comportamento oscilatório acentuado, enquanto, a resistência de Hall apresenta platôs associados com mínimos na resistividade longitudinal que são visíveis em temperaturas criogênicas menores de 4 $\mathrm{K}$.

\subsection{Transporte Quântico num 2DEG}

\subsubsection{O Efeito Shubnikov-de Haas}

A modulação da densidade de estados (DOS,density of states) pela aplicação de um campo magnético leva a oscilações na resistividade longitudinal $\left(\rho_{x x}\right)$. Estas oscilações são chamadas oscilações Shubnikov-de Haas, o que leva o nome do seus descobridores, Shubnikov e De Haas (1930) (Shubnikov e de Haas, 1930). O origem das oscilações Shubnikov-de Haas é o resultado das oscilações da DOS. Os máximos da densidade de estados passam 
através da energia de Fermi $E_{F}$ com o incremento do campo magnético, provocando as oscilações na resistência, periódica com a inversa do campo magnético $1 / B$. As observações experimentais das oscilações SdH requer as seguintes condições.

- O alargamento dos níveis de Landau $\Gamma$ tem que ser menor que a separação entre os níveis de Landau adjacentes $\hbar \omega_{c}: \Gamma \ll \hbar \omega_{c}$ ou $\omega_{c} \tau_{q} \gg 1$.

- O blurring térmico da energia de Fermi $E_{F}$ deve ser menor comparado à separação dos níveis de Landau, e a separação dos níveis de Landau deve ser menor que a energia de Fermi: $k_{B} T \ll \hbar \omega_{c}<E_{F}$.

Os níveis de Landau são formados devido à aplicação de um campo magnético sobre um 2DES, e o conjunto que descreve os estados do 2DES mudam de $(i, \mathbf{k})$ para $(i, n)$ são

$$
\begin{array}{cc}
B=0(2 \mathrm{DEG}) & B \neq 0 \text { (níveis de Landau) } \\
E_{i}(\mathbf{k})=E_{i}+\frac{\hbar^{2}}{2 m^{*}}\left(k_{x}^{2}+k_{y}^{2}\right) \quad \longrightarrow \quad E_{i, n}=E_{i}+\left(n+\frac{1}{2}\right) \hbar \omega_{c}
\end{array}
$$

onde $E_{i}$ corresponde as auto-energias devido ao potencial de confinamento na direção de crescimento $(Z)$ e $i$ denota o índice de cada sub-banda ocupada, e $n=0,1,2, \ldots$ identifica um nível de Landau. Cada nível de Landau é desdobrado pela energia de Zeeman $\left(g \mu_{B} \vec{s} . \vec{B}\right)$. Tanto as energias do cíclotron e Zeeman como o número de estados eletrônicos para cada nível de Landau aumentam de forma linear com o incremento do campo magnético. A temperaturas da ordem de $1 K$, a população de elétrons encontra-se em níveis quânticos de Landau até a energia de Fermi, que se admitiu ser independente do campo magnético. Quando o valor do campo magnético é incrementado, o número de níveis de Landau ocupados decresce cada vez que a energia de um nível se tornar superior à energia de Fermi. Portanto, cada vez que a condição $E_{F}=(n+1 / 2) \hbar \omega_{c}$ é satisfeita, ocorrerá a depopulação de um nível, provocando as oscilações no transporte e nas propriedades termodinâmicas, segundo a lei $1 / B$, no período. A resistividade apresenta zeros em valores periódicos de $1 / B$, mas isto não ocorre para todo o domínio dos valores de campo. Para valores de campo muito baixos, existe um comportamento semiclássico em que a magnetoresistência não apresenta oscilações (Zaremba, 1986). Quando B é suficientemente intenso, o raio da órbita de cíclotron torna-se menor que a dimensão $L$ da amostra e a órbita se fecha dando origem a um comportamento oscilatório. No regime $\Delta \rho_{x x} / \rho x x \ll 1$ e para a ocupação de apenas uma sub-banda (Raikh e Shahbazyan, 1993):

$$
\frac{\Delta \rho_{x x}}{\rho_{x x}} \propto \frac{2 \pi^{2} k T / \hbar \omega_{c}}{\sin \left(2 \pi^{2} k T / \hbar \omega_{c}\right)} \exp \left(-\frac{\pi}{\omega_{c} \tau_{q}}\right) \cos \left(\frac{2 \pi E_{F}}{\hbar \omega_{c}}+\phi\right)
$$


ou seja,

$$
\rho_{x x}(B)=A \frac{2 \pi^{2} k T / \hbar \omega_{c}}{\sin \left(2 \pi^{2} k T / \hbar \omega_{c}\right)} \exp \left(-\frac{\pi}{\omega_{c} \tau_{q}}\right) \cos \left(\frac{2 \pi E_{F}}{\hbar \omega_{c}}+\phi\right)+\rho_{x x}(0)
$$

onde $\phi$ é a fase, T a temperatura e $k$ é a constante de Boltzmann. Essa expressão chamase fórmula de Lifshitz-Kosevich, e o efeito oscilatório da resistividade (função cosseno) é denominado Shubnikov-de Haas.

Pelo ajuste matemático dessa função com as medidas experimentais, podemos extrair, além do tempo quântico, a massa efetiva e a concentração, determinados pelo ajuste do argumento da função cosseno, pois: $n_{s}=\left(m^{*} / \pi \hbar^{2}\right) E_{F}$. Sabendo que o intervalo completo entre duas oscilações sucessivas é de $2 \pi$,

$$
\frac{2 \pi E_{F} m^{*}}{\hbar e} \frac{1}{B_{1}}-\frac{2 \pi E_{F} m^{*}}{\hbar e} \frac{1}{B_{2}}=2 \pi
$$

obtemos dessa igualdade:

$$
n_{s}=\frac{2 e}{h \Delta\left(\frac{1}{B}\right)}
$$

Se $B$ é dado em tesla, podemos obter a concentração $n_{s}$ em $\mathrm{cm}^{-2}$ :

$$
n_{s}=\frac{4.835 \times 10^{10}}{h \Delta\left(\frac{1}{B}\right)}
$$

Para mais de uma sub-banda ocupada, a fórmula fica mais complexa, pois ela envolve as concentrações e os tempos quânticos correspondentes (Ahoujja et al., 1997). A massa efetiva de cada sub-banda define uma frequência de cíclotron própria para cada sub-banda através de $\omega_{c, i}=e B / m_{i}^{*}$.

\subsubsection{Efeito Hall Quântico Inteiro}

As propriedades da mecânica quântica de um 2DES num campo magnético têm um imenso impacto em seu comportamento de transporte. A Figura 1.9, mostra as medidas experimentais da magnetoresistência longitudinal $R_{x x}$ (curva azul) e da resistência de Hall $R_{x y}$ (curva vermelha), as que são tracejadas em função do campo magnético $B^{1}$. A baixos campos $(B<0,2 \mathrm{~T}), R_{x y}$ aumenta linearmente com $\mathrm{B}$, enquanto $R_{x x}$ permanece constante, tal como é esperado a partir da teoria clássica de magnetotransporte num 2DES,

\footnotetext{
${ }^{1}$ Esta amostra tem uma densidade $n=8,6 \times 10^{11} \mathrm{~cm}^{-2}$
} 


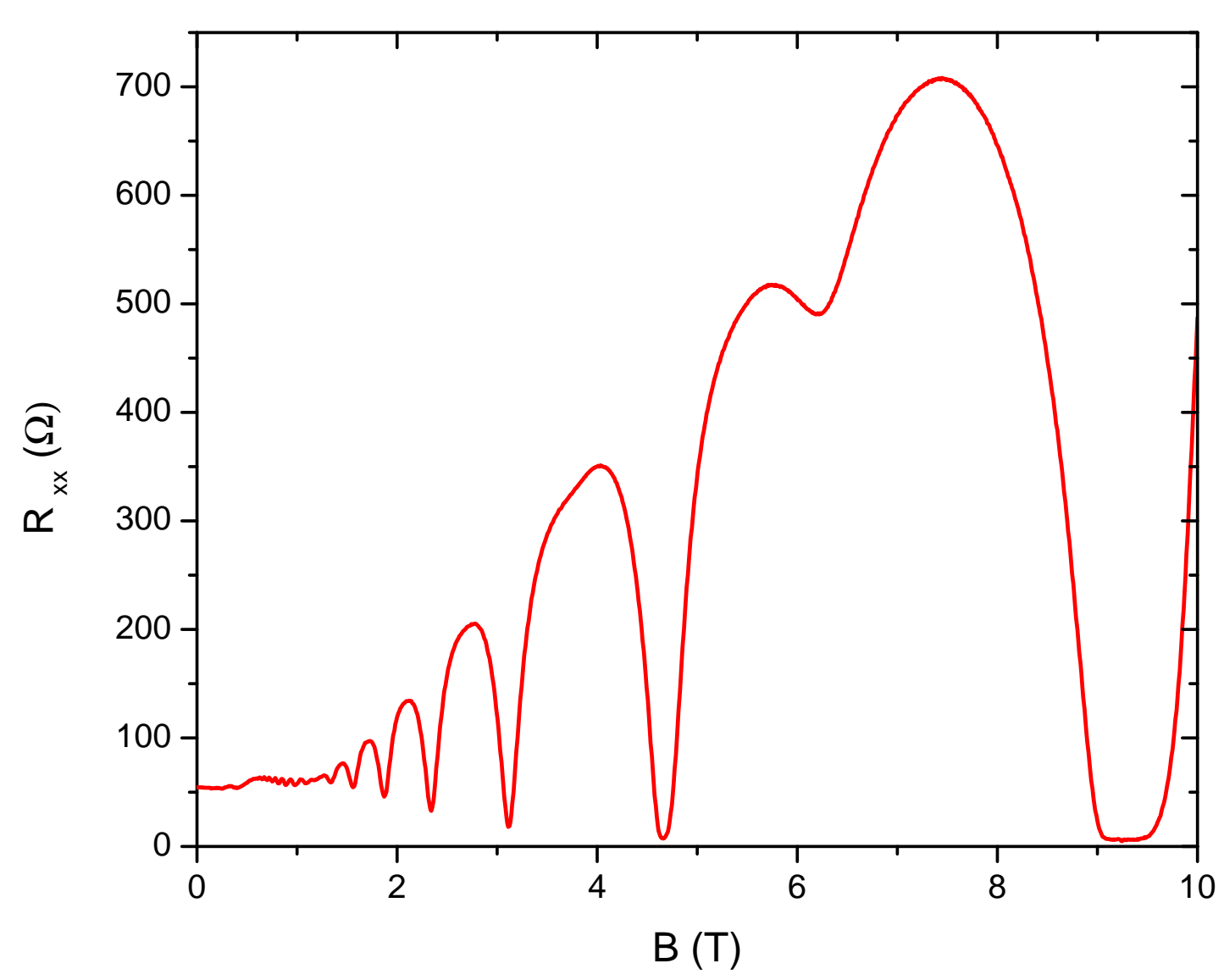

Figura 1.8: Oscilações Shubnikov de Haas da resistência $R_{x x}$ de uma heterojunção de GaAs/AlGaAs a temperatura $T=3,8 K$. Esta amostra tem uma densidade eletrônica $n_{\text {Hall }}=$ $4.5 \times 10^{11} \mathrm{~cm}^{-2}$

como é observado na figura 1.9. No entanto, a maiores campos, uma série de platôs na resistência Hall, acompanhados por um desaparecimento da magnetoresistência longitudinal tornam-se nas características mais relevantes na curva. $O$ valor da resistividade quando exibe platôs bem definidos, é expressa por:

$$
\rho_{x y}=\frac{1}{\nu} \frac{h}{e^{2}}
$$

para um factor de preenchimento inteiro. Este fenômeno, foi descoberto por Klaus von Klitzing, é conhecido como o efeito Hall quântico inteiro (IQHE) (v. Klitzing, 1986; v. Klitzing et al., 1980). O valor da resistência no factor de preenchimento 1 é conhecido como a constante de Klitzing $\left(R_{K}=25,812,807 \ldots\right)$ e é utilizado como a unidade padrão da resistência, podendo ser medido com uma precisão de até $10^{-18}$ (Bachmair et al., 2003; Taylor, 1989). Este depende unicamente das constantes naturais e e $h$ e não é afetado por quaisquer parâmetro da amostra. A constante de estrutura fina $\alpha=\frac{1}{2} \mu_{0} c\left(R_{K}\right)^{-1}$, que 


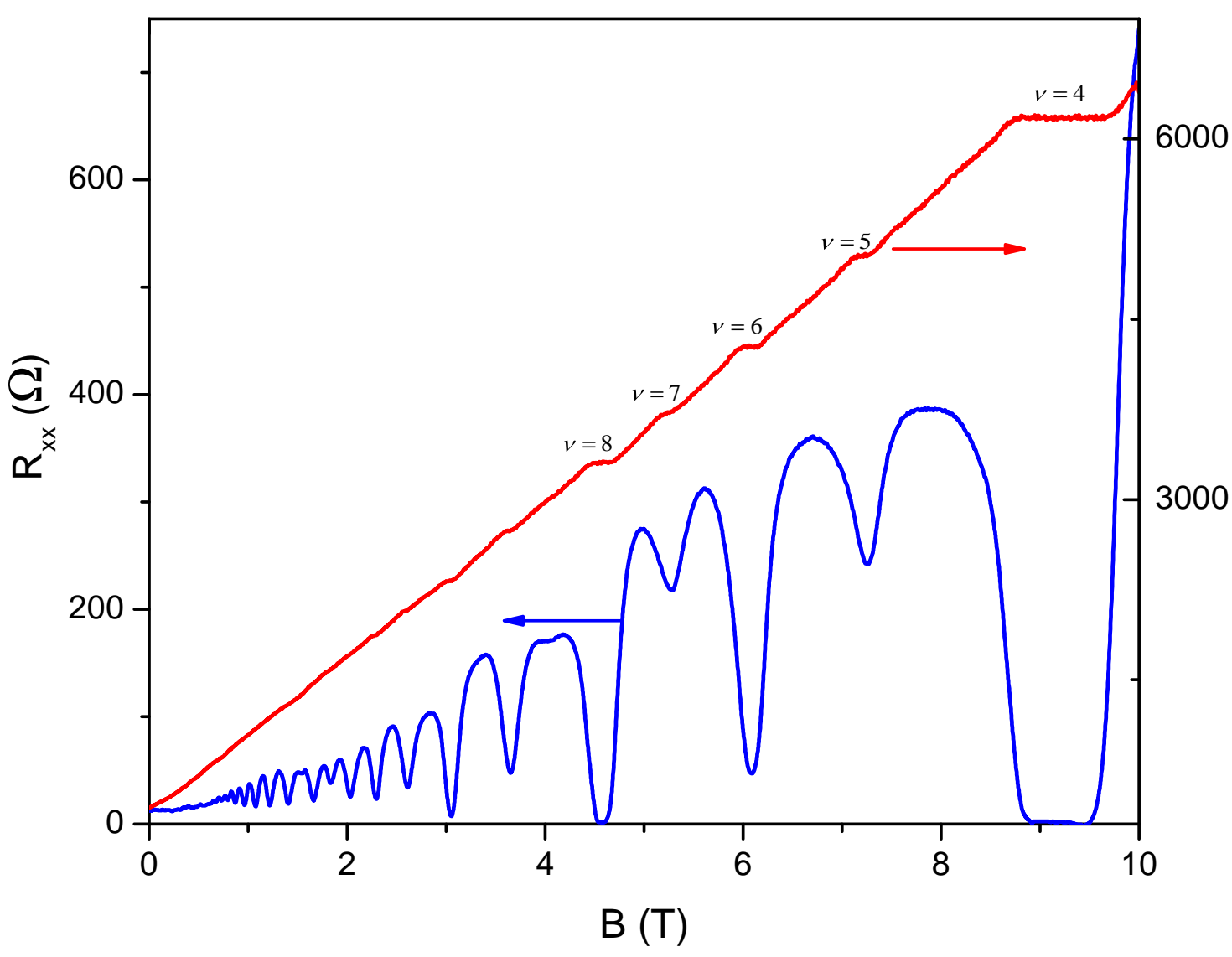

Figura 1.9: Em campos magnéticos elevados a resistência Hall $R_{x y}$ (curva vermelha) é caracterizada por platôs quantizados $(1 / \nu) h / e^{2}$ para valores inteiros de preenchimento, acompanhado por um desaparecimento longitudinal da magnetoresistência $R_{x x}$ (curva azul).

depende da constante de permeabilidade no vácuo $\mu_{0}$, da velocidade da luz $c$ e da constante $R_{K}$, pode ser determinada pela medição da resistência de Hall quantizada (Prange, 1981). As oscilações em $R_{x x}$ a campos baixos onde não há platôs, conhecidas como oscilações Shubnikov-de Haas (SdH), são periódicas com a inversa do campo magnético $(1 / B)$ e inversamente proporcional à densidade: $\Delta(1 / B)=g_{s} e / h n_{e}\left(g_{s}\right.$ é a degenerescência de spin).

Embora que o IQHE foi descoberto há quase 32 anos, ainda existem muitas questões que permanecem sem resposta sobre sua natureza. Várias abordagens e formalismos foram apresentadas, descrevendo com precisão muitos dos fenômenos observados (para uma revisão, ver (Ando et al., 1982; Chakraborty e Pietiläinen, 1995; Janßen et al., 1994; Sarma e Pinczuk, 1996). Em geral, todas estas aproximações incluem a formação dos níveis de Landau a baixas temperaturas $\left(k_{B} T \ll \hbar \omega_{c}\right)$ e a existência de estados localizados. 
Até agora, somente foi considerado a DOS dos níveis de Landau (LLs) como funções tipo $\delta$, ver fig. 1.10(a). No entanto, devido a presença de impurezas e defeitos que reproduzem diferentes mecanismos de interação com os elétrons, evoluindo de um sistema de LLs estritos e finos para um espectro de LLs mais alargados. Nesse novo espectro de LLs existem estados localizados (estados onde os elétrons estão confinados numa pequena região do espaço e não transportam corrente através da amostra) e estados estendidos no centro dos LLs (estados que transportam corrente) [Fig. 1.10(b)]. Em geral, um platô de Hall quantizado em $R_{x y}$ e uma supressão de $R_{x x}$ ocorrem sempre que a energia de Fermi $E_{F}$ encontra-se no gap do cíclotron entre os LLs.

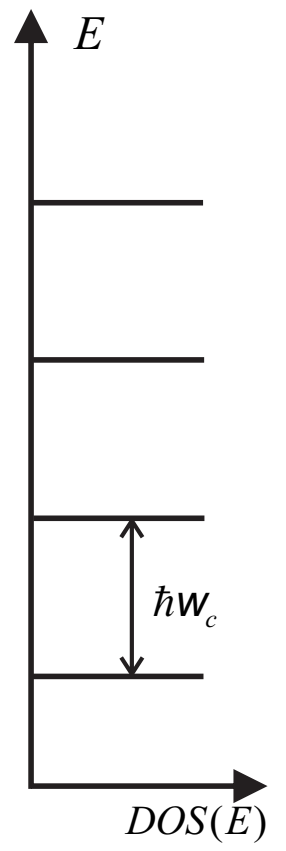

(a)

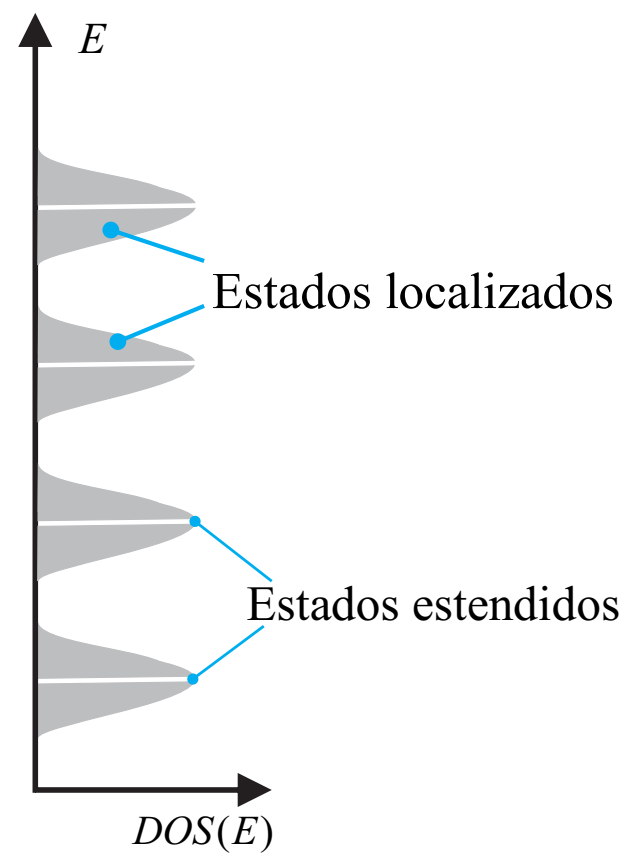

(b)

Figura 1.10: Energia vs densidade de estados (DOS) de um 2DES. (a) Os LLs representados pelas funções tipo $\delta$. (b) A presença de desordem alarga os niveis. Neste novo espectro de LLs existem os estados localizados e os estados estendidos no centro destes LLs alargados. A localização é essencial para a medição do QHE.

Os estados localizados fixam esta energia no gap para uma determinada faixa de valores de campo magnético e os platôs adquirem uma largura finita. Portanto, a existência de estados localizados é essencial para observar os platôs da resistência de Hall $R_{x y}$ no QHE. Se a energia de Fermi cruz a região dos estados estendidos do LL, então $R_{x x}$ terá valores finitos e $R_{x y}$ desvia-se do valor quantizado. Isto pode ser observado na fig. 1.11, 

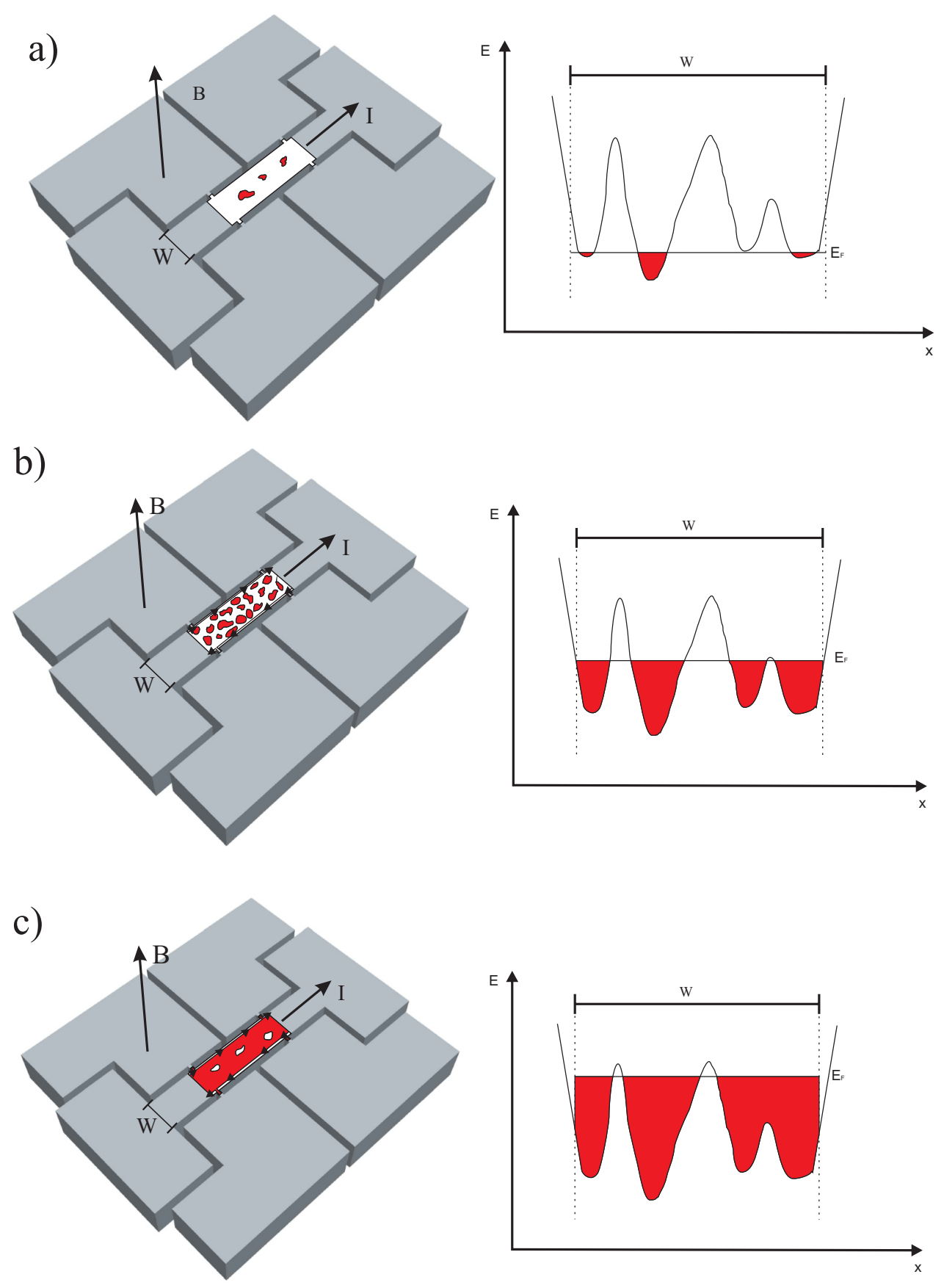

Figura 1.11: Direita: potencial de confinamento para uma amostra de largura $W$. Esquerda: mapas de contorno do potencial. As áreas vermelhas indicam os estados preenchidos e as áreas brancas os estados vazios. (a) Quando o nivel de Fermi, $E_{F}$, cruza a região de estados localizados, os elétrons ocupam apenas vales profundos sem retroespalhamento $\left(R_{x y}\right.$ é quantizada, $\left.R_{x x}=0\right)$. (b) Quando $E_{F}$ está no meio de um LL (estados estendidos), o retroespalhamento dos elétrons é a partir de uma borda para a outra $\left(R_{x y}\right.$ não é quantizado, $\left.R_{x} \neq 0\right)$. (c) $E_{F}$ cruza a região dos estado localizado de maior energia (acima do estado estendido). A corrente flui sobre os contornos de energia dos topos e dos estados de borda, sem retroespalhamento ( $R_{x y}$ é quantizado, $R_{x x}=0$ ). 
onde na presença de um potencial de aleatório de desordem variável (ou seja, quando o comprimento magnético é menor que a escala de comprimento de desordem), os estados dos elétrons se encontram em linhas de contornos de energia constante na paisagem do potencial(potential landscape). A fig. 1.11 mostra no lado direito o potencial de confinamento para uma amostra de largura $\mathrm{W}$, e no lado esquerdo mostra o mapa de contorno do potencial. Neste ponto, $R_{x x}$ é nula e $R_{x y}$ é quantizada.

Com o incremento do campo magnético, mantendo a densidade constante e ocupando um único LL com elétrons, a energia de Fermi move-se através do nível alargado. No estado localizado de menor energia (abaixo do estado estendido), os elétrons primeiramente começam ocupando os vales profundos [Fig. 1.11(a)], e não contribuem para o transporte. A medida que o campo magnético é incrementado, os vales ocupados crescer mais até que suas linhas costeiras, onde os elétrons podem mover-se, atravessando de um lado da amostra para o outro, ver fig. 1.11(b). Os elétrons agora podem mover-se através da amostra e ser espalhados de volta para a fonte. Este processo de retroespalhamento impede a transporte dos elétrons da fonte para o dreno, e portanto, é responsável dos valores finitos de $R_{x x}$ e do afastamento do valor quantizado de $R_{x y}$. Neste caso, a energia de Fermi encontra-se na região dos estados estendidos ou cruza exatamente no centro do nível de Landau. Pode-se observar que nos limites da amostra, a energia do LL aumenta e cruza a energia de Fermi. Os elétrons também podem circular ao longo dos estados de borda, e a direção do fluxo é oposto nas duas bordas da amostra (Halperin, 1982). Com o aumento do campo magnético, os elétrons ocuparão a maior parte da amostra, exceto a parte superior dos máximos do potencial [Fig. 1.11(c)]. As linhas das margens agora podem rodear estes topos ou as bordas da amostra. Neste caso, o retroespalhamento novamente é suprimido e $R_{x x}$ é nulo, enquanto que $R_{x y}$ é quantizada.

Alternativamente, Landau e Büttiker desenvolveram um formalismo para explicar o IQHE empregando estados de borda (Büttiker, 1988): assumindo que o número de estados de borda na amostra depende do número de níveis de Landau que cruzam a energia de Fermi. Estes estados irão transportar corrente, cada um contribuindo uma quantidade $e^{2} / h$ para a condutividade total. Por exemplo, para o fator de preenchimento $\nu=2$, haverá dois estados de borda presentes na amostra. Se a energia de Fermi está situada no gap, então o amostra global é incompressível, ou seja, uma região onde emprega-se uma energia finita para ganhar um elétron extra, e a corrente é transportada entre a fonte e o dreno nas bordas sem retroespalhamento. Como consequência, $R_{x x}$ é nula e $R_{x y}=h / i e^{2}$, onde i é o número de estados de borda. Se a energia de Fermi encontra-se no centro de um LL (no estado estendido), a amostra global torna-se compressível (emprega-se apenas uma pequena quantidade de energia para ganhar um elétron extra) e ocorre o retroespalhamento. Desde que o formalismo de Landauer-Büttiker está relacionado principalmente com os estados 
de borda, considera-se ao sistema que seja quase unidimensional. Esta aproximação tem sido proveitosa para descrever numerosas experiências (Haug et al., 1988; Müller, 1992; Müller et al., 1990, 1992; van Wees et al., 1989; Washburn et al., 1988).

Até agora, foram negligenciadas as interações elétron-elétron para explicar o IQHE. Embora o modelo de partícula única não interativa é muito poderosa para descrever muitos dos fenômenos observados, este não significa que seja completa. Por exemplo, no IQHE, a blindagem do potencial de desordem causada pelas interações de Coulomb entre os elétrons também é importante para entender a natureza dos estados localizados, como foram mostrados nos diversos trabalhos experimentais e teóricos (Ahlswede, 2002; Chklovskii et al., 1992; llani et al., 2004; Siddiki e Gerhardts, 2003). Além disso, a existência de valores quantizados fracionários da resistência de Hall é causada por correlações fortes de elétrons. O tema da próxima seção é o efeito Hall quântico fracionário, que foi descoberto por Störmer e Tsui e explicado por Laughlin.

\subsubsection{Efeito Hall Quântico Fracionário}

Em 1982, depois do descobrimento do efeito Hall inteiro numa estrutura de MOS de silício, Tsui et al., 1982, fizeram estudos refinados do efeito Hall quântico e descubriram novos platôs na resistência Hall para valores fracionários do fator de preenchimento fracionário.

A figura 1.12 mostra o resultado de uma medição do efeito Hall (Willett et al., 1987). O fenômeno só pode ser observado em amostras com alta mobilidade [tipicamente, maior a $10^{6} \mathrm{~cm}^{2} / \mathrm{Vs}$. A teoria do Efeito Hall Quântico Fracionário foi fortemente influenciado pelas idéias de Laughlin (Laughlin, 1983), considerando importante as interações entre os elétrons para a ocorrência do efeito. Tsui, Störmer, e Laughlin ganharam o premio Nobel de Física em 1998 pelo descobrimento experimental e a descrição teórica do efeito Hall Quântico Fracionário.

O efeito Hall quântico fracionário tem semelhanças ao efeito inteiro (desaparecimento de $R_{x x}$ e a quantização de $R_{x y}$ ), mas o efeito Hall quântico fracionário tem um origem distinto. Os platôs na resistência de Hall ocorrem para valores

$$
\rho_{x y}=\frac{h}{e^{2}} \frac{1}{p / q}
$$

onde $q$ e $p$ são inteiros, mas $q$ é limitado a ser ímpar (quase) em todos os casos. Nos campos magnéticos onde a resistividade de Hall $\rho_{x y}$ apresenta platôs, a resistividade longitudinal $\rho_{x y}$ mostra mínimos que se aproximam a zero a temperaturas suficientemente 
baixas (ver $\nu=p / q=2 / 5$ ou $2 / 3$ na figura 1.12). Os mínimos na resistividade longitudinal $\rho_{x x}$ foram encontrados exibindo uma dependência exponencial da temperatura, é dizer, $\rho_{x x}(T) \alpha \exp \left(-\Delta_{p / q} k_{B} T\right)$, e semelhante ao efeito Hall quântico inteiro, indica a formação de estados eletrônicos fundamentais separados por um gap de energia $\Delta_{p / q} \ll \hbar \omega_{c}$. A existência deste gap de energia é o resultado das correlações eletrônicas provocadas pela interação de Coulomb entre os elétrons, formando-se uma nova estrutura dentro de cada nível de Landau.

O efeito Hall quântico fracionário só pode ser observado se a escala do potencial de desordem no 2DEG, a baixas temperaturas, é menor que a escala de energia $\Delta_{p / q}$. Não obstante, para a observação geralmente é importante um pequeno desordem, porque serve para localizar as quase partículas e gerar os platôs na resistência de Hall de largura finita, semelhante ao efeito Hall quântico inteiro.

Na faixa de valores do fator de preenchimento $\nu<1$, todos os elétrons estão no nível de Landau de spin polarizado mais baixo, é dizer, todos os spins estão orientados de forma paralela. Nesta faixa de altos campos magnéticos, nenhum outro nível de Landau desempenha uma função, e a energia cinética é a mesma para todos os elétrons, e portanto é uma constante irrelevante. Como uma conseqüência, a interação de Coulomb entre os elétrons torna-se dominante para a dinâmica dos elétrons. Bob Laughlin publicou a teoria do efeito Hall quântico fracionário em 1983 (Laughlin, 1983), no qual sugeriu a função de onda do estado fundamental de muitos corpos para o fator de preenchimento $\nu=1 / \mathrm{m}$ ( $m>0$ é um número ímpar)

$$
\psi_{1 / m}=\prod_{j<k}\left(z_{j}-z_{k}\right)^{m} e^{-\sum_{l}\left|z_{l}\right|^{2} / 4}
$$

Aqui, $z_{j}=x_{j}+i y_{j}$ é a posição do j-ésimo elétron em notação complexa. Os fatores exponenciais desta função de onda correspondem à função de onda do estado fundamental dos elétrons não interagentes no campo magnético. O prefator (fator de Laughlin-Jastrow) cria nodos na função de onda para o caso no qual duas posições dos elétrons coincidem. Isto incorpora correlações espaciais entre os elétrons, diminuindo a interação de Coulomb entre os elétrons. O número $m$ tem que ser ímpar, para garantir que a função de onda muda de signo quando duas partículas são trocadas. Pode-se observar que esta função de onda trabalha, em principio, mantendo todas as coordenadas dos elétrons $z_{j}$ fixas na equação 1.52 , com $j>0$, e traçando a função de onda resultante como uma função de $z_{0}$. Por conseguinte, se pode falar de partículas compostas, onde três quantas de fluxo estão ligados a cada elétron. Os nodos na função de onda correspondente aos pontos de singularidade da fase são chamados vortices. Uma consequência importante da teoria de Laughlin é a percepção de que as excitações das quase partículas do sistema com 


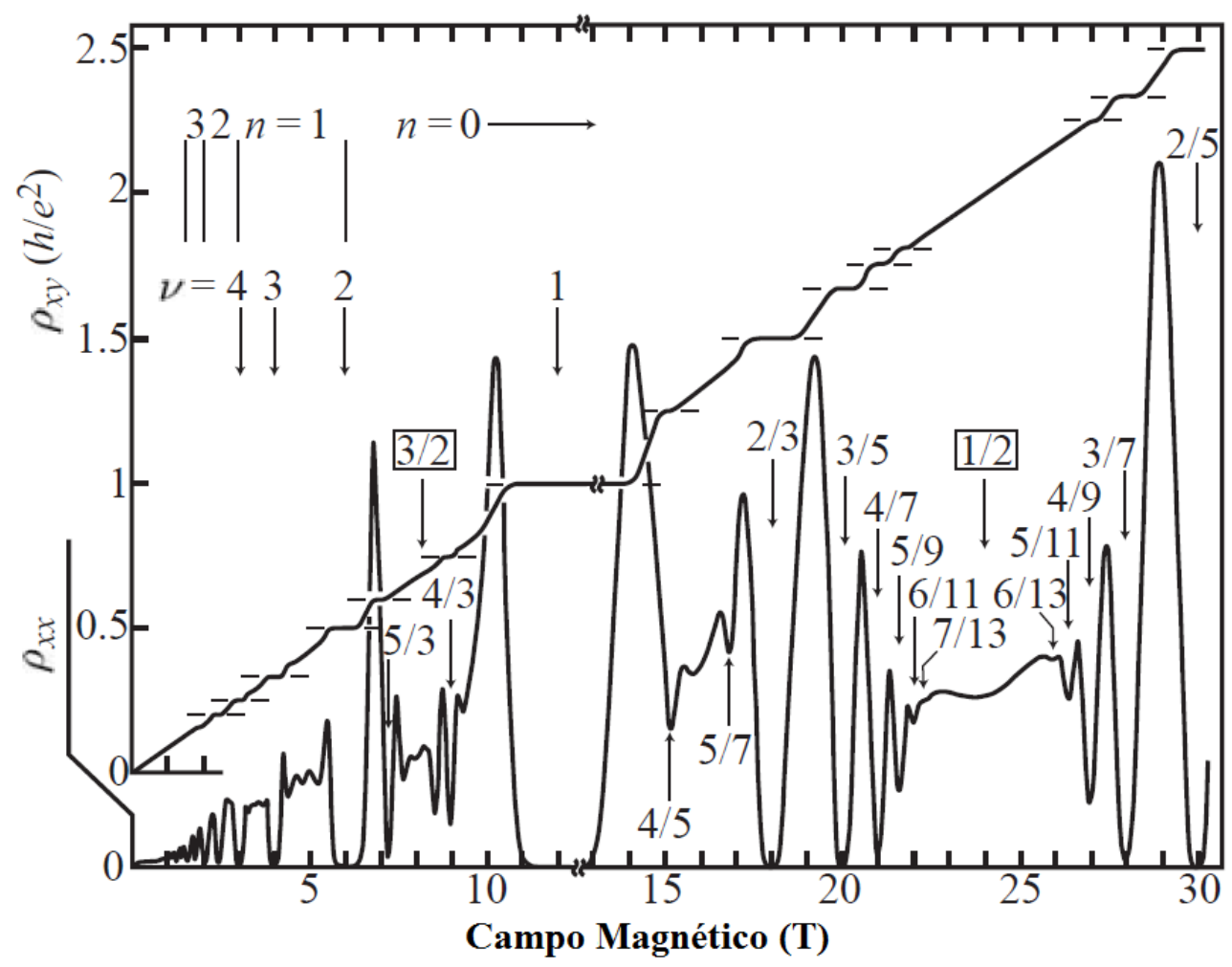

Figura 1.12: Medição do efeito Hall quântico fracionário numa heteroestrutura de GaAs/AlGaAs a temperatura $T=100 \mathrm{mK}$. Os números na figura indicam os fatores de preenchimento (Willett et al., 1987).

fator de preenchimento $\nu=1 / m$ transportam a carga fracionária $q_{e f f}=-|e| / m$. Neste caso, a quantização de $G_{x y}$ ocorre para fatores de preenchimento inteiros da condutância quântica - $|e| q_{e f f} / h$. Semelhante como no efeito Hall quântico inteiro, as resistências Hall quantizadas $h /\left(e q_{e f f}\right) \cdot 1 / \nu_{\text {eff }}$ são obtidas juntamente com $G_{x x} \approx 0$.

\subsection{Bicamadas}

Os sistemas bidimensionais de elétrons (2DES) tem sido intensamente investigado no limite quântico, onde somente uma sub-banda elétrica é ocupada. Interessantes fenômenos físicos deverão ocorrer se mais sub-andas são ocupadas. Isto também é de interesse em aplicações técnicas, onde várias sub-bandas ocupadas são desejáveis para obter uma densidade de portadores maior. Fenômenos peculiares relacionados à ocupação de duas sub-bandas em heteroestruturas de semicondutores foram anteriormente relatados (Fletcher et al. , 1990; L. et al., 1982; Smith et al., 1988; van Houten et al., 1988).

Existem dois métodos diferentes para realizar uma bicamada eletrônica num 2DES. Ambas empregam heteroestruturas de GaAs/AlGaAs crescidas por epitaxia de feixe molecular (MBE). O primeiro método consiste de dois 2DES paralelos de largura $w$ separados 
por uma barreira de tunelamento de espessura $d$. Esta estrutura é chamada poço quântico duplo (DQW), onde duas camadas finas de GaAs são incorporadas na liga de $A l_{x} G a_{1-x} A s$. Dopando-se as barreiras externas aos poços quânticos, haverá transferência de elétrons dos átomos dopantes para a região de cada poço. Estas duas camadas de elétrons constitui uma bicamada eletrônica. Num sistema de DQW dopado, forma-se um 2DEG cuja densidade eletrônica concentra-se majoritariamente no interior de cada um dos poços, tendendo a anular-se nas regiões das barreiras. Neste caso, o sistema assemelha-se ao de dois 2DEG quase independentes, localizados em planos paralelos e separados uma pequena distância. O sistema de DQW pode ser simétrico o assimétrico, dependendo das distribuições de carga nos dois poços. Então, um DQW é simétrico quando as distribuições de carga nos dois poços são simétricos com respeito ao centro da barreira. Como os dois poços quânticos são simétricos, a medida que estes vão sendo aproximados um do outro, existira tunelamento entre os dois poços, o que ocasionara a quebra da degenerescência das energias. Como consequência, haverá o aparecimento dos estados chamados simétrico e antisimétrico, onde o estado simétrico tem a energia menor $\left(E_{S}\right)$ e o estado antisimétrico tem a energia maior $\left(E_{A S}\right)$. Estas energias encontram-se separadas por um gap de energia $\Delta_{S A S}=E_{A S}-E_{A S}$. Este parâmetro $\Delta_{S A S}$ expressa a força de tunelamento dos elétrons entra as camadas. Este gap de energia depende da separação $\Delta Z$ entre as camadas, da espessura $d$ e da altura da barreira. A Figura 1.13 mostra o perfil da banda de condução de um DQW dopado, onde as funções de onda dos estados simétrico e antisimétrico são indicadas por $\phi_{S}$ e $\phi_{A S}$, respectivamente.

O segundo método para produzir um sistema de bicamadas eletrônicas é utilizando um único poço quântico largo (WQW) (Y. W. Suen, 1991) dopado nas barreiras, dentro do qual se forma uma bicamada eletrônica devido à repulsão de Coulomb entre os elétrons. Os elétrons que formam o gás, e que foram capturados dos átomos dopantes localizados na barreira, irão localizar-se em cada heterointerface do poço com a barreira. Desta forma, estes portadores localizados em cada uma das interfaces do poço com a barreira também constituem uma bicamada eletrônica. A estrutura eletrônica do sistemas do poço quântico largo difere do poço quântico duplo porque a barreira de tunelamento entre as camadas dos elétrons se origina da repulsão de Coulomb dos elétrons no poço. A troca de portadores de carga aparece entre as duas camadas eletrônicas que residem em cada uma das interfaces, quando são aproximadas uma da outra. Se, inicialmente a densidade de portadores de carga é baixa, a distribuição eletrônica ao longo do poço quântico largo não exibirá um mínimo evidente no seu centro e o sistema comporta-se como uma camada única. Entretanto, aumentando a densidade de portadores, dois picos são resolvidos, aparecendo um mínimo na distribuição eletrônica. Então, o sistema se comportará como um sistema de bicamadas. Para densidades de portadores maiores, os dois picos na distribuição eletrônica são mais puxados às interfaces, e a profundidade relativa do mínimo 


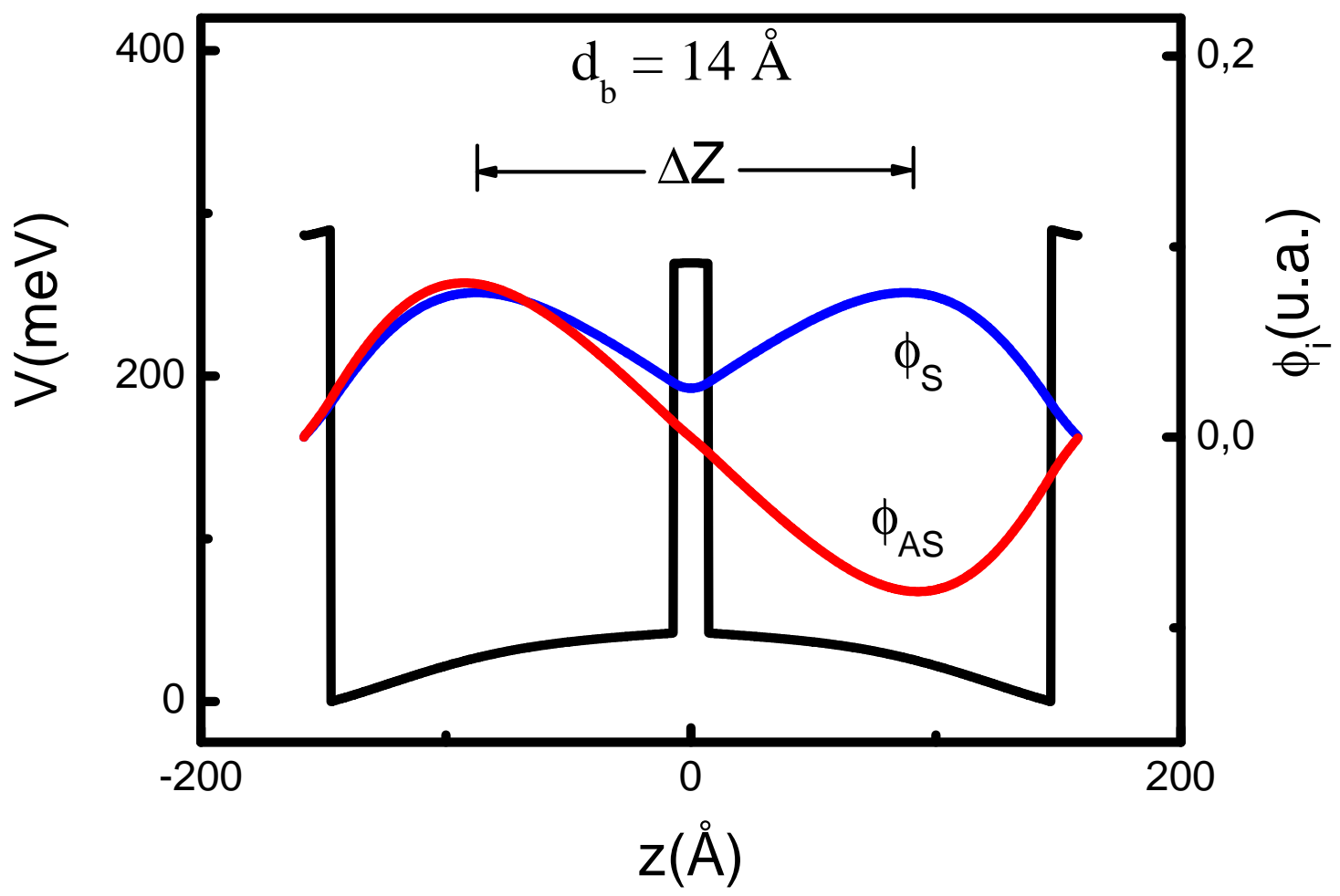

Figura 1.13: Perfil da banda de condução de um $D Q W$ dopado, que esta constituído por dois poços quânticos e separados por uma barreira de tunelamento de espessura $d_{b}$. Também são indicadas as funções de onda simétrica $\phi_{S}$ e antisimétrica $\phi_{A S}$, assim como a distância de separação $\Delta Z$ entre as camadas.

na distribuição eletrônica torna-se maior, é dizer, as camadas são separadas mais e mais. Esta separação progressiva é devido à repulsão de Coulomb entre os elétrons. Quando o poço quântico largo esta balanceado, é dizer, a distribuição de carga é simétrica, as duas sub-bandas ocupadas são os estados simétrico (S) e antisimétrico (AS), e as correspondentes energias estão separadas por um gap de energia $\Delta_{S A S}=E_{A S}-E_{A S}$. Uma propriedade importante do sistema eletrônico num poço quântico largo quando a largura do poço quântico é mantida fixa, é a dependência do gap de energia $\Delta_{S A S}$ e da distância de separação entre as camadas $\Delta Z$ da densidade de elétrons $n$ : aumentando $n$ faz aumentar $\Delta Z$ e diminuir $\Delta_{S A S}$, de modo que o sistema pode ser tunelado de um sistema de bicamadas forte para um sistema de camada única diminuindo $n$. Esta evolução com a densidade afeta os estados eletrônicos correlacionados, e portanto as propriedades da magnetotransporte. A Figura 1.14 mostra o perfil da banda de condução de um WQW dopado, onde as funções de onda dos estados simétrico e antisimétrico são indicadas por $\phi_{S}$ e $\phi_{A S}$, respectivamente. 


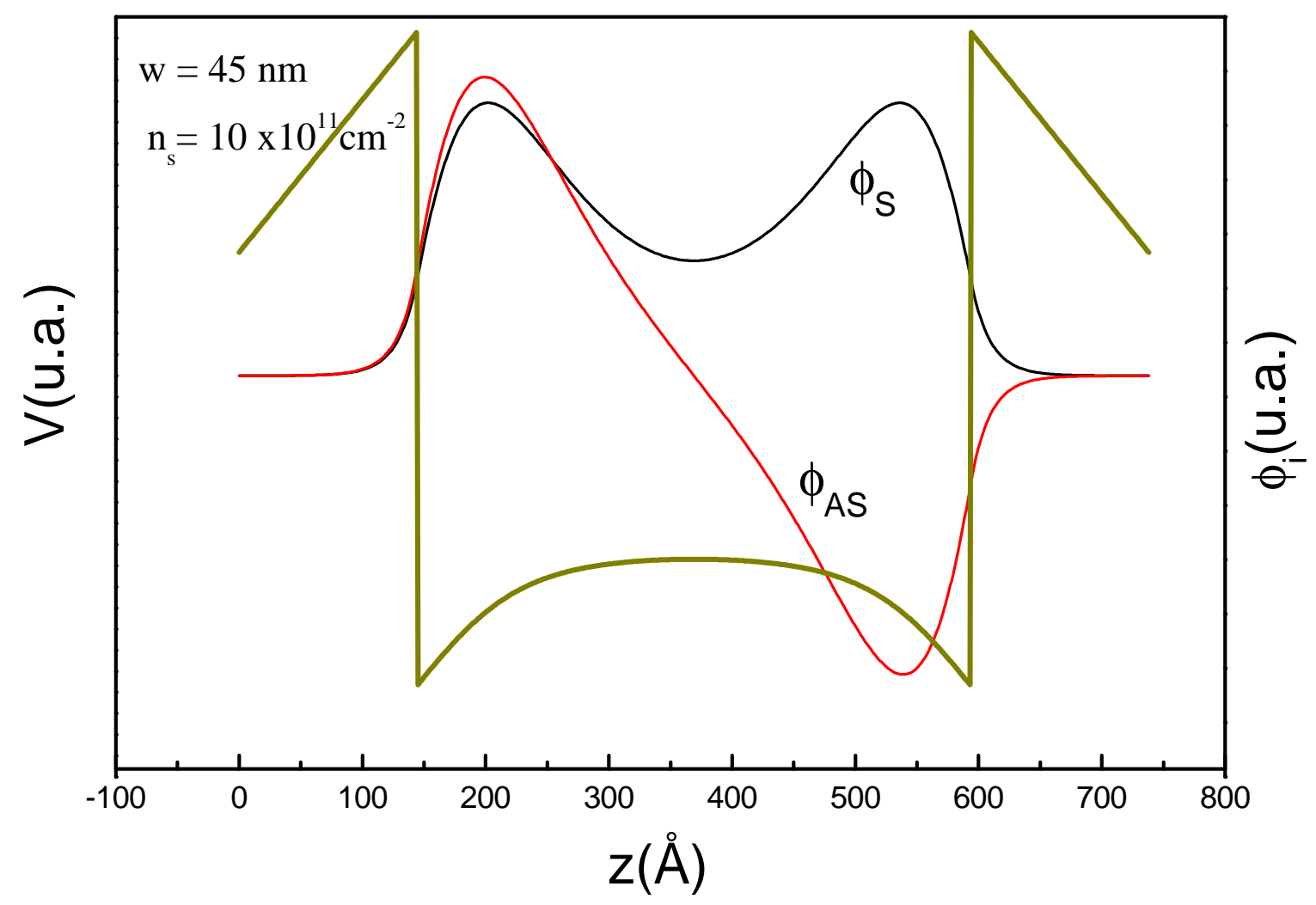

Figura 1.14: Perfil da banda de condução de um WQW, onde um sistema de bicamadas se forma devido à repulsão de Coulomb entre as camadas. Mostra-se as funções de onda simétrica $\phi_{S}$ e antisimétrica $\phi_{A S}$.

\subsubsection{Níveis de Energia de uma Bicamada e Cruzamento dos Ní- veis de Landau em um Campo Magnético Perpendicular}

A densidade de estados (DOS) associada com cada sub-banda é discretizada numa série de níveis de Landau (LL), como se mostra na figura 1.15, quando um sistema 2DEG com duas sub-bandas ocupadas está na presença de um campo magnético perpendicular. Cada nível de Landau é descrito por três números quânticos: o índice da sub-banda (S,AS), o número quântico orbital $(0,1,2, \ldots)$ e a orientação de spin $(\uparrow, \downarrow)$. Numa 2DEG com duas sub-bandas ocupadas, o cruzamento dos LLs pode ser descrito com o pseudospin, ou seja, um spin generalizado aplicado a um sistema de com duas sub-bandas ocupadas (Ezawa , 2000). O pseudospin é a coleção dos três números quânticos $(i, N, s)$ das partículas que residem num LL. Os níveis de Landau são sucessivamente depopulados com o aumento do campo magnético, ao mesmo tempo que ocorre um aumento do gap de Zeeman. Desde que as funções de onda associadas com os indices das sub-bandas S e AS são diferentes, a função de distribuição eletrônica é permanentemente mudada a um grau menor durante este processo de depopulação. 


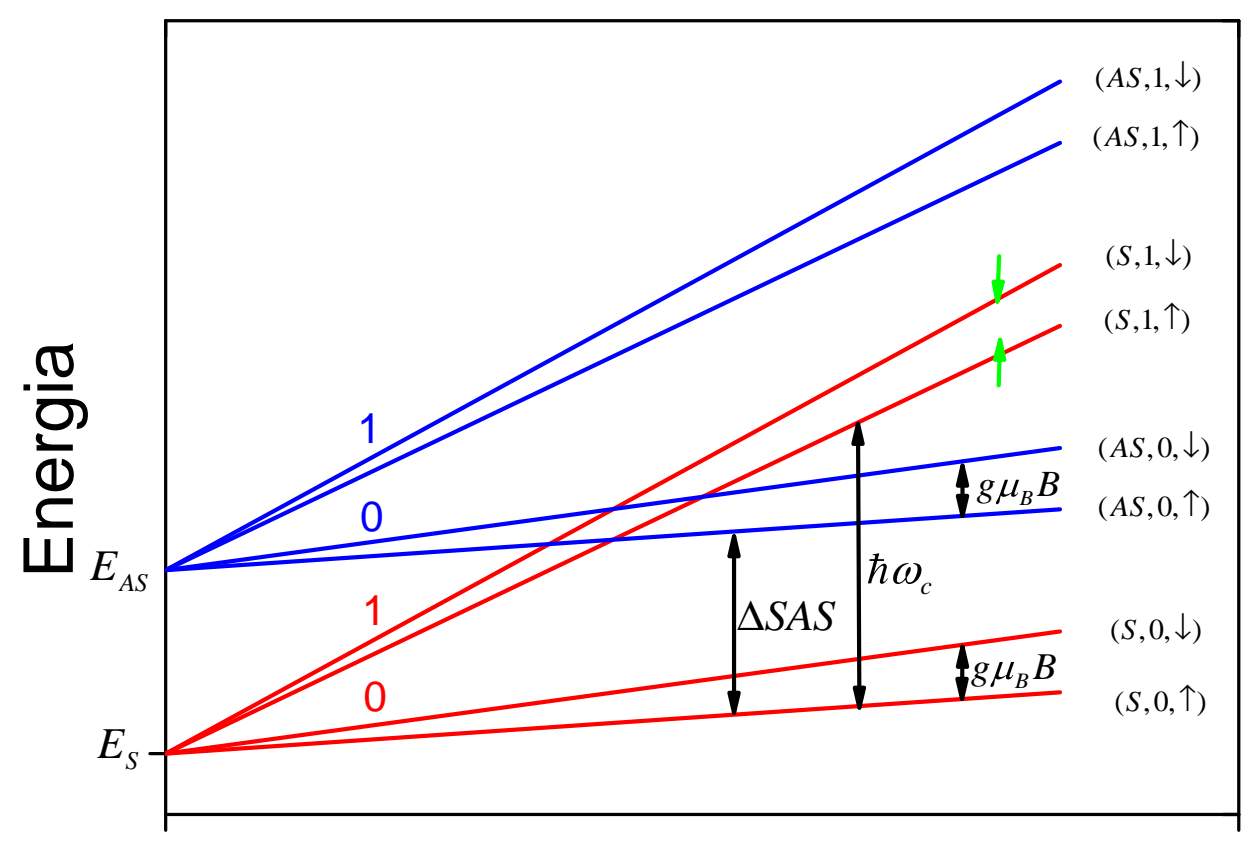

B

Figura 1.15: Representação da formação de dois leques de níveis de Landau, devido à ocupação de duas sub-bandas separadas pela energia $\Delta S A S$. Aumentando o campo magnético os dois leques de niveis penetram-se, originado o cruzamento dos niveis de Landau. Os niveis de Landau são rotulados por três números quânticos: índice da sub-banda, o número quântico orbital e a orientação do spin.

As experiências de transporte a baixos campos magnéticos são caracterizados pelas oscilações Shubnikov-de Haas ( $\mathrm{SdH}$ ) devido as duas diferentes periodicidades $1 / \mathrm{B}$, que correspondem as diferentes densidades das sub-bandas $n_{S}$ e $n_{A S}$. Elas podem ser extraídas do análise de Fourier e esta diretamente relacionada com o desdobramento das sub-bandas. Esta correlação é usada experimentalmente para determinar o desdobramento entre as sub-bandas.

Os dois leques de níveis de Landau penetram-se e o cruzamento dos níveis de Landau ocorre com o aumento do campo magnético. O campo magnético crítico de qualquer ponto de cruzamento entre dois níveis de Landau pertencentes a diferentes leques de níveis Landau, é controlado pela energia de desdobramento entre as sub-bandas $\triangle S A S$.

\subsubsection{Espalhamento Magneto-Inter-sub-banda}

O efeito Shubnikov-de Haas $(\mathrm{SdH})$ é amplamente usada para caracterizar os sistemas bidimensionais de elétrons (2DES) em heterojunções semicondutoras. Quando uma única 
sub-banda elétrica é povoada, as oscilações SdH na magnetoresistência têm uma forma matemática simples (Isihara e Smrc?ka, 1986). Heterojunções de $A l_{0.3} G a_{0.7} A s / G a A s$ com duas sub-bandas ocupadas foram crescidas. As experiência de transporte em tais amostras podem ser encontrados nas refs.(Harris et al., 1987; L. et al., 1982)

Experimentalmente e teoricamente foi descoberto que a magnetoresistência oscilatória num 2DEG de alta mobilidade com duas sub-bandas ocupadas contém pelo menos três componentes (Coleridge, 1990; Leadley et al., 1992; Raikh e Shahbazyan, 1994; Sander et al., 1996): as oscilações SdH das duas sub-bandas e uma oscilação devido ao espalhamento elástico entre as sub-bandas. Esta terceira componente foi chamada efeito de espalhamento magneto-inter-sub-banda (MIS) por Raikh e Shahbazyan (Raikh e Shahbazyan , 1994). Uma diferença fundamental entre as oscilações MIS e as oscilações SdH, e que as oscilações MIS apresentam uma sensibilidade muito baixa à supressão com a temperatura, isto é, permanecem até temperaturas altas onde as oscilações SdH já foram suprimidas. O campo fundamental das oscilações MIS é a medida do desdobramento das sub-bandas no 2DES, assumindo a massa efetiva independente da sub-banda (Sander et al., 1996).

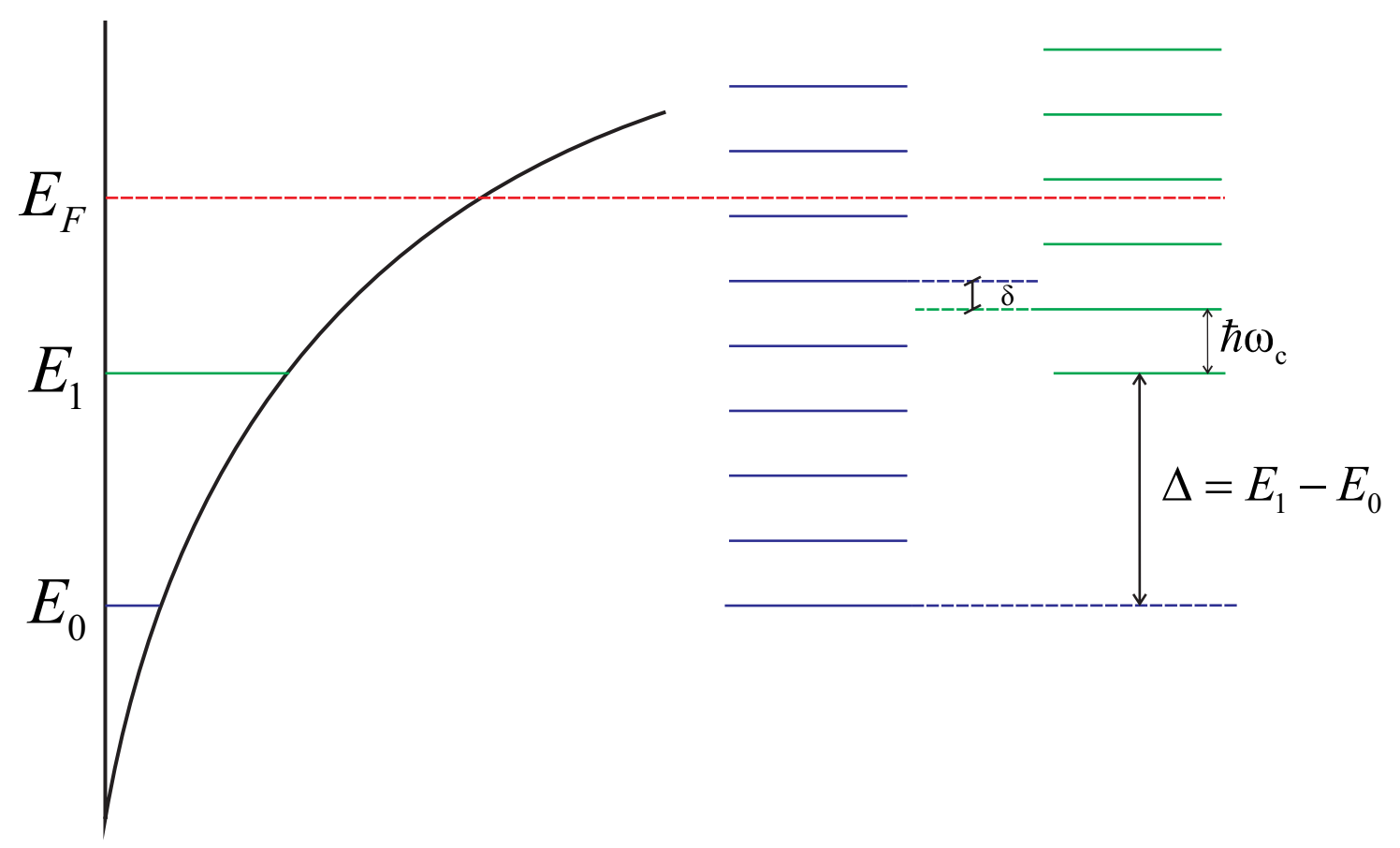

Figura 1.16: Representação esquemática das oscilações MIS. Espectro de energias para a primeira e a segunda sub-banda, representados por uma série de niveis de Landau para cada subbanda ocupada. Quando $\Delta / \hbar \omega_{c}$ é um número inteiro (ou seja, $\delta=0$ ), dois níveis de Landau diferentes são alinhados, resultando um máximo na magnetoresistência.

A Figura 1.53 mostra o mecanismo físico que gera as oscilações MIS a baixos campos magnéticos, quando duas sub-bandas são ocupadas (Raikh e Shahbazyan, 1994). Na presença de um campo magnético perpendicular, cada sub-banda é discretizada numa 
série de níveis Landau associados com as energias de confinamento $E_{i}(i=0,1)$ de cada sub-banda. O espectro de energias dos estados eletrônicos para cada sub-banda são dados pela expressão:

$$
E_{i n}=E_{i}+\hbar \omega_{c}\left(n_{i}+\frac{1}{2}\right)
$$

Onde $\omega_{c}$ é a frequência do cíclotron. Quando $\delta=E_{0 n}-E_{1 m}=0$, então $\Delta=k \hbar \omega_{c}$, onde $k=n_{0}-n_{1}$ é um número inteiro, portanto ocorre o alinhamento dos níveis de Landau, e uma modulação periódica é observada.

O efeito de espalhamento elástico inter-sub-banda sobre as oscilações SdH num 2DES com duas sub-bandas tem sido estudado teoricamente, utilizando a inversão do tensor de condutividade de duas sub-bandas (Coleridge, 1990; Leadley et al., 1992), e o formalismo de Kubo (Raikh e Shahbazyan, 1994). As duas diferentes aproximações predizem uma componente oscilatória adicional na magnetoresistência. O efeito MIS é devido ao aumento do espalhamento elástico inter-sub-banda no cruzamento dos níveis de Landau das subbandas. Este cruzamento ocorre para frequências dadas por:

$$
f=\frac{E_{01} m^{*}}{\hbar e\left(n_{0}-n_{1}\right)}
$$

onde $E_{01}=E_{1}-E_{0}$ é a energia de desdobramento entre as sub-bandas, $n_{i}$ são os números quânticos de Landau da primeira sub-banda $(i=0)$ e da segunda sub-banda $(i=1)$. Os índices $n_{i}$ cumprem a condição $n_{0}-n_{1}>0$ quando o $n_{i}$-ésimo nível de Landau da subbanda mais baixa pode cruzar o correspondente nível de Landau da segunda sub-banda. É conveniente definir $f_{M I S} \equiv E_{01} m^{*} / \hbar e$, a frequência fundamental das oscilações MIS (Sander et al., 1998). Na eq. 1.54, substituindo $E_{01}$ por $E_{F, i}=E_{F}-E_{i}(i=0,1)$ e a diferença $n_{0}-n_{1}$ pelo fator de preenchimento $\nu$, e usando a relação entre $E_{F, i}$ e a densidade de portadores $n_{s, i}$ de cada sub-banda do 2DES, é obtida a frequência fundamental das oscilações SdH para cada sub-banda: $f_{S d H, i}=h n_{s, i} / 2 e$.

Leadley et al e Coleridge (Coleridge, 1990; Leadley et al., 1992), desenvolveram o tensor da condutividade para duas sub-bandas, a qual depende da energia. Depois de inverter este tensor e calculando a média com a função de Fermi-Dirac, a seguinte equação é obtida, que somente é aplicável a baixos campos magnéticos e a baixas temperaturas: 


$$
\begin{aligned}
\frac{\Delta \rho_{x x}}{\rho_{0}} & =2 A_{0} \frac{X}{\sinh X} \exp \left(-\frac{\pi}{\omega_{c} \tau_{0}}\right) \cos \left[\frac{2 \pi\left(E_{F}-E_{0}\right)}{\hbar \omega_{c}}+\pi\right] \\
& +2 A_{1} \frac{X}{\sinh X} \exp \left(-\frac{\pi}{\omega_{c} \tau_{1}}\right) \cos \left[\frac{2 \pi\left(E_{F}-E_{1}\right)}{\hbar \omega_{c}}+\pi\right] \\
& +2 B_{01} \frac{2 X}{\sinh 2 X} \exp \left[-\frac{\pi}{\omega_{c}}\left(\frac{0}{\tau_{0}}+\frac{0}{\tau_{1}}\right)\right] \cos \left[\frac{2 \pi\left(2 E_{F}-E_{0}-E_{1}\right)}{\hbar \omega_{c}}\right] \\
& +2 B_{01} \exp \left[-\frac{\pi}{\omega_{c}}\left(\frac{0}{\tau_{1}}+\frac{0}{\tau_{1}}\right)\right] \cos \left(\frac{2 \pi E_{01}}{\hbar \omega_{c}}\right)
\end{aligned}
$$

Os fatores das amplitudes $A_{0}, A_{1}$ e $B_{01}$ estão relacionados às probabilidades de espalhamento intra-sub-banda e inter-sub-banda $P_{i j}(i, j=0,1)$ e $X=2 \pi^{2} K_{B} T / \hbar \omega_{c}$. Os dois primeiros termos (equações 1.55a e 1.55b) são os típicos termos das oscilações SdH na presença de duas sub-bandas. O terceiro termo, eq. ( $1.55 \mathrm{c})$, contem o fator de amortecimento térmico $2 X / \sinh (X)$, que leva ao amortecimento da temperatura muito mais forte do que dos termos das oscilações SdH. O quarto termo, a equação ( $1.55 \mathrm{~d}$ ), é o termo das oscilações MIS. Ele não contém o fator de amortecimento térmico $X / \sinh (X)$ e frequência MIS é proporcional ao desdobramento entre sub-bandas, $E_{01}$.

Usando a relação $A_{i}>B_{01}$ (Leadley et al., 1992) e assumindo que os fatores das amplitudes nas equações ( 1.55) não diferem por várias ordens de magnitude, pode ser facilmente verificado que o diferente comportamento do amortecimento térmico dos termos $\mathrm{SdH}$ e MIS conduz a três regimes de temperatura na magnetoresistência. A baixas temperaturas, os termos SdH dominam e a altas temperaturas o termo MIS. A temperaturas intermédias, a magnetoresistência oscilatória é dividida num regime de campo baixo e campo alto, o termo MIS é dominante abaixo de um determinado campo e os termos SdH acima desse campo. Os termos SdH das equações (1.55a) e (1.55b) e o termo MIS da equação ( $1.55 \mathrm{~d}$ ) têm uma diferença de fase $\Delta \phi=\pi$, ou seja, têm um sinal diferente quando os fatores das amplitudes $A_{0}, A_{1}$, e $B_{01}$ são positivos. É interessante considerar o caso $f_{S d H, 1} \approx f_{M I S}$ nas equações ( $1.55 \mathrm{a}$ ) e ( $1.55 \mathrm{~d}$ ). Para certo valor de campo $B_{\text {node }}$ a amplitude dos termos $\mathrm{SdH}$ e MIS serão iguais, e devido à diferença de fase deve ocorrer a interferência destrutiva. Acima e abaixo de $B_{\text {node }}$, as amplitudes são diferentes e, portanto, a supressão da oscilação será incompleta. No entanto, um nodo claro no envelope da oscilação é esperado. Para $f_{S d H, 0} \neq f_{M I S}$ o nodo se tornará mais fraco quando a diferença entre as duas frequências fundamentais aumenta. 
A diferença de fase pode ser entendida por simples argumentos. Se o nível de Fermi está exatamente entre os níveis de Landau, um número inteiro $n$ de níveis de Landau é preenchido, correspondendo a $\left(E_{F}-E_{0}\right) / \hbar \omega_{c}=n$, com $n>0$ e assumindo a degenerescência de spin. Para estes campos, a resistência provocada pelo espalhamento elástico intra-subbanda, tem um mínimo devido ao mínimo na densidade de estados. Isto corresponde à fase $\phi=\pi$ no cosseno dos termos SdH. No cruzamento dos níveis de Landau das sub-bandas, ou seja, quando $E_{01} / \hbar \omega_{c}=n$, o canal de espalhamento elástico inter-sub-banda se abre e a resistência tem um máximo local. Portanto, a fase é igual a zero no cosseno do termo MIS.

\subsubsection{Oscilações MIS em um Poço Quântico Duplo}

Uma descrição quantitativa do magnetotransporte em poços quânticos duplos (DQWs), tendo em conta o espalhamento elástico dos elétrons, esta baseada no hamiltoniano escrito como uma matriz de $2 \times 2$ na base de auto-estados de um poço simples:

$$
\hat{H}=\left|\begin{array}{cc}
\frac{\pi^{2}}{2 m}+\frac{\Delta}{2}+V_{\mathbf{r}}^{u} & -\frac{\Delta_{S A S}}{2} \\
-\frac{\Delta_{S A S}}{2} & \frac{\pi^{2}}{2 m}-\frac{\Delta}{2}+V_{\mathbf{r}}^{l}
\end{array}\right|
$$

onde $\pi=-i \nabla_{r}-(e / c) \mathbf{A}_{\mathbf{r}}$ é o operador momentum cinético, $\mathbf{A}_{\mathbf{r}}$ é o potencial vetor, $V_{\mathbf{r}}^{i}$ são os potenciais aleatórios das impurezas e outras inomogeneidades para o poço perto da superfície $(i=u)$ e para o poço mais distante da superfície $(i=l)$, e $\mathbf{r}=(x, y)$ é o vetor posição no plano $X Y . \Delta_{S A S}$ denota o desdobramento das sub-bandas devido ao acoplamento dos poços, e $\Delta$ é o desdobramento na ausência de tunelamento. Para DQWs simétricos ou balanceados, $\Delta=0$. O espectro de energia do elétron livre é dado pelas duas séries de níveis de Landau das sub-bandas superior $(+)$ e inferior (-): $\varepsilon_{n}^{ \pm}= \pm \Delta_{T} / 2+\varepsilon_{n}$, onde $\varepsilon=\hbar \omega_{c}(n+1 / 2)$ e $\Delta_{T}=\sqrt{\Delta_{S A S}^{2}+\Delta^{2}}$ é o desdobramento inter-sub-banda total. Em DQWs simétricos, $\Delta_{T}=\Delta_{S A S}$ é o gap de energia entre os estados com funções de onda simétrica $\psi_{z}^{(-)}$e antisimétrica. Para campos magnéticos suficientementes fracos, o desdobramento Zeeman é desprezível.

Para calcular a resistividade $\rho_{d}$ no sistema, é considerado um potencial simétrico de curto alcance, caracterizado pela correlação $\left\langle\left\langle V_{\mathbf{r}}^{i} V_{\mathbf{r}^{\prime}}^{i^{\prime}}\right\rangle\right\rangle \simeq w \delta_{i i^{\prime}} \delta\left(\mathbf{r}-\mathbf{r}^{\prime}\right)$, no limite de desordem baixa, quando a taxa de espalhamento é $1 / \tau=m w / \hbar^{3}$. A condutividade é obtida a partir do formalismo de Kubo e fazendo uso da técnica das funções de Green na aproximação auto-consistente de Born (SCBA). A resistividade em DQWs com duas sub-bandas ocupadas em termos do fator de Dingle $e^{-\alpha}\left(\alpha=\pi / \omega_{c} \tau\right)$, tanto para sistemas simétricos quanto assimétricos, é expressa por (Mamani et al., 2008; Mamani, 2009): 


$$
\rho_{x x}=\rho_{0}\left\{1-4 e^{-\alpha} \mathcal{T} \cos \left(\frac{2 \pi \varepsilon_{f}}{\hbar \omega_{c}}\right) \cos \left(\frac{\pi \Delta_{T}}{\hbar \omega_{c}}\right)+e^{-2 \alpha}\left[a_{+}+a_{-} \cos \left(\frac{2 \pi \Delta_{T}}{\hbar \omega_{c}}\right)\right]\right\}
$$

onde $\rho_{0}=m / e^{2} n_{s} \tau$ é a resistividade de Drude em campo zero, $a_{ \pm}=1 \pm \delta^{2}-(1 \pm$ $\left.\delta^{4} /\left[1+\left(\omega_{c} \tau\right)^{2}\right]\right)$ e $\delta=\Delta / \Delta_{T}$. A energia de Fermi $\varepsilon_{F}$ é considerada a partir do ponto médio do gap das duas sub-bandas e a função $\mathcal{T}=\left(2 \pi^{2} T / \hbar \omega_{c}\right) / \sinh \left(2 \pi^{2} T / \hbar \omega_{c}\right)$ descreve o amortecimento térmico das oscilações da resistividade. O segundo termo que contém $e^{-\alpha}$ descreve a oscilações $\mathrm{SdH}$ e o batimento devido às duas sub-bandas; o termo que contém $e^{[}-2 \alpha$ descreve a contribuição das oscilações MIS (termo com cosseno) e também contém a componente positiva da resistência $\left(a_{+}\right)$, e o fator de amortecimento térmico não está presente em ele (as correções dependentes da temperatura para este termo são desprezíveis devido a que são pequenas em comparação con o segundo termo). O fator de amortecimento está presente só no termo correspondente às oscilações SdH. As expressões para os coeficientes $a_{ \pm}$podem ser expressos em termos dos tempos de espalhamento inter-sub-banda e intra-sub-banda em DQWs, que são dados por $\tau_{\text {inter }}=2 \tau /\left(1-\delta^{2}\right) \mathrm{e}$ $\tau_{\text {intra }}=2 \tau /\left(1+\delta^{2}\right)$, respectivamente, assim que $\tau^{-1}=\tau_{\text {inter }}^{-1}+\tau_{\text {intra }}^{-1}$. Esta representação mostra que a contribuição MIS (no coeficiente $a_{-}$)é proporcional à taxa de espalhamento $\tau_{\text {inter }}^{-1}$.

Quando a temperatura aumenta, o segundo termo do lado direito da equação 1.57 desaparece e somente as oscilações MIS permanecem. Estas oscilações são periódicas com o inverso do campo magnético $1 / B$ e apresenta máximos quando $\Delta_{T}=k \hbar \omega_{c}$. Em DQWs balanceados $\left(\delta=0\right.$ e $\left.a_{+}=a_{-}\right)$, a distribuição da amplitude das funções de onda $\left|\psi_{z}^{-}\right|$ e $\left|\psi_{z}^{+}\right|$são iguais, e a probabilidade de espalhamento inter-sub-banda é a maior possível. Quando a simetria do sistema é modificada pela aplicação de um potencial externo (uma voltagem de porta), $\delta^{2}$ aumenta, então as funções de onda começam a estar localizadas em cada poço, e o espalhamento inter-sub-banda é amortecido, assim que as amplitudes das oscilações MIS (dependente do coeficiente $a_{-}$) é diminuída, enquanto que a magnetoresistência positiva não oscilatória (coeficiente $a_{+}$) torna-se maior. 


\section{Capítulo 2}

\section{Redes de Antipontos Quânticos}

\subsection{Introdução}

O transporte através dos arranjos de dispersores estacionários é um dos modelos motivadores da dinâmica não-linear. Experimentos em dispositivos semicondutores foram desenhados e realizados para simular o transporte eletrônico. O progresso em litografia submicrométrica tornou possível estudar o transporte no regime balístico, que é principalmente governado pela forma do contorno da amostra. Por outro lado, a dinâmica dos bilhares magnéticos tem sido empregada para entender o caos clássico e sua ligação com o caos quântico (Heller, 1984). Em tais sistemas, as partículas são confinadas numa região do espaço definido pelo contorno, e são livres para executar colisões balísticas. Para certas formas regulares dos bilhares (por exemplo, circulares), o sistema é integrável e o movimento é completamente previsível.

Os arranjos de antipontos em heteroestruturas semicondutoras em um sistema bidimensional de elétrons (2DES) têm sido um modelo do sistema que permitiu o estudo da dinâmica caótica clássica na matéria da física condensada. Uma ilha isolante rodeada por um 2DEG é comumente chamado "antiponto"(Ensslin e Petroff, 1990). O comportamento dos elétrons neste tipo de super-redes de antipontos está estreitamente relacionado com o movimento de partículas em um sistema conhecido na literatura científica como o bilhar de Sinai (Sinai e Chernov, 1987). O bilhar de Sinai é um modelo teórico proposto por Ya. G. Sinai em 1987, para o estudo da dinâmica clássica e suas manifestações nos espectros quânticos. O problema dos bilhares do Sinai tem recebido uma ampla atenção no campo da física matemática. No caso ideal, os elétrons se movem semi-classicamente num plano que contem discos refletores (antipontos) de rádio $d / 2$, centrados nos sítios de uma rede quadrada com período de rede $a$, como se mostra na figura 2.1(a).

Vários fenômenos interessantes têm sido observados nas redes de antipontos na presença de campos magnéticos, incluindo o quenching do efeito Hall (Fleischmann et al., 1994; 
(a)

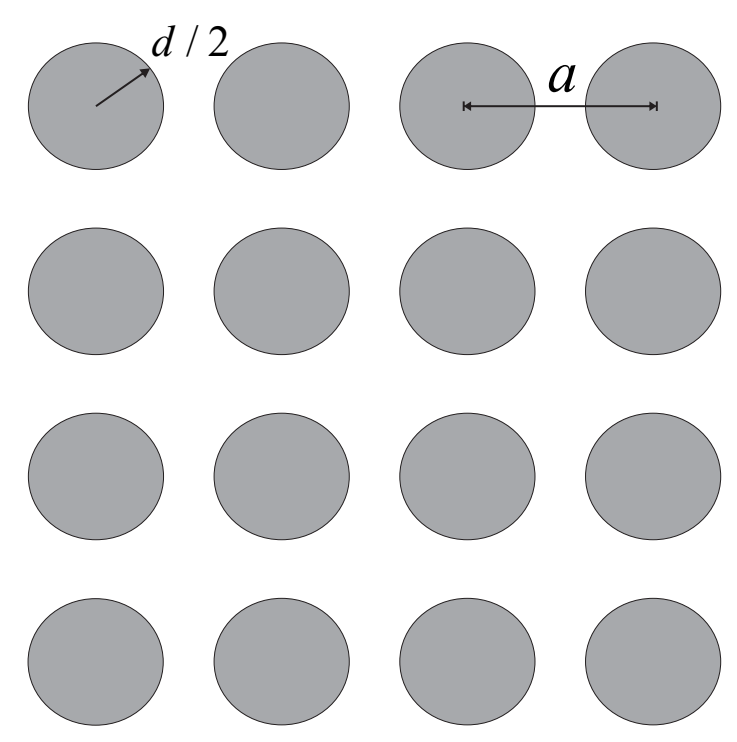

(b)

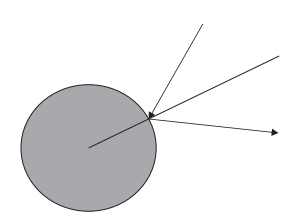

Figura 2.1: (a) Uma rede de antipontos. (b)Reflexão elástica de um elétron desde um antiponto.

Weiss et al., 1991), oscilações Altshuler-Aronov-Spivak (Gusev et al., 1992c; Nihey et al., 1995), picos de comensurabilidade em magnetoresistência (Lorke et al., 1991; Schuster et al. , 1993, 1994a), e oscilações finas em torno deles (Weiss et al., 1993).

\subsection{Redes de Antipontos}

Arranjos artificiais de dispersores (antipontos) fabricados pela gravação de buracos com diâmetro submicrométrico através de um 2DES de alta mobilidade tem atraído muita atenção devido à possibilidade da criação de super-redes laterais com diferentes configurações: quadrada (Gusev et al., 1991, 1992a; Weiss et al., 1991), triangular (Yamashiro et al. , 1991), retangulares e desordenadas (Gusev et al., 1992b). Uma rede de antipontos é um 2DES modulado por um potencial periódico repulsivo forte é ilustrado na figura 2.3. A rede de antipontos é caracterizada pelo período $a$ e o diâmetro $d$ do antiponto.

O modelo do potencial do antiponto frequentemente usado para um arranjo quadrado de antipontos é dado por:

$$
U(x, y)=U_{0}\left[\cos \left(\frac{2 \pi x}{a}\right) \cos \left(\frac{2 \pi y}{a}\right)\right]^{\beta}
$$

onde $U_{0}$ é o máximo potencial e o parâmetro $\beta$ controla o grau de dureza do potencial. Em uma rede triangular, o correspondente potencial é dado por: 


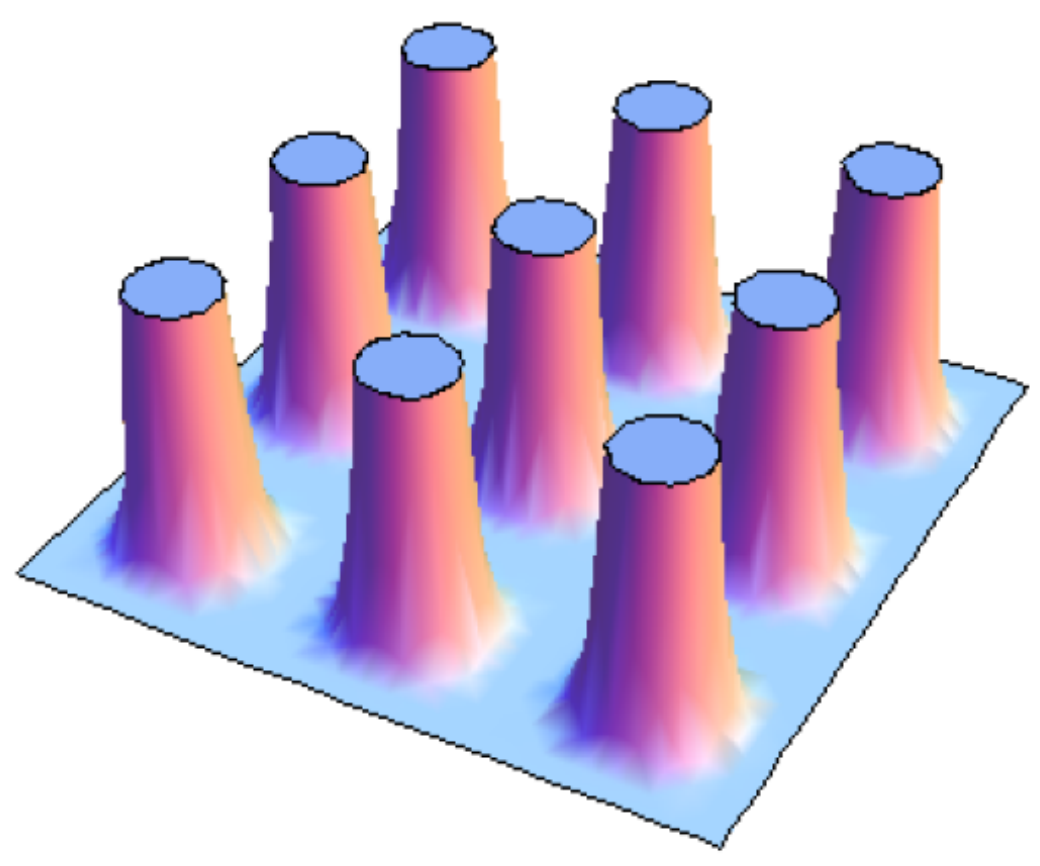

Figura 2.2: Diagrama esquemático o efeito de modulação do potencial eletrostático de um arranjo quadrado de antipontos com $\beta=2$ na equação 2.1.

$$
U(x, y)=U_{0}\left[\cos \left(\frac{\pi \vec{a}_{1} \cdot \vec{r}}{a^{2}}\right) \cos \left(\frac{\pi \vec{a}_{2} \cdot \vec{r}}{a^{2}}\right) \cos \left(\frac{\pi\left(\vec{a}_{1}-\vec{a}_{2}\right) \cdot \vec{r}}{a^{2}}\right)\right]^{4 \beta / 3}
$$

onde $\vec{a}_{1}=(\sqrt{3} a / 2, a / 2)$ e $\vec{a}_{2}=(0, a)$.

Os elétrons viajam através das regiões dos antipontos, sendo espalhados pelos mesmos e pelos contornos da amostra, se o 2DES esta suficientemente limpo e o espalhamento pelas impurezas não é frequente. Numa rede de antipontos em particular, fabricada em uma heteroestrutura de GaAs/AlGaAs de alta mobilidade, o comprimento de onda de Fermi $\lambda_{F}$ é: $\lambda_{F} \sim 50 \mathrm{~nm}$, o caminho livre médio $l_{m}$ é: $l_{m} \sim 2-20 \mu m$, e o comprimento de coerência $l_{\phi}$ é muito maior que $l_{m}$ a $T<4.2 \mathrm{~K}$. O diâmetro $d$ do antiponto é: $d \sim 100-1000 \mathrm{~nm} \mathrm{e}$ o período $a$ da rede de antipontos é: $a \sim 200-1000 \mathrm{~nm}$. Para $l_{m}>a>\lambda_{F}$, uma rede de antipontos pode ser considerada dentro do âmbito semi-clássico. Quando o tamanho da amostra é maior que $l_{m}$ e $l_{\phi}$, os fenômenos medidos são a média de toda a amostra.

Um parâmetro fundamental que caracteriza uma rede de antipontos é $d / a$, que é a razão entre o diâmetro do antiponto e o período da rede. Uma rede de antipontos com a razão $d / a$ pequena $\left(l_{m}>a>d\right)$, pode ser visto como um 2DES sujeito a um arranjo periódico de espalhadores, ou seja, uma situação de pinball balístico. Por outro lado, uma rede de antipontos com a razão $d / a$ grande $\left(l_{m} \gg a-d \approx \lambda_{F}\right)$ é mais parecida a uma 


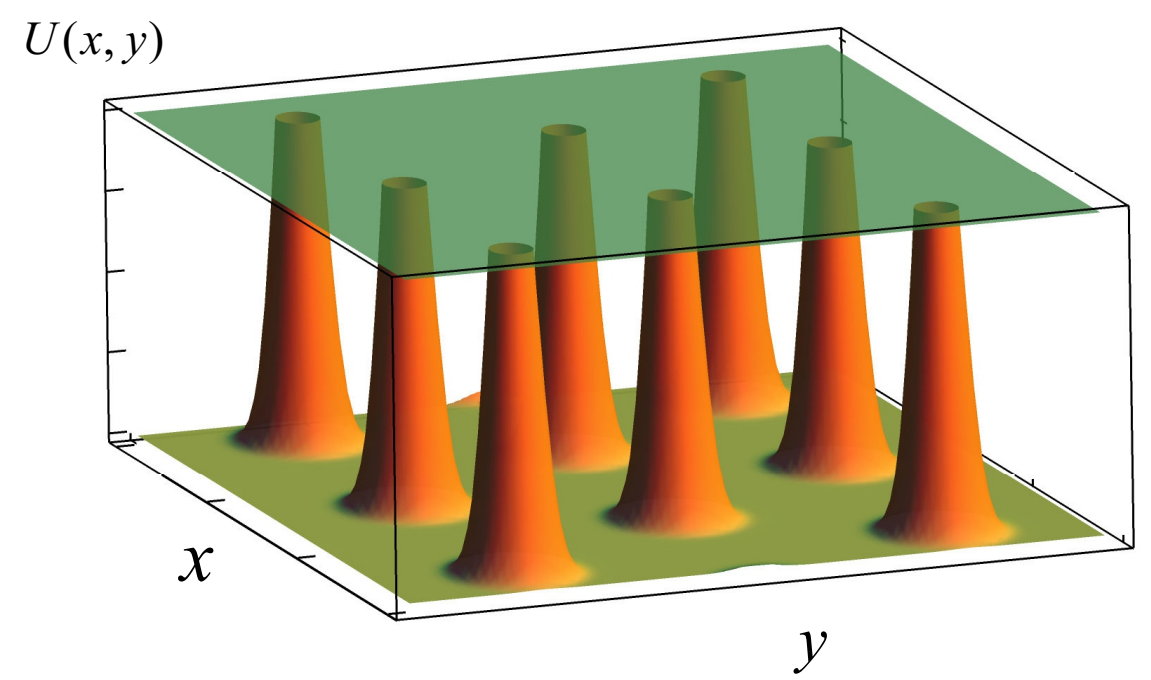

(a)

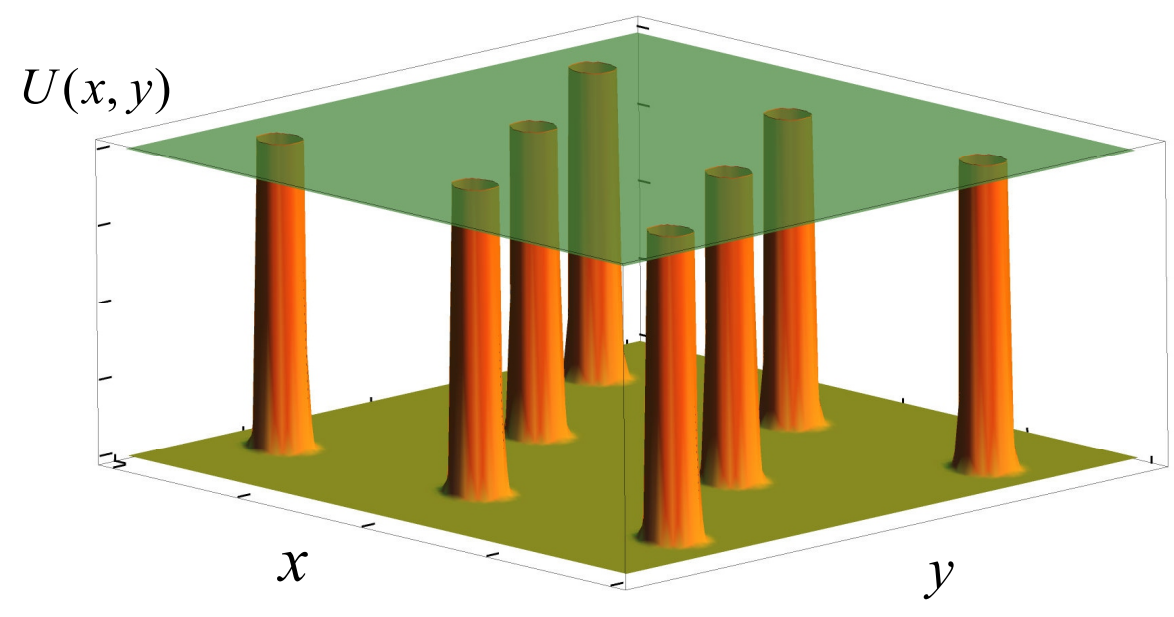

(b)

Figura 2.3: (Potenciais eletrostáticos num arranjo triangular de antipontos:(a) fraco $(\beta=6$ e $\left.U_{0}=1.8 E_{F}\right)$ e $(b)$ forte $\left(\beta=180\right.$ e $\left.U_{0}=80 E_{F}\right)$. As superficies dos potenciais periódicos só são mostrados até o nivel de energia de Fermi.

rede de canais estreitos formados entre os antipontos.

\subsubsection{Picos de Comensurabilidade}

Um dos fenômenos mais característicos de uma rede de antipontos é a estrutura dos picos na magnetoresistência chamados picos de comensurabilidade. A figura 2.4 mostra (a) a resistividade longitudinal $\rho_{x x}$ e (b) a resistividade de Hall $\rho_{x y}$ para amostras padronizadas e não padronizadas com uma rede de antipontos (Weiss et al., 1991). Num campo magnético fraco $(\mathrm{B}<1 \mathrm{~T})$ dois picos aparecem em $\rho_{x x}$, e estão acompanhados pelos degraus de $\rho_{x y}$. Um pico de comensurabilidade ocorre, por exemplo, quando: 


$$
2 R_{c}=a ; \quad R_{c}=\frac{\hbar k_{F}}{e B}
$$

a)

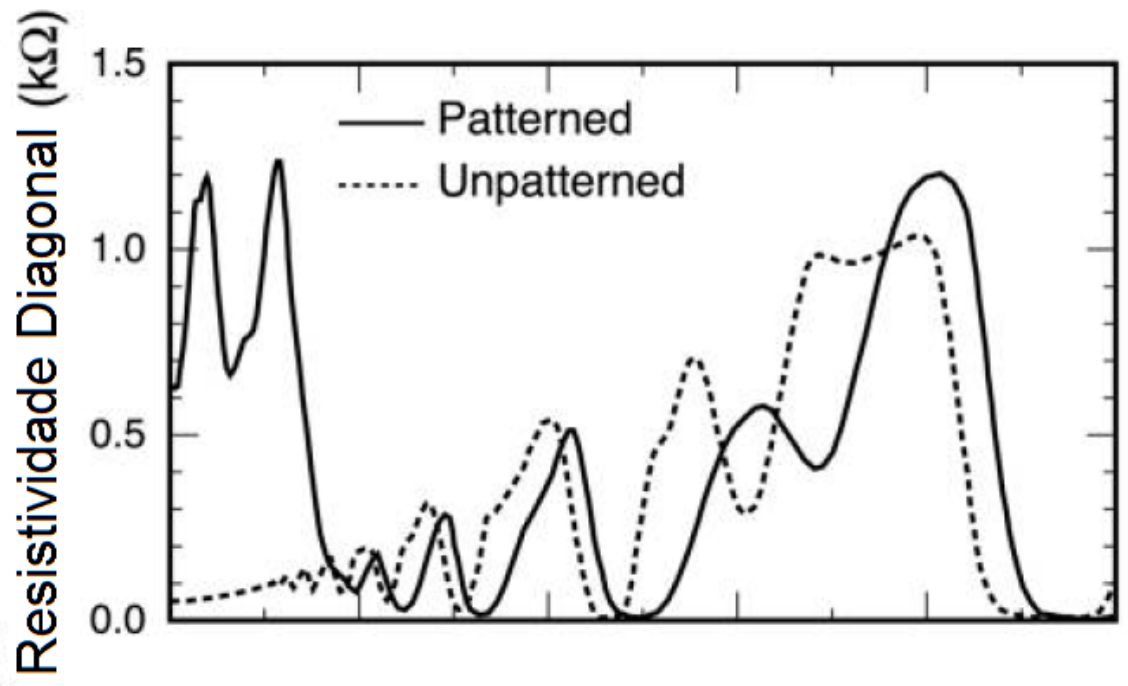

b)

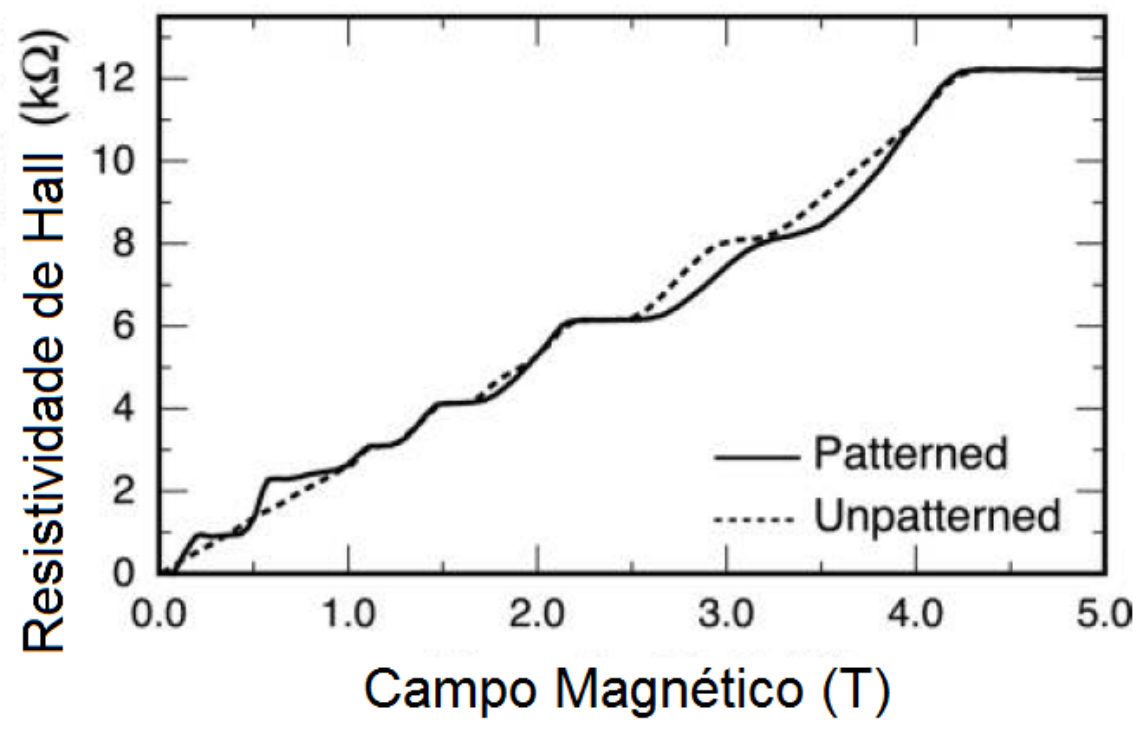

Figura 2.4: As resistividades (a) $\rho_{x x} e(b) \rho_{x y}$ para amostras padronizadas com redes de antipontos (linha continua) e para amostras não padronizadas com redes de antipontos (linha pontilhada) em função do campo magnético. Dois picos proeminentes e dois platôs aparecem na resistividade diagonal e de Hall, respectivamente, a campos magnéticos $\sim 0.2$ e $\sim 0.6 T$ (Weiss et al., 1991).

onde $R_{c}$ é o rádio do cíclotron clássico na energia de Fermi. O número de picos e degraus a baixos campos magnéticos dependem da razão $d / a$. Quanto maior é a razão $d / a$, menos picos são observáveis em $\rho_{x x}$. O modelo baseado sobre "órbitas localizadas"foi proposto para explicar o origem dos picos de comensurabilidade. Para cada pico, $R_{c}$ pode estar associado com uma órbita de comensurabilidade (circular), rodeando um número especifico de antipontos, como mostra a figura 2.5(c). Como os elétrons localizados nas órbitas de 
comensurabilidade não podem transportar nenhuma corrente, espera-se incrementar $\rho_{x x}$ para aqueles valores de campo magnético.

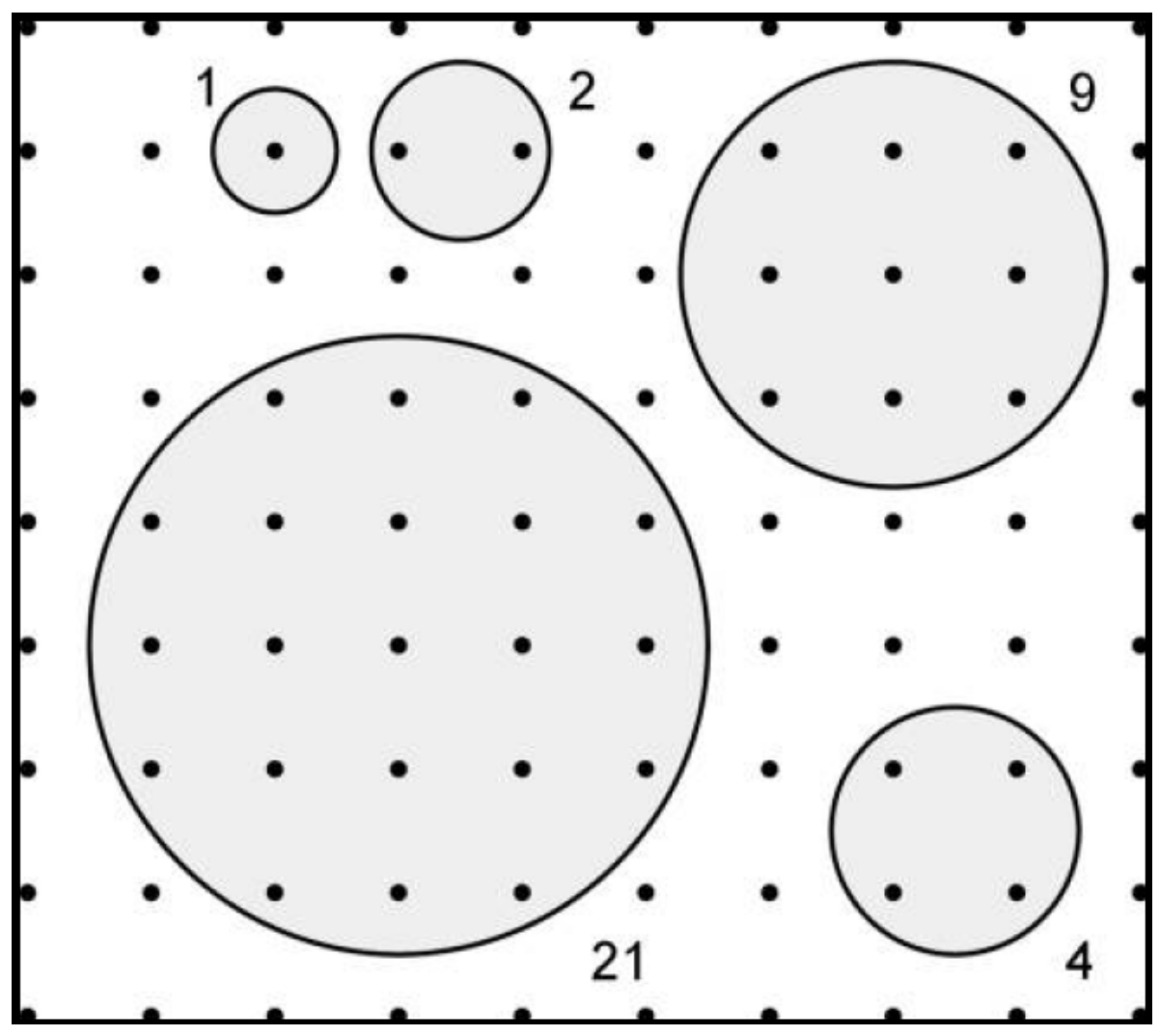

Figura 2.5: Alguns exemplos de órbitas localizadas. $\rho_{x x}$ exibe picos de comensurabilidade a campos magnéticos onde as órbitas do cíclotron clássico rodeiam 1, 2, 4, 9 e 21 antipontos (Weiss et al., 1991).

Por outro lado, a simulação numérica baseada na mecânica clássica e no potencial eletrostático dos antipontos da equação 2.1 sugere que o movimento caótico dos elétrons é mais importante para os picos de comensurabilidade (Ando et al., 1997). As órbitas caóticas tem um carácter próximo às órbitas localizadas para um antiponto, dando maior contribuição aos picos de comensurabilidade do que das próprias órbitas localizadas. De fato, a mudança no volume das órbitas localizadas no espaço de fases não é suficiente para originar as oscilações de comensurabilidade observadas nas experiências.

Outro importante mecanismo caracterizado pelo movimento caótico dos elétrons são as trajetórias fugitivas, onde o elétron pula de um antiponto até seu antiponto vizinho na mesma direção, como mostra a figura 2.6. Esta interpretação foi proposta por (Baskin et al., 1992) e comprovado nas experiências em redes de antipontos retangulares e desordenadas (Tsukagoshi et al., 1996a). No limite da pequena razão $d / a$, as órbitas fugitivas são responsáveis dos picos de comensurabilidade em $\rho_{x x}$. Neste caso, um elétron perde a propriedade de conservar a direção da velocidade quando colide com um 

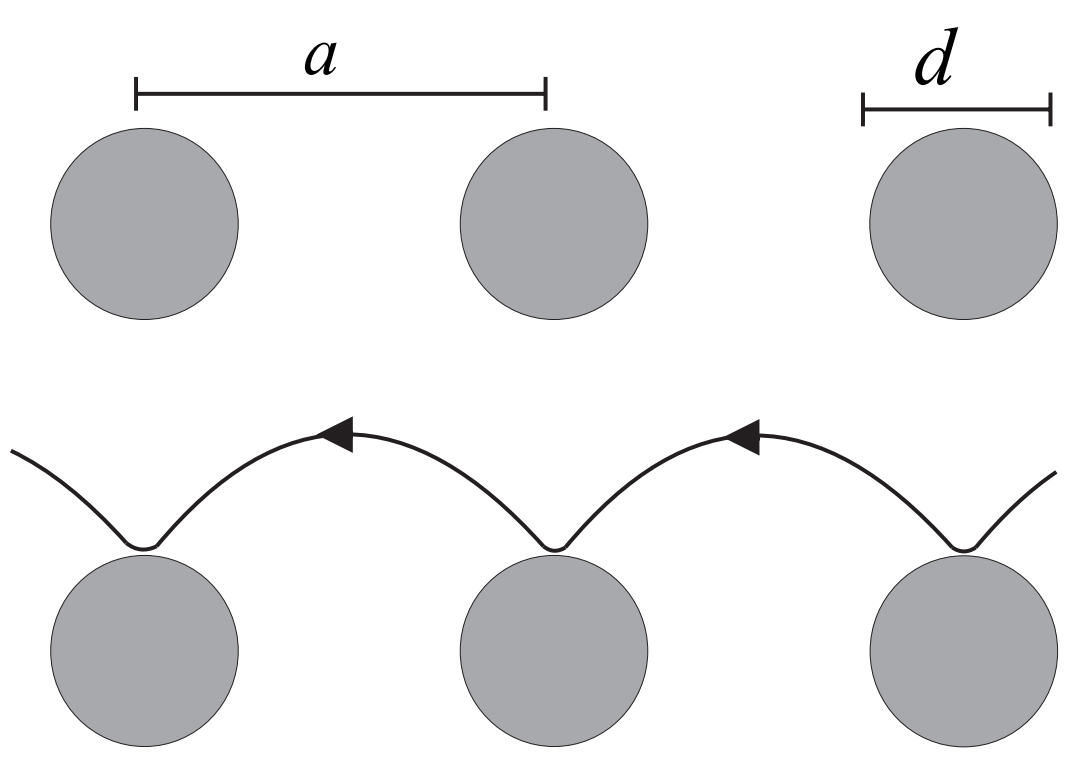

Figura 2.6: Ilustração esquemática de uma órbita fugitiva que pula regularmente de um antiponto a seu antiponto vizinho na mesma direção (Ando et al., 1997).

antiponto, e portanto, os sucessivos espalhamentos com os antipontos podem ser considerados independentes um do outro (Ishizaka e Ando, 1997a).

Uma razão $d / a$ grande usualmente corresponde a um pequeno período da rede de antipontos e a um espaçamento estreito entre os antipontos vizinhos mais próximos comparável a $\lambda_{F}$. Portanto, os efeitos quânticos podem ser importantes nas redes de antipontos. Por exemplo, para $d / a=0.5$, o cálculo mecânico-quântico deu como resultado que a condutividade diagonal $\sigma_{x x}$ não exibe nenhuma estrutura e a condutividade de Hall tem um dip fraco para $2 R_{c} \approx a$, gerando um pico de comensurabilidade (Ishizaka e Ando, 1997b; Ishizaka et al., 1995). As experiências nas redes de antipontos para valores grandes de $d / a$, as quais mostram as relações entre $\rho_{x x}$ e $\sigma_{x x}$ (Schuster et al., 1994b) e entre $\rho_{x y}$ e $d \rho_{x y} / d B$ (Tsukagoshi et al., 1996b), sugeriram que as órbitas localizadas caóticas em torno dos antipontos dão a contribuição dominante dos picos de comensurabilidade neste caso.

\subsubsection{Focalização Magnética e Órbitas Difusivas}

Primeiramente, considere-se a relação $d / a \ll 1$. Neste caso, o elétron perde a propriedade de conservar a direção da velocidade quando colide com os antipontos, e portanto, os espalhamentos sucessivos com os antipontos podem ser geralmente considerados como independentes um do outro. (Kubo et al., 1965) Isso significa que os antipontos são apenas espalhadores independentes. 
Na presença de campos magnéticos, o transporte é possível através da migração do centro do movimento do cíclotron e, portanto a condutividade $\sigma_{x x}$ desaparece na ausência de espalhamento. (Kubo et al., 1965) De fato, a condutividade é escrita como $\sigma_{x x}=$ $e^{2} D\left(E_{F}\right) D^{*}$, onde $D^{*}$ é o coeficiente de difusão e $D\left(E_{F}\right)$ é a densidade de estados no nível de Fermi. Na ausência de espalhamento, o centro das órbitas ciclotrônicas permanece na mesma posição e o coeficiente de difusão desaparece.

Nos sistemas de antipontos no regime clássico, a densidade de estados não tem uma estrutura considerável, e portanto, os picos de comensurabilidade surgem do coeficiente de difusão. Quando o diâmetro do cíclotron é menor que o período da rede, isto é, $2 R_{c}<a$, onde $R_{c}$ é o rádio do cíclotron, o espalhamento de um elétron desde um antiponto não pode dar origem a difusão ou a condução, devido a que o elétron é aprisionado pelo antiponto. O espalhamento dos elétrons na rede de antipontos começa a contribuir para a condutividade quando $2 R_{c}>a$.

A migração do centro das órbitas do cíclotron ocorre mais frequentemente devido aos espalhamentos sucessivos dos antipontos vizinhos mais próximos a campos magnéticos correspondentes a $2 R_{C}=a$. De fato, se mostra na figura 2.7 um elétron emitido desde um antiponto é focalizado sobre um antiponto vizinho. Isto conduz a um aumento do volume do espaço de fases das órbitas que contribuem ao aumento do coeficiente de difusão em $2 R_{c} \sim a$. Na presença de campos magnéticos, a resistividade é dada em termos da condutividade diagonal $\sigma_{x x}$ e da condutividade de Hall $\sigma_{x y}: \rho_{x x}=\sigma_{x x} /\left(\sigma_{x x}^{2}+\sigma_{x y}^{2}\right)$. A campos altos, em particular, usualmente temos $\left|\sigma_{x x}\right| \gg \sigma_{\xi \xi} / \sigma_{x y}^{2}$, e portanto $\rho_{x x} \sim \sigma_{\xi \xi}$ mostra que os picos na resistividade são dados por um pico em $\sigma_{\xi \xi}$.

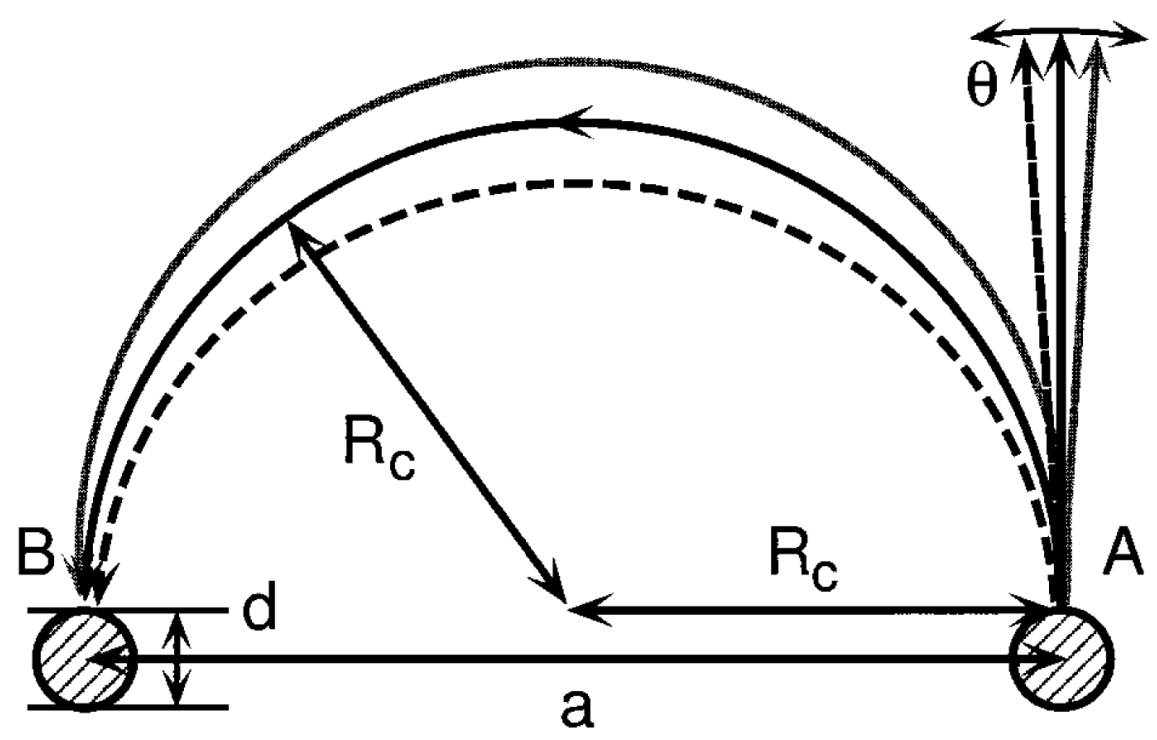

Figura 2.7: Ilustração esquemática da focalização magnética que conduz ao pico de comensurabilidade fundamental (Ando et al., 1997). 
A figura 2.8 mostra que as órbitas correspondentes a $2 R_{c}=a$ podem ser denotadas como $\left(n_{x}, n_{y}\right)=( \pm 1,0)$ ou $(0, \pm 1)$, onde o segmento de linha que une o ponto $\left(n_{x}, n_{y}\right)$ e o origem, constitui o diâmetro do círculo. Com uma nova diminuição do campo magnético, espalhamentos sucessivos com o antiponto vizinho mais proximo tornam-se possíveis e a condutividade tem um pico em torno de $2 R_{c}=\sqrt{2} a$ correspondente a $( \pm 1, \pm 1)$. Esta contribuição torna-se menos importante, porém, porque a órbita passa através da posição do antiponto vizinho mais próximo. O próximo pico origina-se de $( \pm 2,0)$ ou $(0, \pm 2)$ e $( \pm 2, \pm 1)$ ou $( \pm 1, \pm 2)$, que se encontram perto uns dos outros. A última contribuição deve ser maior, porque a sua medida é dois vezes mais grande em quanto ao anterior, e por conseguinte os picos ocorrem em torno de $2 R_{c} \sim \sqrt{5} a$. Este pico deve ser mais fraco, porém, visto que estas órbitas também passam através da posição de outros antipontos. O próximo pico importante é dado por $( \pm 2, \pm 2),( \pm 3,0),(0, \pm 3),( \pm 3, \pm 1)$, e $( \pm 1, \pm 3)$.

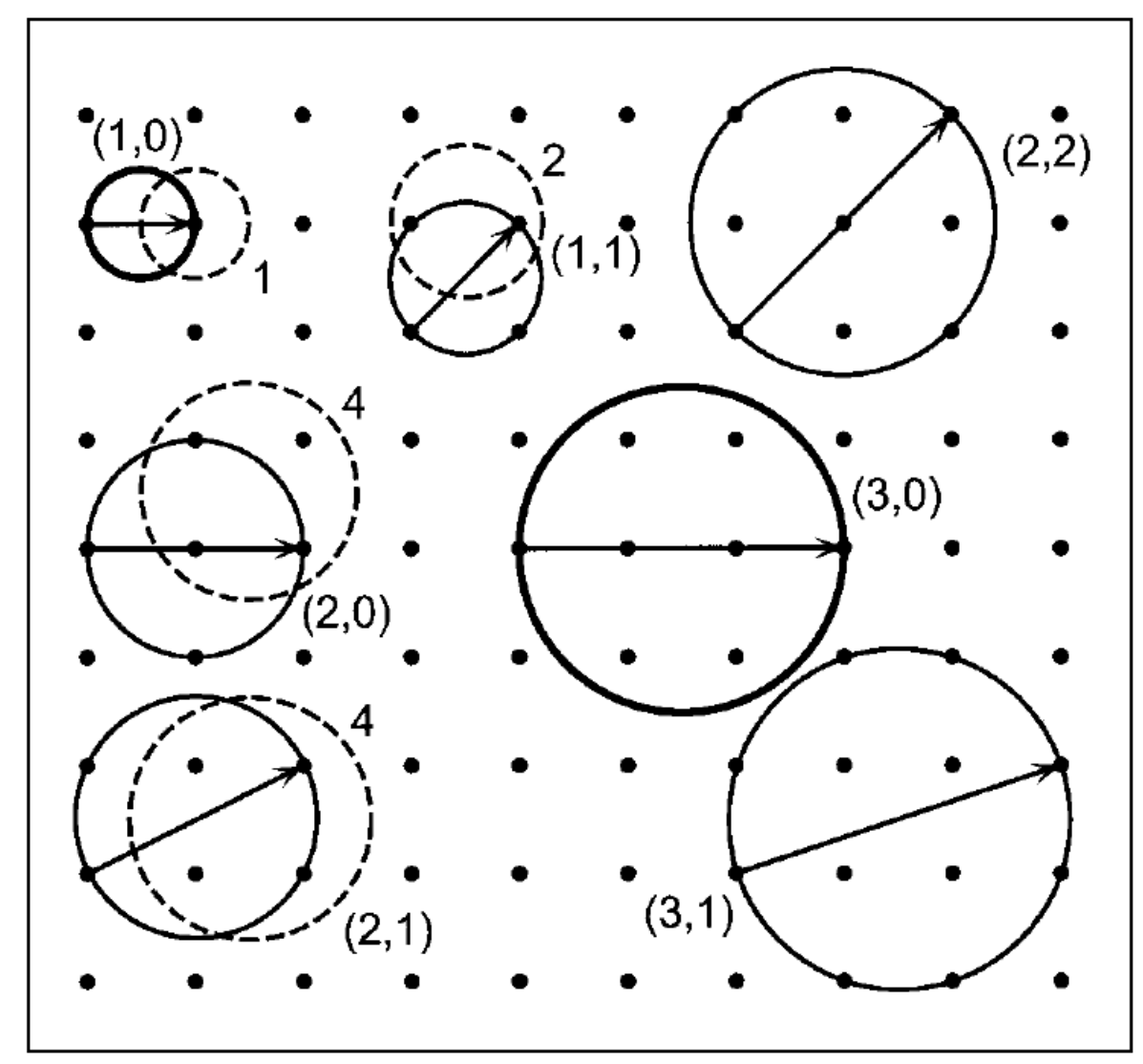

Figura 2.8: Alguns exemplos de órbitas ciclotrônicas difusivas que contribuem à migração dos centros guias. Os círculos tracejados correspondem às órbitas localizadas (o número denota a quantidade de antipontos dentro da órbita) (Ando et al., 1997).

Deste modo pode-se explicar a maioria de picos de comensurabilidade observados experimentalmente. As posições dos picos também podem ser explicadas pelas órbitas localizadas, ver a figura 2.8 que mostra as órbitas rotuladas por $\left(n_{x}, n_{y}\right)$, correspondentes aproximadamente para certas órbitas localizadas pelo leve deslocamento da posição do 
centro guia.

Quando o diâmetro $d$ comparado com o período a não pode ser negligenciado, o pico de comensurabilidade na condutividade $\sigma_{x x}$ desvia-se da condição $2 R_{c}=a$. A órbita ciclotrônica que começa num antiponto e colide com um antiponto vizinho tem o centro na região esquematicamente ilustrada na figura 2.9, para o qual o volume do espaço de fases de tais órbitas é proporcional. A figura 2.10 mostra a área como uma função do campo magnético. A área tem um máximo em $2 R_{c}=a+f d$, com $f \sim 0.3$ que é uma constante fracamente dependente de $d / a$. Isto significa que o pico de comensurabilidade é deslocado ao lado do campo fraco aproximadamente em proporção a $d / a$.

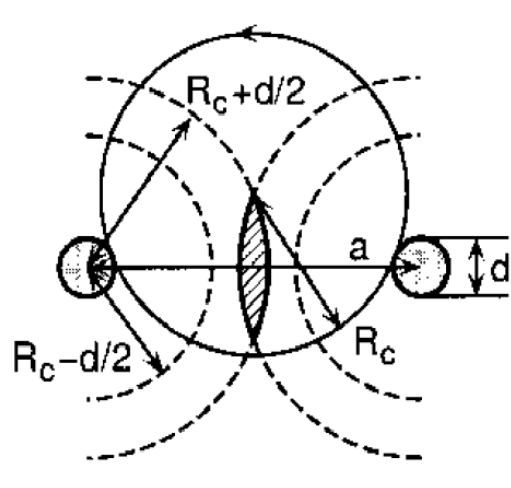

$a-d<2 R_{c}<a$
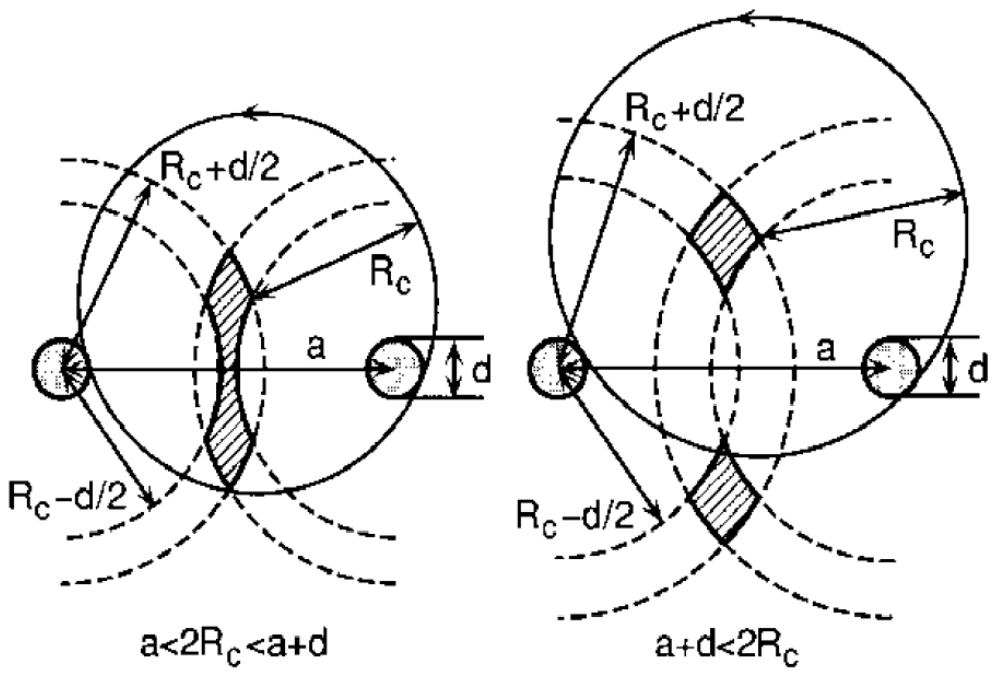

Figura 2.9: A região (tracejada) do centro das órbitas do cíclotron que passam através de dois antipontos vizinhos muito próximos (Ando et al., 1997).

Para $d / a$ não desprezível, a correlação entre espalhamentos sucessivos torna-se importante. Na verdade, ela manifesta-se mais diretamente na condutividade de Hall. Como se mostra na figura 2.11, ela tende a aumentar o movimento circular esquerdo dos elétrons na região de campo fraco $2 R_{c}>_{\sim} a$ e reduzi-lo na região de campos altos $2 R_{c}<_{\sim} a$. Isto conduz a um aumento de $\left|\sigma_{x y}\right|$ para $2 R_{c}<_{\sim}$ a e uma redução para $2 R_{c}>_{\sim} a$, dando origem a uma estrutura tipo degrau em torno de $2 R_{c} \approx a$.

Com o aumento de $d / a$, as medidas das órbitas difusivas aumentam, como mostra a figura 2.10, e a condutividade diagonal aumenta e torna-se comparável a $\sigma_{x y}$ (cálculos numéricos mostram que $\sigma_{x x} \approx\left|\sigma_{x y}\right|$ em torno de $d / a \approx 0.5$ ). (Ishizaka e Ando, 1997a) Então, os picos de comensurabilidade na resistividade tornam-se diferente de aqueles em $\sigma_{x x}$. Deixamos que $\Delta \sigma_{x x}$ e $\Delta \sigma_{x y}$ serem uma pequena mudança em torno do campo correspondente ao pico de comensurabilidade e $\bar{\sigma}_{x x}$ e $\bar{\sigma}_{x y}$ é a média $\left(\Delta \sigma_{x x} \ll \bar{\sigma}_{x x},\left|\Delta \sigma_{x y}\right| \ll\left|\bar{\sigma}_{x y}\right|\right)$. 


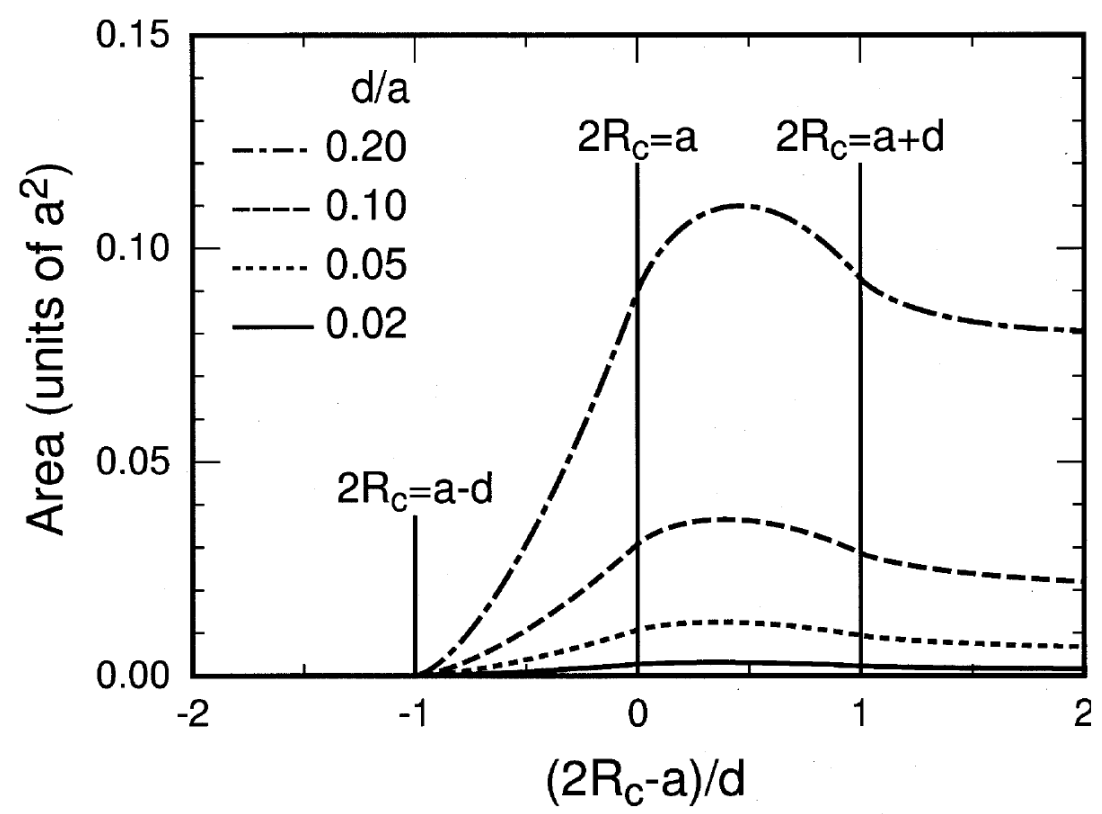

Figura 2.10: A área da região onde as órbitas ciclotrônicas passam através de dois antipontos vizinhos. A condutividade diagonal é aproximadamente proporcional ao área (Ando et al., 1997).

$$
\Delta \rho_{x x}=\frac{\left(\bar{\sigma}_{x y}^{2}-\bar{\sigma}_{x x}^{2}\right) \Delta \sigma_{x x}-2 \bar{\sigma}_{x x} \bar{\sigma}_{x y} \Delta \sigma_{x y}}{\bar{\sigma}_{x x}^{2}+\bar{\sigma}_{x y}^{2}}
$$

Isto significa que $\Delta \sigma_{x y}$ determina a estrutura de $\rho_{x x}$ quando $\bar{\sigma}_{x x} \approx\left|\bar{\sigma}_{x y}\right|$, isto é, a redução de $\left|\sigma_{x y}\right|$ a campos altos dá um pico em $\rho_{x x}$ para $d / a$ grande.

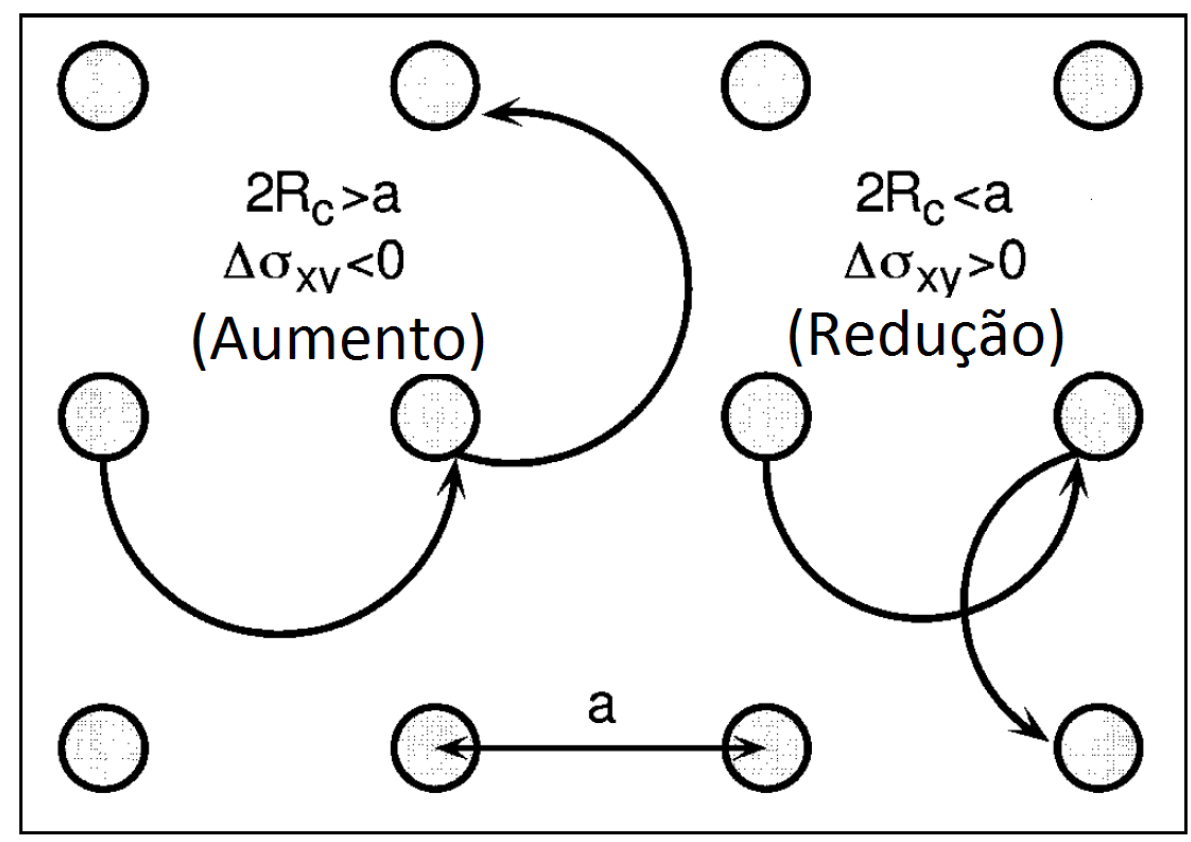

Figura 2.11: Ilustração esquemática de espalhamento de dois antipontos adjacentes. Isto conduz a um aumento de $\left|\sigma_{x x}\right|$ para $2 R_{c}<_{\sim}$ a e uma redução para $2 R_{c}>_{\sim}$ a (Ando et al., 1997). 
A figura 2.12 mostra alguns exemplos de resultados das simulações numéricas das referencias (Ishizaka e Ando, 1997a, 1998). Estes resultados mostram que o pico em $\sigma_{x x}$ é alargado consideravelmente com o aumento de $d / a$ e ao mesmo tempo é deslocado ao lado do campo magnético mais baixo. Um step structure correspondente à primeira derivada de $\sigma_{x x}$ com o campo magnético aparece em $\sigma_{x y}$. É interessante, contudo, que o pico de comensurabilidade na resistividade $\rho_{x x}$ permanece em torno de $2 R_{c}=a$ independente de $d / a$. Para $d / a \geq 0.5$, as estruturas em $\sigma_{x x}$ e $\sigma_{x y}$ desaparecem quase completamente e $\rho_{x x}$ não mostra algum pico de comensurabilidade.

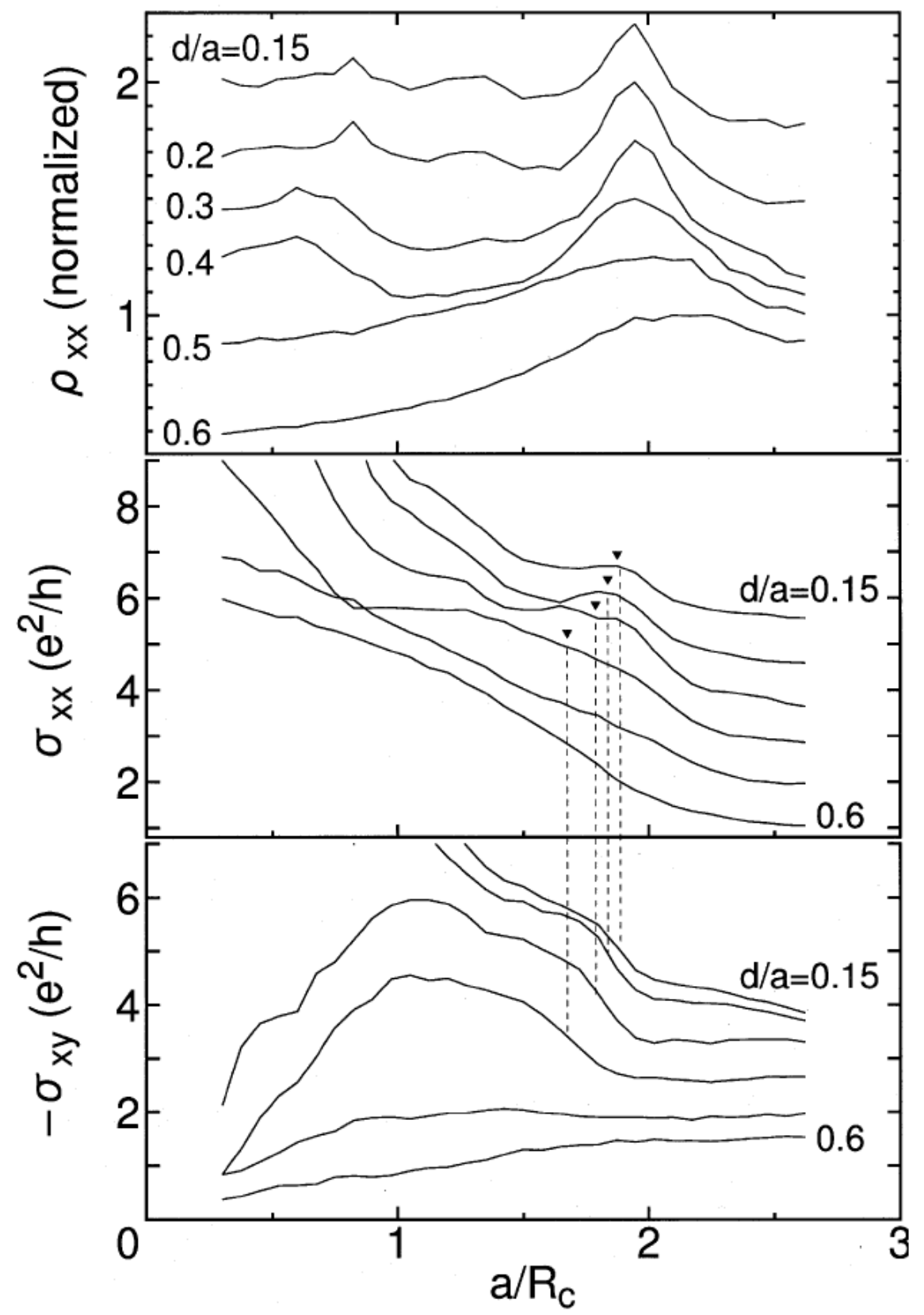

Figura 2.12: Alguns exemplos da resistividade e condutividade calculada usando a mecânica clássica para redes de antipontos quadrados (Ishizaka e Ando, 1997a) 


\subsubsection{Redes de Antipontos Triangulares}

Os picos de comensurabilidade também têm sido observados em redes de antipontos triangulares. A sua origem é a mesma como nas redes de antipontos quadrados e é entendido em termos das órbitas difusivas e da focalização magnética. A figura 2.13 mostra alguns exemplos das órbitas difusivas que contribuem a migração dos centros guias das órbitas ciclotrônicas. Eles são especificados por dois números inteiros $\left(n_{1}, n_{2}\right)$ de tal forma que $n_{1} a_{1}+n_{2} a_{2}$ corresponde ao vetor cujo comprimento é igual ao diâmetro do cíclotron (isto é, $2 R_{c} / a=\sqrt{n_{1}^{2}+n_{2}^{2}+n_{1} n_{2}}$ ).

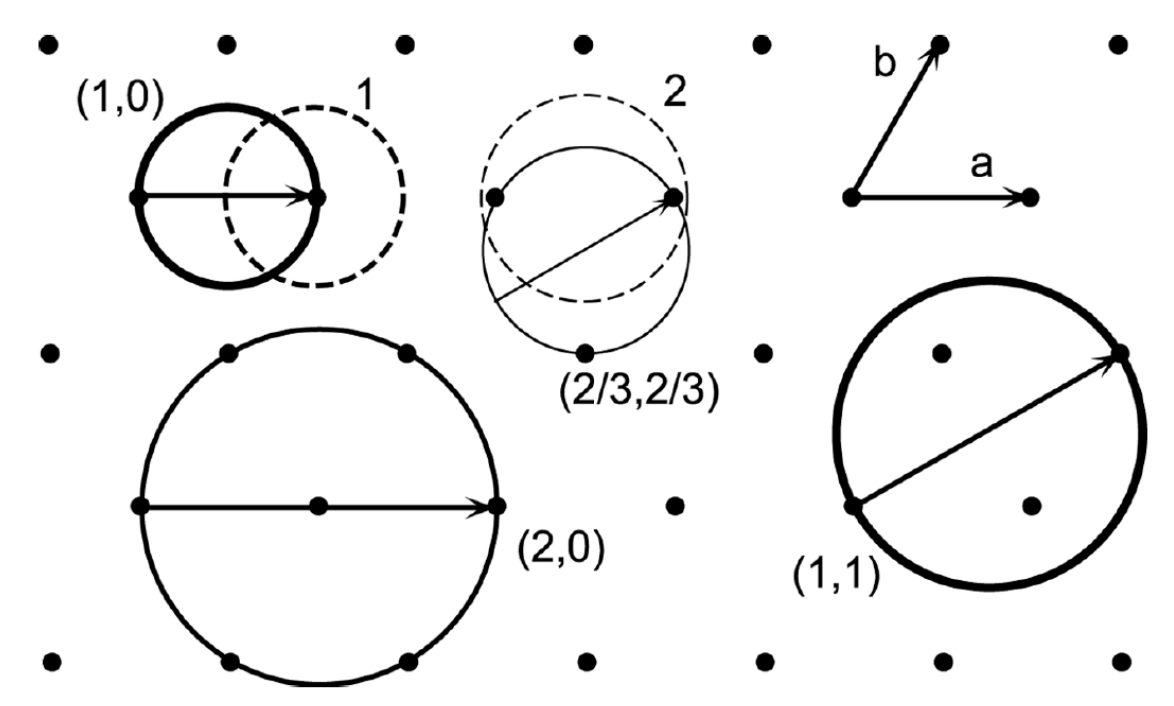

Figura 2.13: Alguns exemplos de órbitas ciclotrônicas difusivas que contribuem à migração dos centros guias numa rede triangular de antipontos. Os círculos tracejados correspondem às órbitas presas (o número denota os antipontos dentro da órbita). A medida das órbitas difusivas tem um dip em torno do campo correspondente a $\left(n_{1}, n_{2}\right)=(2 / 3,2 / 3)$ (Ando et al., 1997).

Há algumas diferenças importantes com respeito a rede quadrada. Primeiro, as órbitas difusivas são fortemente perturbadas pela presença de outros antipontos com o aumento do diâmetro do antiponto. A figura 2.14 mostra como as órbitas difusivas são influenciadas para $d / a>(\sqrt{3}-1) / 2 \approx 0.37$ no caso triangular, em contraste a $d / a>2 / 3 \approx 0.67$ no caso quadrado. Então, os picos de comensurabilidade são muito mais sensíveis à razão $d / a$.

Segundo, há uma grande diferença no campo magnético entre o pico fundamental dado por $a / R_{c}=2\left[\left(n_{1}, n_{2}\right)=( \pm 1,0)\right.$ ou $\left.(0, \pm 1)\right]$ e o seguinte pico dado por $a / R_{c}=2 / \sqrt{3}$ $\left[\left(n_{1}, n_{2}\right)=( \pm 1, \pm 1)\right]$. A figura 2.15 mostra a área da região correspondente ao centro guia da órbita ciclotrônica que passa através do par de antipontos vizinhos mais próximos para sobrepor-se com outro par em um campo magnético dado pela condição $R_{c}+d / 2=a / \sqrt{3}$. Isto conduz a redução das órbitas difusivas em torno de $a / R_{c} \sim \sqrt{3}$ dando origem a um dip pequeno no coeficiente de difusão neste campo magnético. 

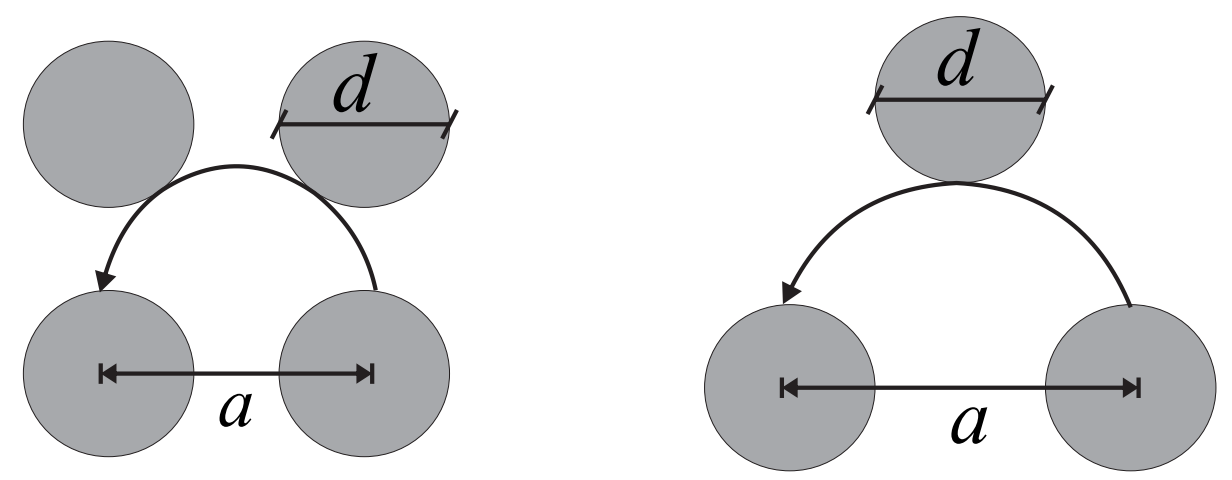

Figura 2.14: Ilustração esquemática das órbitas difusivas que dão origem aos picos de comensurabilidade fundamentais em redes (a) quadradas e (b) triangulares. As órbitas começam a ser perturbadas por outros antipontos para o caso de d/a no caso da rede triangular (Ando et al., 1997).

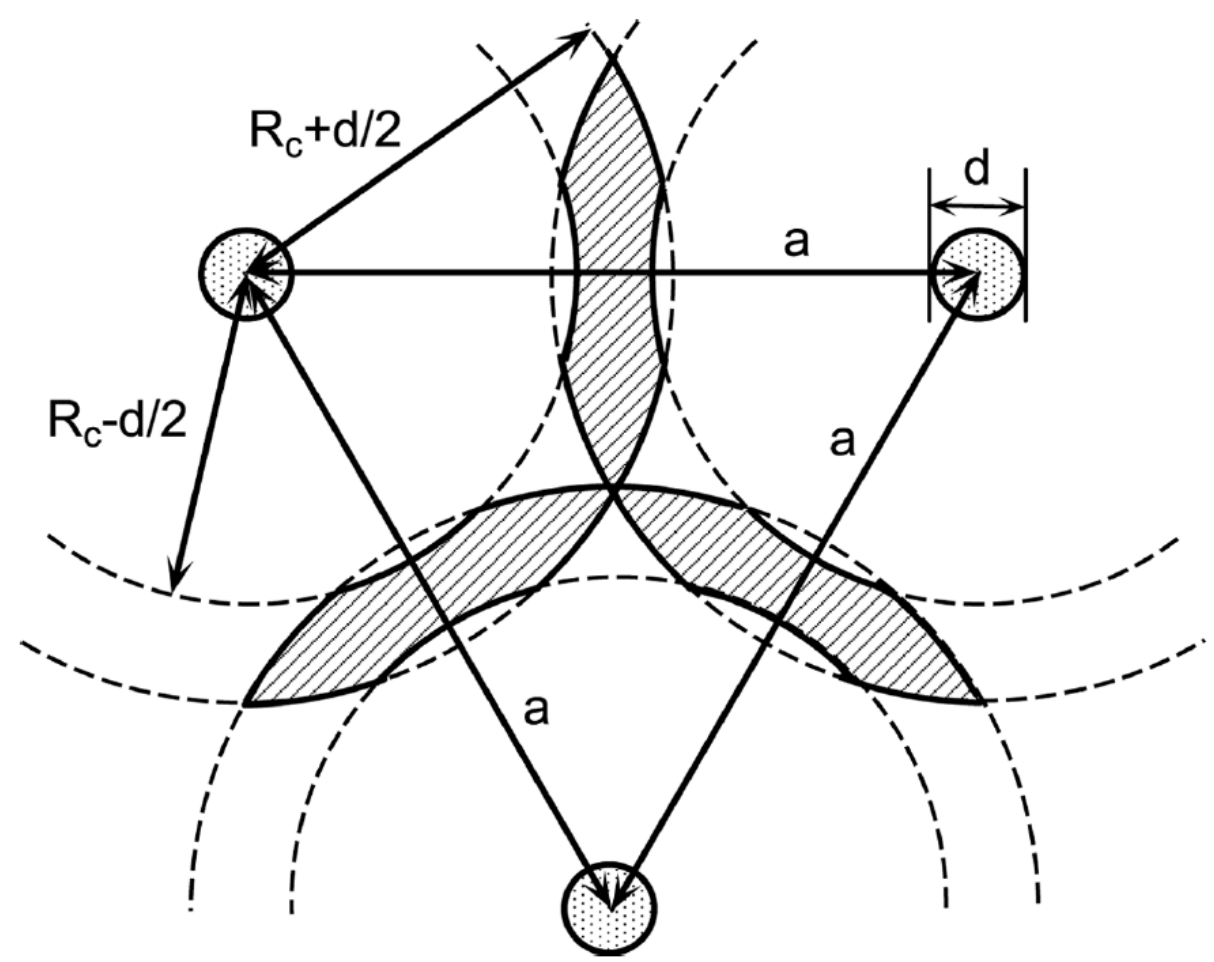

Figura 2.15: A região (tracejada) dos centros guias das órbitas ciclotrônicas passam através de dois antipontos vizinhos mais próximos numa rede triangular quando $R_{c}+d / 2 \approx a / \sqrt{3}$ (Ando et al., 1997).

A forte perturbação das órbitas difusivas nas redes triangulares com uma grande razão $d / a$, sugere que o número de eventos onde um elétron é espalhado pelo mesmo antiponto, é maior que nas redes quadradas. Isto significa que a trajetória dos elétrons é muito mais complicada nas redes triangulares do que nas redes quadradas, explicando a razão porque a condutividade é consideravelmente menor nas redes triangulares, e porque a amplitude das oscilações Altshuler-Aronov-Spivak é muito maior. 


\subsubsection{Oscilações Altshuler-Aronov-Spivak}

A condutância num condutor cilíndrico oscila como uma função do fluxo magnético que passa através da sua seção transversal com um período dado pela metade do fluxo quântico $\Phi_{0}=c h / e$. Esta oscilação é o resultado dos efeitos de interferência, e é chamada a oscilações Altshuler-Aronov-Spivak (Altshuler et al., 1981). Esta oscilação foi observada experimentalmente em filmes metálicos cilíndricos (Sharvin e Sharvin, 1981) e redes de fios finos metálicos (Dolan et al., 1986) no regime difusivo, onde o caminho livre médio é muito menor do que o tamanho da amostra ou a largura do fio.

Oscilações semelhantes também foram observadas nas redes de antipontos. (Gusev et al. , 1994, 1992c; Nakamura et al., 1994; Nihey et al., 1995). A Fig. 2.16 mostra um exemplo (Nihey et al., 1995). As características essenciais das experiências podem ser resumidas da seguinte forma: 1) as oscilações são observadas claramente nas redes triangulares, mas são quase invisíveis nas redes quadradas (Nakamura et al., 1994; Nihey et al., 1995); e 2) a magnetoresistência negativa é observada junto com a oscilação. A seguir, o estudo numérico de Nakanishi e Ando (Nakanishi e Ando, 1996a,b), é brevemente comentado. As redes de antipontos reais têm aleatoriedade inerente resultante dos processos de fabricação, além das impurezas cuja força é caracterizada pelo caminho livre médio $\Lambda$. Esta desordem é introduzida através de flutuações nos diâmetros do antiponto em torno do valor médio $d$. A quantidade de flutuações é caracterizada pela raiz do desvio médio quadrático $d_{f}$. A condutância é calculada pela técnica da função de Green (Ando, 1991) para sistemas com comprimento $L_{x}$ e $L_{y}$ de largura contendo um número finito de antipontos $(\sim 25)$.

A figura 2.17 da condutância calculada de uma rede de antipontos triangular com $a / \lambda=$ 4 na ausência de desordem do potencial de antipontos. No regime balístico $\Lambda / \lambda=16$, onde o caminho livre médio $\Lambda$ é maior do que o período do antiponto, a condutância exibe uma oscilação irregular. Isto é uma consequência do fato de que uma oscilação irregular com período $\Phi_{0}$ causada por efeitos de interferência tem uma contribuição dominante. De fato, tanto na fase e a forma da oscilação variam sensivelmente dependendo dos parâmetros, tais como $d / a, a / \lambda_{F}$, e $\beta$. Com a diminuição do caminho livre médio, a amplitude da oscilação irregular torna-se menor e a oscilação Altshuler-Aronov-Spivak, caracterizada por período de $\Phi_{0} / 2$, torna-se cada vez mais dominante. Em particular, uma boa oscilação manifesta-se no regime difusivo onde $\Lambda / \lambda_{F}=2$ ou $\Lambda / a=1 / 2$.

Analogamente, a contribuição da oscilação irregular diminui com o aumento da desordem no potencial de antipontos, como se mostra na fig. 2.18. A oscilação com período $\Phi_{0} / 2$ torna-se dominante para um desordem tão grande como $d_{f} / a=0.07$. A fig. 2.18 mostra que a oscilação é acompanhada pela magnetoresistência negativa fraca, ou um li- 


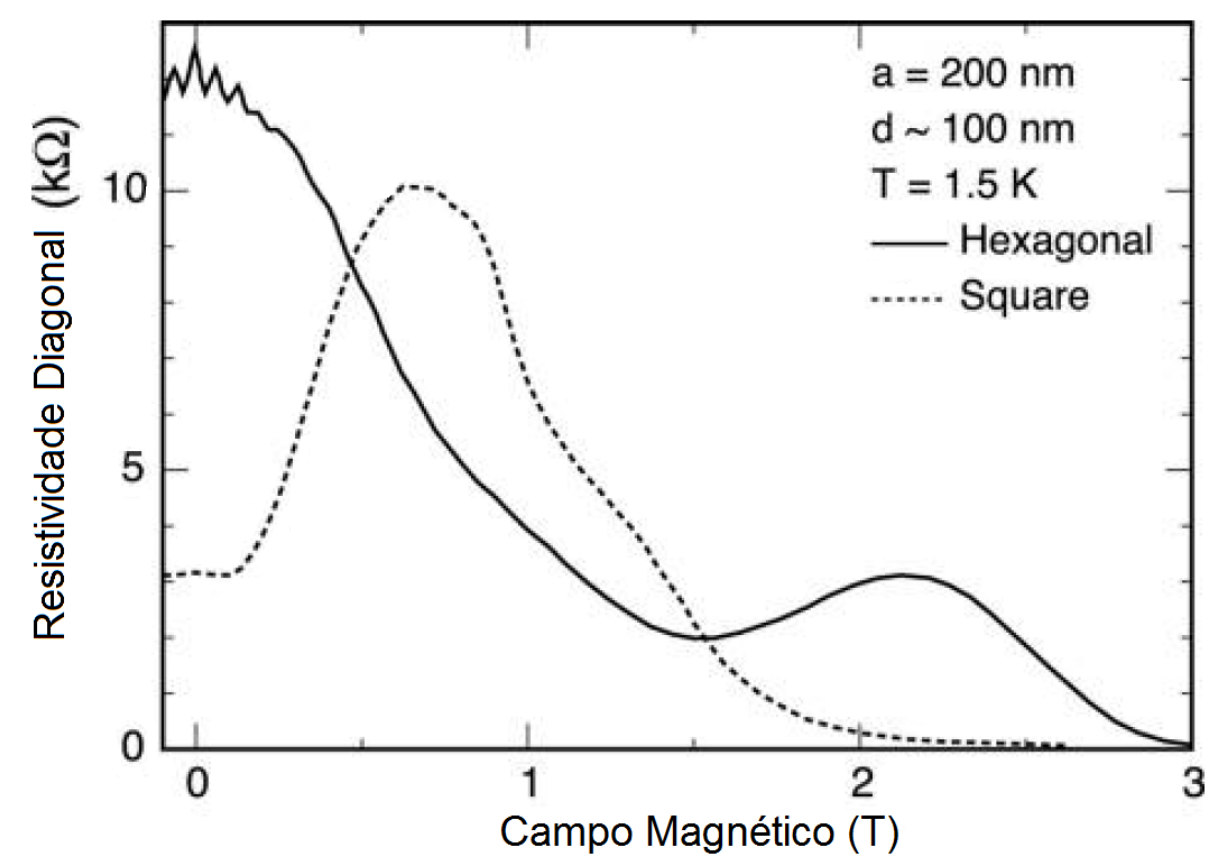

Figura 2.16: Comparação da resistividade de uma rede de antipontos triangular (linha sólida) e quadrada (linha pontilhada) (Nihey et al., 1995).

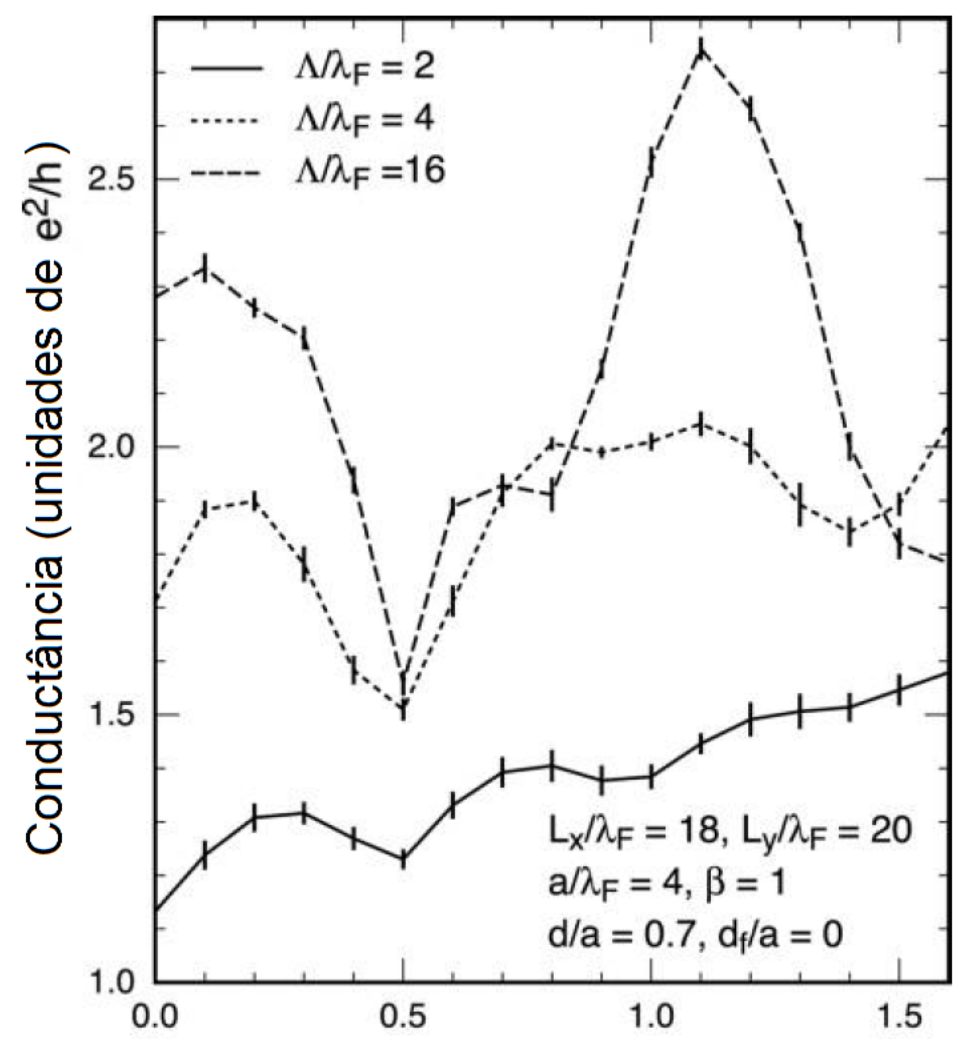

Fluxo Magnético (unidades de $\Phi_{0}$ )

Figura 2.17: Condutância de uma rede de antipontos triangular com dimensões $L_{x} \times L_{y}$ como uma função do campo magnético que passa através de uma cela unitária. Fonte: das referências Altshuler et al e Nakanishi e Ando (Altshuler et al., 1981; Nakanishi e Ando, 1996a) 
geiro aumento na condutância como uma função do campo magnético. Isto está de acordo com uma das características das experiências discutidas acima. A amplitude das oscilações saturadas para $d_{f} / a>0.07$.

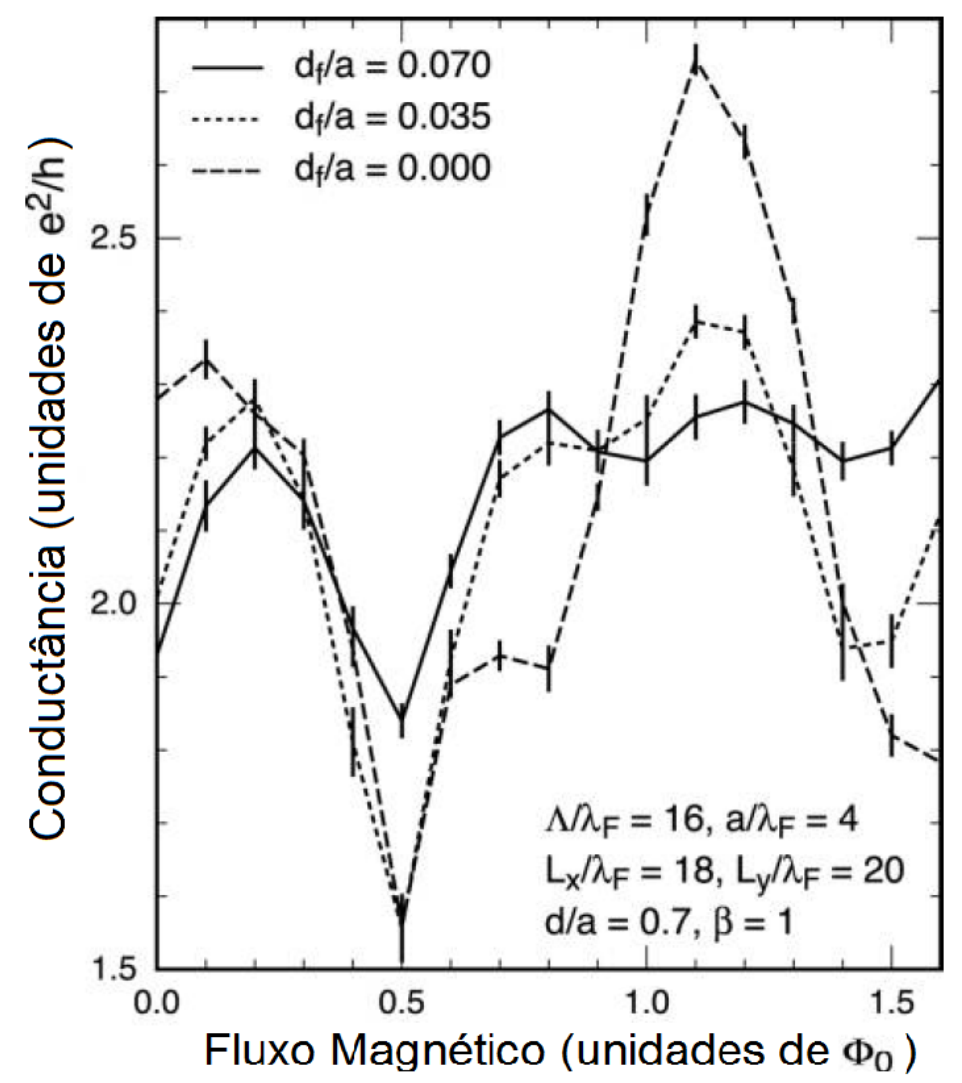

Figura 2.18: Condutância de uma rede de antipontos triangular na presença de flutuaçôes no diâmetro do antiponto. Fonte: das referências Altshuler et al e Nakanishi e Ando (Altshuler et al., 1981; Nakanishi e Ando, 1996a)

$\mathrm{Na}$ rede quadrada, a oscilação tem uma amplitude menor que numa rede triangular, e tem uma boa concordância com as experiências não mostradas aqui explicitamente. Note-se que a condutância da rede triangular é muito menor do que da rede quadrada. Os elétrons executam movimentos mais complicados e ficam mais tempo na rede triangular do que na rede quadrada (Nakamura et al., 1994; Nihey et al., 1995). Este é provavelmente a principal origem do aumento da oscilação na rede triangular. 
54 REDES DE ANTIPONTOS QUÂNTICOS 


\section{Capítulo 3}

\section{Métodos Experimentais}

\subsection{Descrição do Sistema}

As super-redes de antipontos são um arranjo periódico e padronizado de buracos mecânicos com forma aproximadamente cilíndrica e diâmetro microscópico, realizados por processos combinados de litografia eletrônica e ataque químico (etching). O padrão de forma dos antipontos é transferido de modo transversal à superfície das heteroestruturas compostas de múltiplas camadas de materiais semicondutores cristalinos as quais contém o gás bidimensional de elétrons (2DEG) em uma de suas interfaces.

O processo de gravação dos antipontos é realizado até uma profundidade determinada. A gravação dos buracos retira o material das diferentes camadas semicondutoras, gerando estados superficiais carregados negativamente. A presença desses estados superficiais eleva o perfil da banda de condução em torno de cada um dos antipontos, produzindo um potencial espalhador rodeado por uma região de depleção a qual pode ser reduzida por iluminação. Esse fato, além de motivar o nome de antipontos, produz também uma modulação periódica do potencial eletrostático, através do qual estão se locomovendo os elétrons da banda de condução à energia de Fermi.

A modulação do potencial eletrostático pode ser fraca ou forte e depende da profundidade de gravação. A modulação fraca acontece quando a profundidade de penetração do ataque químico atinge levemente a camada do gás bidimensional de elétrons sem atravessálo. No caso da modulação forte a profundidade de penetração dos antipontos ultrapassa amplamente a região do gás bidimensional de elétrons penetrando no interior da camada do GaAs.

Os arranjos de antipontos são a realização experimental do modelo teórico do bilhar de Sinai na Física do Estados Sólido, onde o modelo teórico de Sinai é usado na pesquisa da dinâmica caótica clássica e as suas manifestações nos espectros quânticos. Os elétrons são 
considerados como partículas clássicas (partículas mecânicas pontuais), que se movem num plano que contém discos refletores (antipontos) de rádio $r$, centradas na rede de antipontos com um período de rede $a$. As trajetórias de cada uma das partículas espalhadas assemelham-se (em um sentido estatístico) ao fenômeno do caminho aleatório.

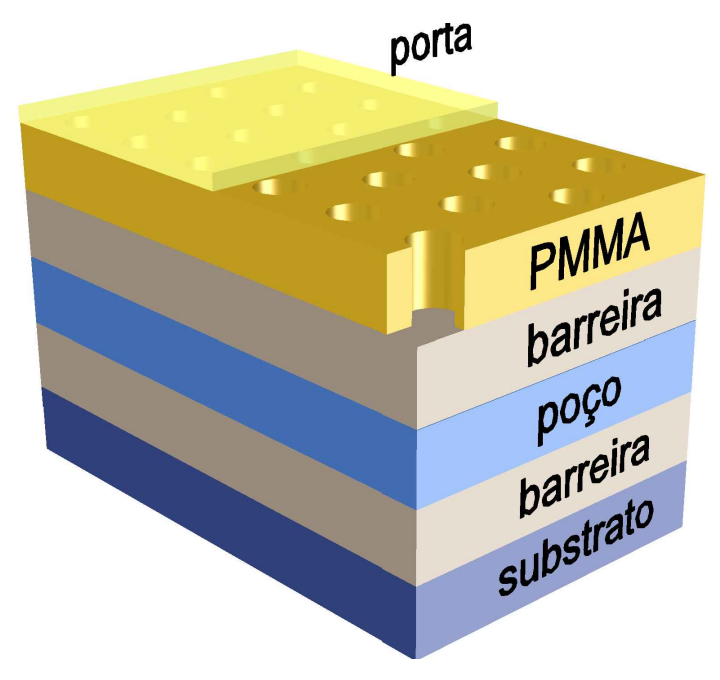

Figura 3.1: Diagrama esquemático de uma heteroestrutura de AlGaA-GaAs mostrando a rede de antipontos triangulares.

A dinâmica dos elétrons nas redes de antipontos é bidimensional, independente e clássica, quando o comprimento de onda de Fermi dos elétrons $\lambda_{F}=\sqrt{2 \pi / n_{s}}$ é menor que o período da rede antipontos $a$. A dinâmica destes sistemas é conservativa, com manisfestações de alta sensibilidade às condições iniciais, podendo o sistema apresentar a coexistência de trajetórias regulares e caóticas. O transporte dos elétrons nestes sistemas é estudado dentro do regime do transporte balístico (ou seja, os elétrons são espalhados pelo potencial dos antipontos e não pelas impurezas). Isso implica que o caminho livre médio dos elétrons $\left(\lambda_{e}\right)$ é muito maior que o período $(a)$ entre antipontos. Para constantes de rede significativamente maiores do que o comprimento de onda de Fermi, onde a estrutura de bandas destes sistemas está estreitamente ligado ao movimento dos elétrons no potencial periódico, a estrutura de bandas do sistema não pode ser resolvida na experiência (Choque, 2002). 


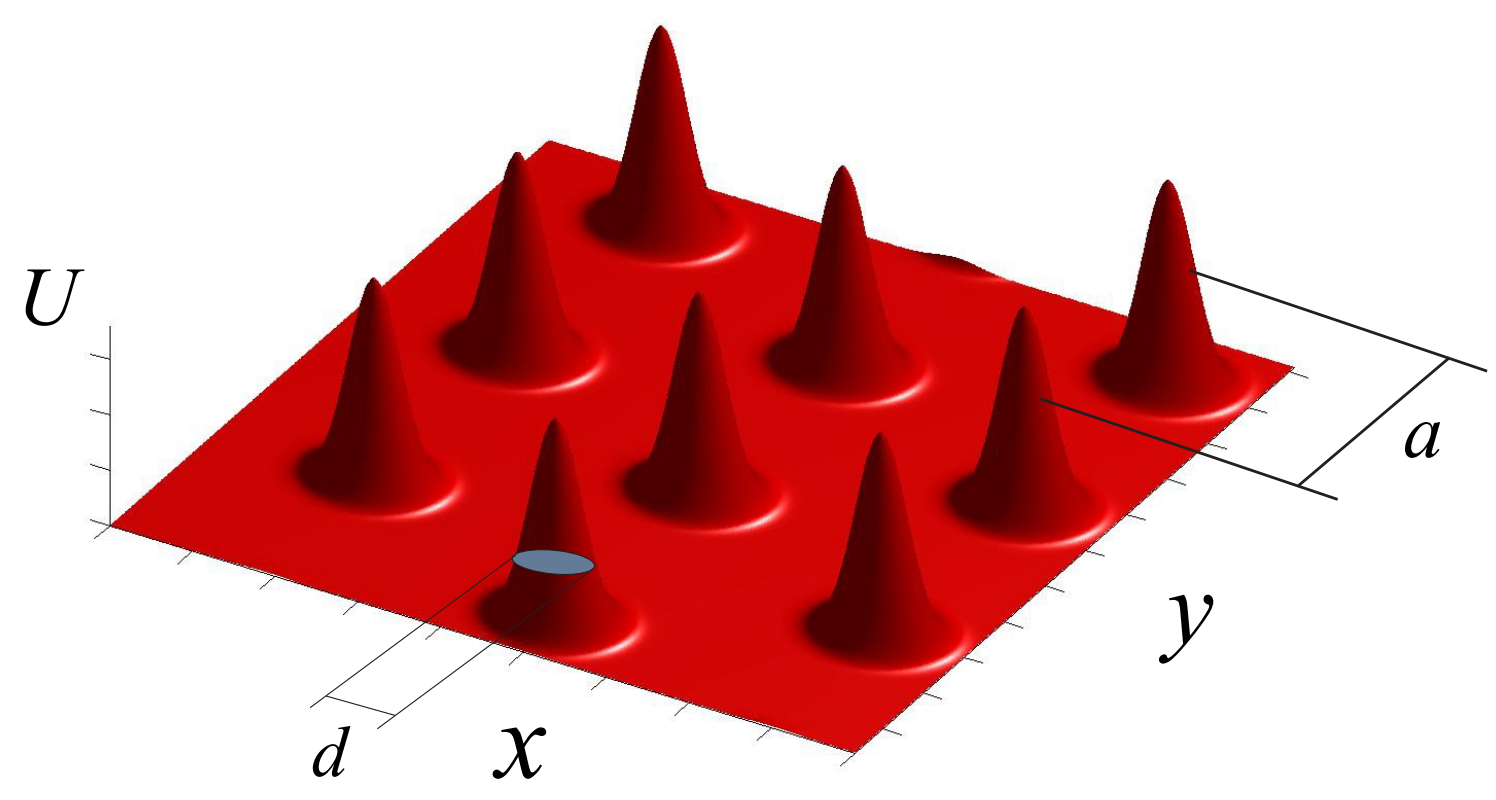

Figura 3.2: Diagrama esquemático mostrando o efeito de modulação do potencial eletrostático devido à presença de uma rede triangular de antipontos.

\subsection{Processamento das amostras}

As amostras utilizadas em nossos estudos foram crescidas usando o método de epitaxia por feixe molecular (Molecular Beam Epitaxy, MBE), sobre substratos semi-isolantes de GaAs no Institute of Semiconductor Physics (Novosibirsky-Russia). As amostras utilizadas en nossos estudos são poços quânticos largos (Wide Quantum Well, WQW) com uma largura do poço de $45 \mathrm{~nm}$. Estas amostras contêm um sistema de bicamadas eletrônicas. O processamento da amostra foi realizado em outros laboratórios: a criação da barra Hall e gravação das super-redes de antipontos foi realizada no Grupo de Semicondutores do Instituto de Física de São Carlos (IFSC) da Universidade de São Paulo (USP); a deposição da porta metálica foi feita no Laboratório de Pesquisas de Dispositivos (LDP) do Instituto de Física da Universidade Estadual de Campinas (UNICAMP). O procedimento de fabricação das super-redes de antipontos em um sistema de bicamadas pode ser descrito nas seguintes etapas:

\subsubsection{Deposição da camada fotoresistiva}

A barra Hall é elaborada em cada uma das amostras para otimizar as medidas de magnetotransporte. Para isso, é necessária a deposição de uma camada muito fina de uma resina fotoresistiva sobre a superfície das amostras. Antes da deposição da camada de resina fotoresistiva é realizada uma limpeza da superfície das amostras, para poder retirar possíveis resíduos de gordura e outras impurezas procedentes do meio externo. A 
limpeza é realizada colocando as amostras em um vaso de precipitado contendo acetona sobre um aquecedor elétrico. Com o aquecimento lento a acetona começa a evaporar, arrastrando os resíduos de gordura.

Após a conclusão do processo de limpeza, a superfície da amostra está pronta para a gravação da barra Hall. A primeira parte deste processo consiste na deposição uniforme de uma camada de resina fotosensível sobre a superfície da amostra. O Photoresist é uma resina que perde a sua resistência ao ataque químico (etching) quando é exposta à radiação eletromagnética de comprimento de onda curto UV (ultravioleta). Para a deposição da camada de Photoresist, a base do substrato da amostra é fixado (a vácuo) em um aparelho chamado spinner, o qual é basicamente um suporte giratório onde são colocadas as amostras. A parte 1 e 2 da figura 3.3 mostra como a amostra fica presa na superfície do suporte, devido à sucção provocada por uma bomba de vácuo através de um capilar. Quando a amostra está girando, a resina fotosensível é espalhada sobre a mesma com um conta gotas. Neste processo o fotorresiste fica espalhado uniformemente pela superfície da amostra, devido ao efeito de rotação rápida.

Depois do processo de deposição do Photoresist, é feito um pré-aquecimento sobre a amostra, colocando-a em um forno elétrico, para evaporar o solvente da resina e fixar a resina sobre a superfície da amostra (parte 3 da figura 3.3). Este passo deve ser feito sob luz amarela para que o fotorresiste não seja sensibilizado. Depois a amostra é retirada do forno e colocada na fotoalinhadora para o processo de gravação da máscara de litografia. A máscara com o perfil da barra Hall é um filme opaco que contém na parte central o desenho transparente e em tamanho real do negativo dela (o entorno do desenho é totalmente opaco à radiação). Posiciona-se a máscara diretamente sobre a superfície da amostra e é fixada cuidadosamente para evitar possíveis vibrações. Logo após a fixação da máscara sobre a amostra, expõe-se a amostra na luz ultravioleta. Desta forma a luz penetrará na máscara através do padrão transparente da barra Hall e atingirá a camada fotosensível, fazendo que a superfície do fotorresiste que não estava protegida pela máscara seja sensibilizada. O processo de exposição produz a polimerização das regiões expostas.

\subsubsection{Gravação do Padrão da Super-rede de Antipontos}

Após a gravação do formato da barra Hall procede-se à gravação do padrão da superrede de antipontos. $\mathrm{O}$ arranjo de antipontos pode ser retangular, quadrado, triangular e deverá estar localizado em um dos extremos do canal de corrente na barra Hall. O arranjo periódico de antipontos é gravado sobre a superfície da camada resistiva do polímero polimetil-metacrilato (PMMA), empregando-se a litografia por feixe eletrônico para fazer a gravação. O processo consiste na aplicação de um feixe de elétrons de alta resolução o qual pode definir qualquer tipo de formato de antiponto sobre a superfície da camada 

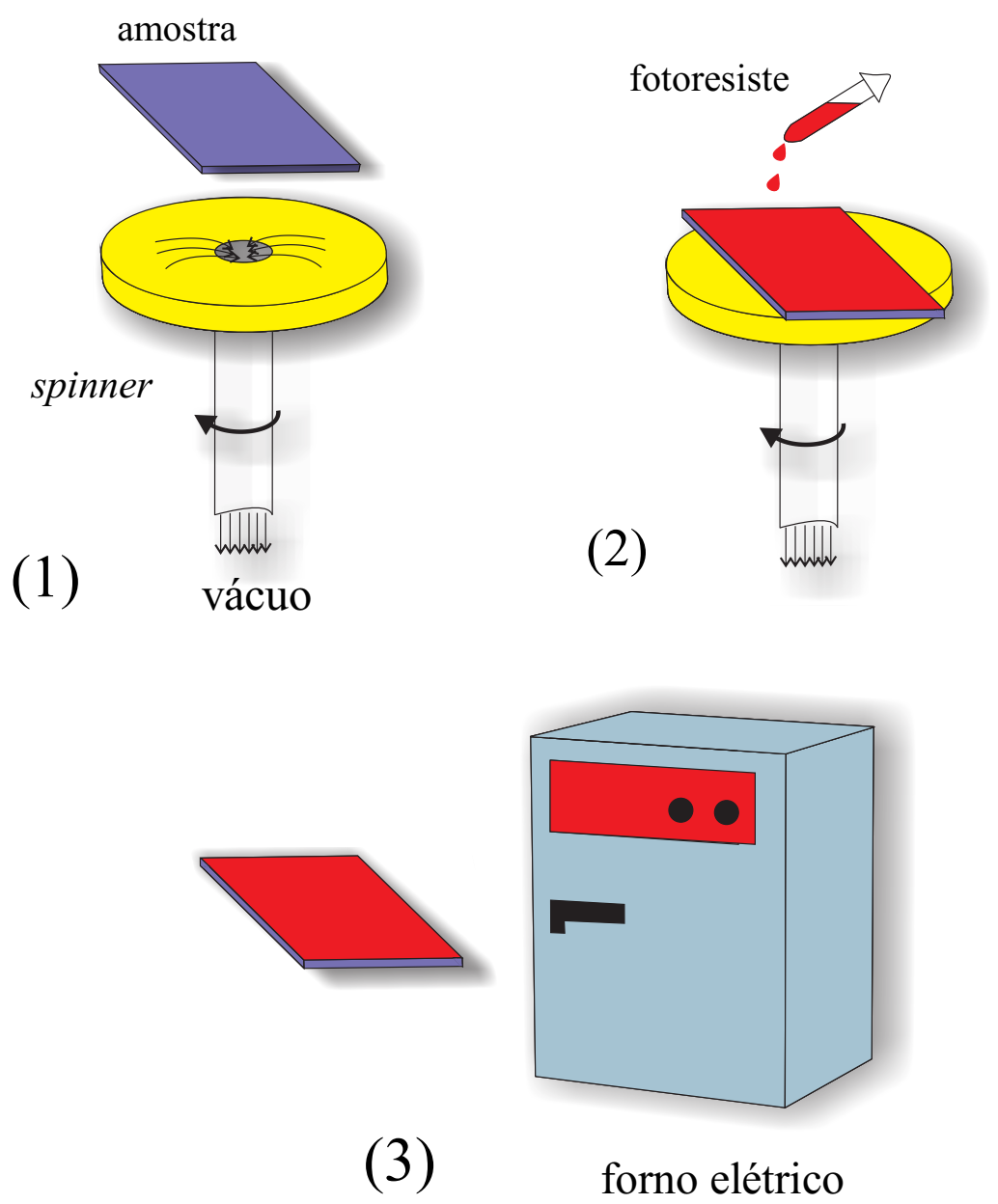

Figura 3.3: Procedimento empregado para a gravação da barra Hall para as amostras que contém um sistema de bicamadas.

fotosensível. A energia dos elétrons é aproximadamente da ordem de $50 \mathrm{KeV}$ concentrados em um feixe de aproximadamente 150 A de diâmetro, o que torna possível a gravação de motivos com tamanhos da ordem de $\sim 0.02 \mu \mathrm{m}$ (Weiss et al., 1991).

Para este estudo foram empregados antipontos com forte modulação eletrostática, portanto, para elaboração de super-redes com essas características é necessário gravar o padrão da rede através da camada fotosensível, até o nível do gás de elétrons. No processo de gravação são empregados dois métodos: o "wet etching"e o "dry etching".

\section{O wet etching}

Esta é uma técnica simples que consiste na gravação das camadas de AlGaAsGaAs através da camada fotosensível por processo de ataque químico, portanto, são necessários um contendor para a solução líquida e o material a ser disolvido. As soluções empregadas são escolhidas de acordo com as velocidades de ataque e dos materiais a serem atacados. Para o GaAs pode ser empregada a solução de hidróxido de amônia em peróxido de 


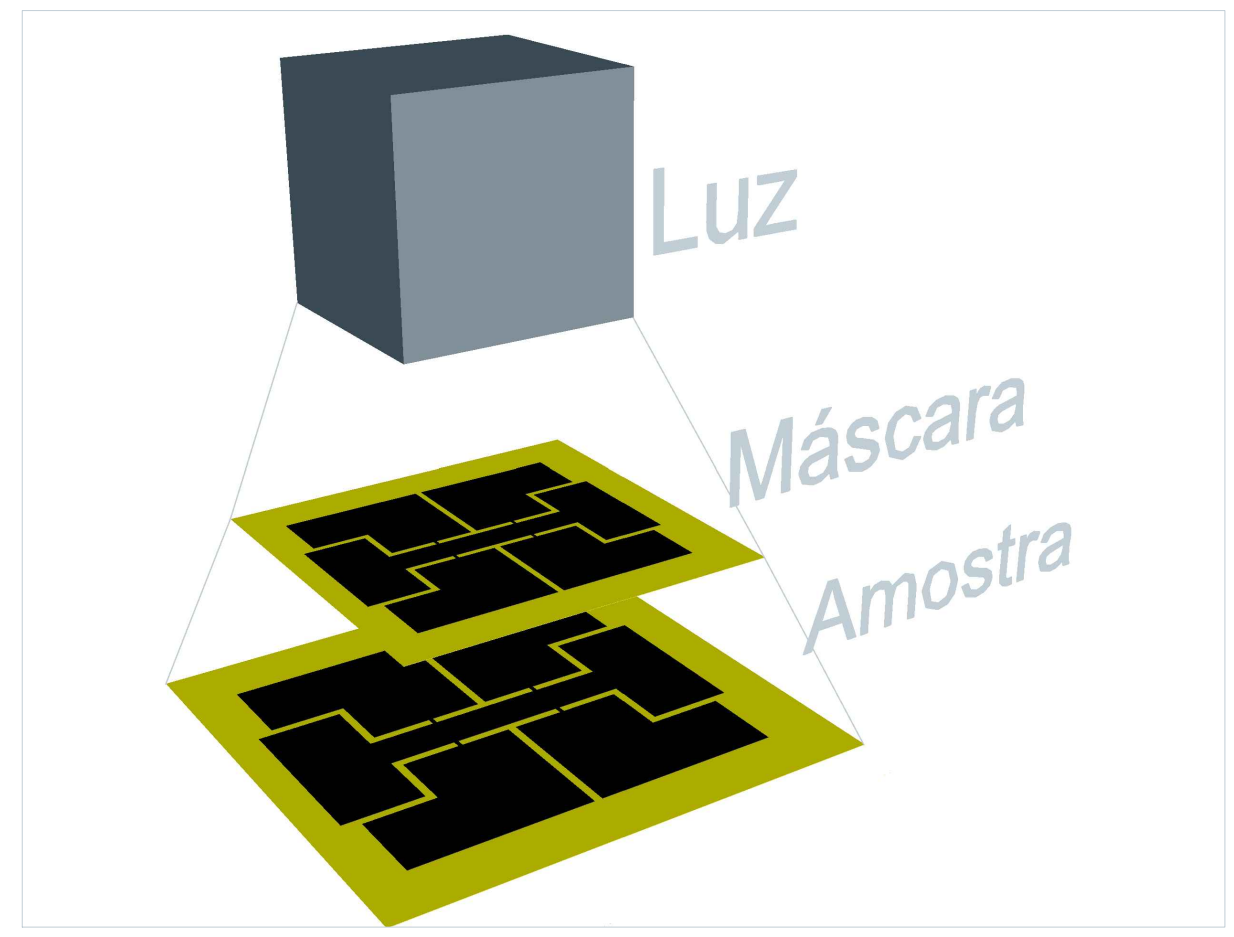

Figura 3.4: Processo de polimerização da região correspondente ao negativo do padrão da barra Hall.

hidrogênio e água $\left(\mathrm{NH}_{4} \mathrm{OH} / \mathrm{H}_{2} \mathrm{O}_{2} / \mathrm{H}_{2} \mathrm{O}\right)$ na proporção 1:1:100 de acordo com a referência (Blanchet, 1994). A técnica do wet etching tem algumas desvantagens em materiais que apresentam certa anisotropia ao ataque químico, evitando um controle preciso do processo.

\section{O dry etching}

Com este tipo de processo é possível obter tanto um baixo índice de corrosão nas amostras como um controle preciso da profundidade do ataque. São utilizadas as propriedades reativas de fases gasosas em plasmas para a realização da gravação do padrão dos antipontos; normalmente esse plasma contém o tretacloreto de silício $\mathrm{SiCl}_{4}$ como elemento base. O ataque por plasma é alternativamente composto por um processo de sputtering, uma reação química ou uma combinação das duas. O processo do sputtering é dominado pela aceleração de íons energéticos formados no plasma contra a superfície das amostras. As energias típicas dos íons são aproximadamente $>200 \mathrm{eV}$. Parte do material é ejetado da superfície devido à transferência de energia e momento à superfície. 


\subsubsection{Gravação da Barra Hall}

Após o processo de iluminação com luz ultravioleta, retira-se a máscara e coloca-se a amostra em um vaso de precipitado (becker) com uma solução de monocloro-benzeno, material que realiza a fixação dos contornos do padrão gravado na resina fotosensível (definição das bordas). Logo após esse processo que leva aproximadamente 3 minutos, retira-se a amostra e a seca com um jato leve de gás nitrogênio. Em seguida, a amostra é introduzida em outro vaso com o líquido revelador. A mesma é presa em uma pinça apropriada para ser deslocada suavemente dentro do vaso, até visualizar-se, com boa definição, o padrão da barra Hall. Finalmente, a amostra é colocada em um terceiro vaso contendo água para neutralização da solução reveledora, secando-a com gás nitrogênio.

O desenho das barras Hall usada em nossas amostras é mostrado na figura 3.5. Esta barra Hall possue 6 regiões bem definidas, que indicaremos como contatos. A barra de Hall é desenhada para passar a corrente pelo canal entre os contatos c1 e c2, denominado canal de corrente. Assim , é possível medir a voltagem longitudinal ao longo do canal entre os contatos c3 e c4 (ou c5 e c6). A voltagem transversal ao fluxo de corrente é medida entre os contatos c3 e c6 (ou c4 e c5). Os contatos c3 ao c6 são denominados contatos de voltagem.

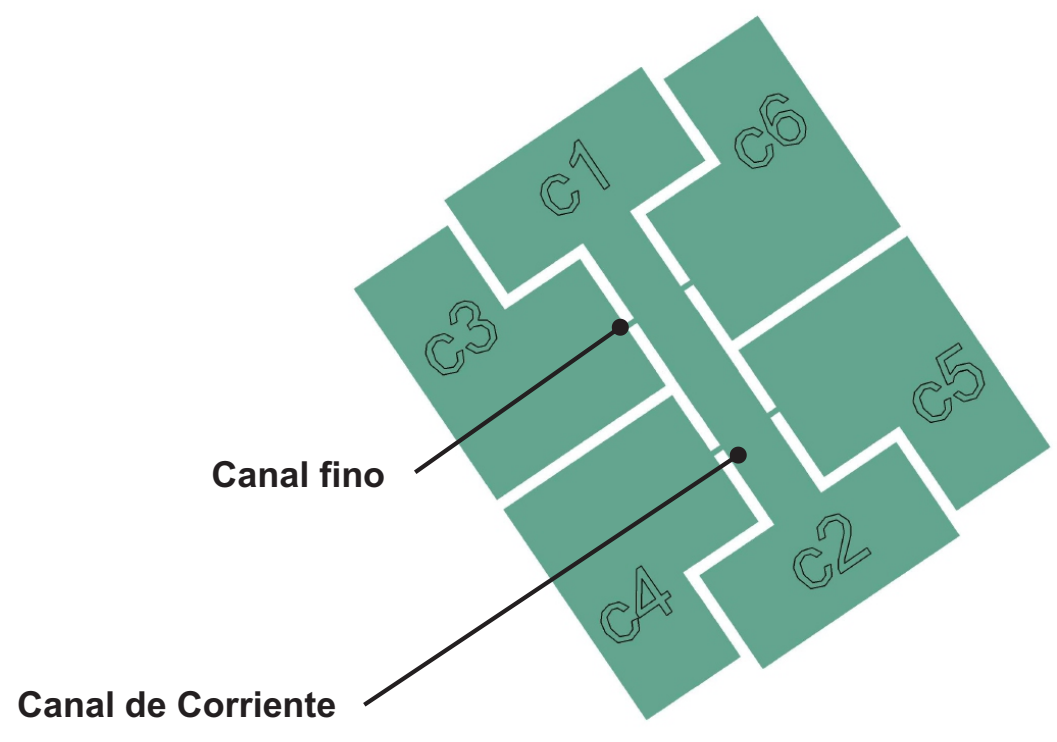

Figura 3.5: Desenho da barra Hall para realizar as medidas de voltagens longitudinal e transversal ao fluxo de corrente. $c 1, \ldots, c 6$ indicam as regiões onde vão os contatos elétricos. c1 e c2 são os contatos de corrente; os restantes são contatos de voltagem. O canal de corrente com os contato de voltagem é indicado pela seta vermelha. 
A figura 3.6 mostra um esquema resumido em quatro passos o processo de gravação da barra Hall e da super-rede de antipontos em uma amostra semicondutora cristalina. Na parte (1), a amostra está sem tratamento. Na parte (2), gravação do formato da barra Hall. A parte (3), transferência do padrão da barra Hall, obtida por wet etching. Finalmente, na parte (4) mostra-se a gravação da super-rede de antipontos por litografia de feixe eletrônico e dry etching.

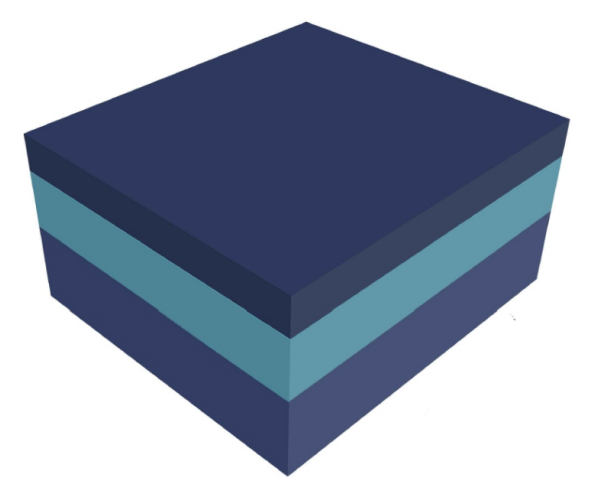

(1)

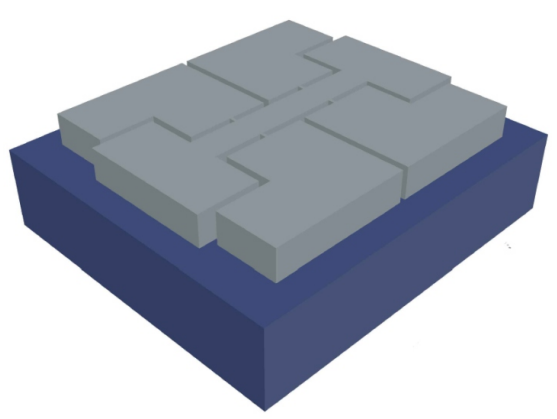

(3)

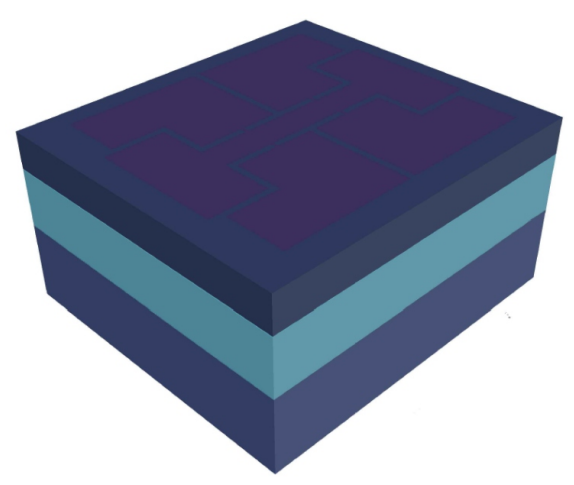

(2)

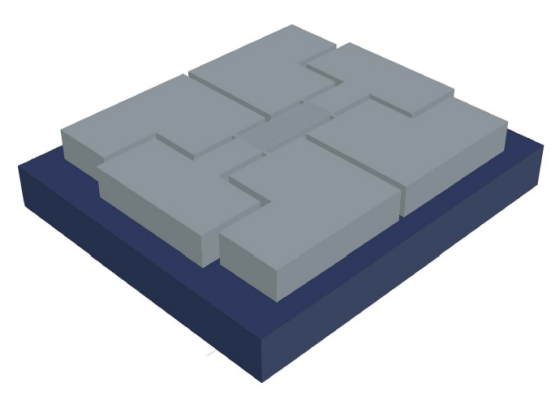

(4)

Figura 3.6: Diagrama esquemático do processo de gravação das super-redes de antipontos em amostras contendo uma barra Hall. (1) amostra sem tratamento, (2) gravação do formato da barra, (3) transferência do padrão da barra, obtida por wet etching, (4) gravação da super-rede de antipontos por litografia de feixe eletrônico e dry etching. 


\subsubsection{Colocação dos Contatos Ôhmicos e da Porta Metálica}

A última etapa é a colocação de contatos ôhmicos de índio através de um procedimento de difusão a $400^{\circ} \mathrm{C}$ durante $3 \mathrm{~min}$, em atmosfera de $N_{2}$. Outro processo importante é a colocação da porta metálica sob a região de interesse. Primeiramente coloca-se sobre a amostra uma máscara com um pequeno furo no centro, a qual deve cobrir toda a amostra exceto a região desse furo, que é posicionado acima do centro da barra Hall (região de interesse). Logo, a amostra é colocada numa câmara de vácuo de uma evaporadora, onde se encontra um cadinho que está verticalmente alinhado com a amostra, a qual sustenta o metal a ser evaporado. O vácuo é feito dentro da câmara, e depois deposita-se os filmes de titânio, $T i$, e ouro, $A u$. Finalmente se coloca o contato ôhmico sob a porta, solda-se um terminal elétrico ao filme, o qual pode ser feito com cola de prata $(A g)$ ou índio (In), através do qual é feita a aplicação dos potenciais elétricos. A figura 3.7 mostra os passos na colocação dos contatos ôhmicos e da porta metálica.

\subsection{Equipamento Básico para o Estudo do magneto- transporte a baixas temperaturas}

Para o estudo dos fenômenos de magnetotransporte, ou seja, de como se processa a condução elétrica na presença de campo magnético, as temperaturas baixas são um fator importante. Nestas temperaturas é possível a observação de efeitos quânticos. O estudo também requer a aplicação de sistemas que criem campos magnéticos externos. O grupo do LNMS do instituto de Física da Universidade de São Paulo possui este sistema. Para a utilização correta é necessário um conhecimento básico sobre mesmo.

O LNMS tem um criostato com uma bobina supercondutora para produzir campo magnético. A bobina permanece imersa num banho de ${ }^{4} \mathrm{He}$. A parte superior deste criostato pode ser trocada. Assim o sistema pode ser usado como um sistema VTI (variable temperature insert) ou também como um sistema de ${ }^{3} \mathrm{He}$. A câmara contendo $\mathrm{N}_{2}$ líquido permite limitar a diminuição da temperatura até $77 \mathrm{~K}$, e finalmente uma câmara externa em alto vácuo para melhorar o isolamento térmico do sistema. Assim, os dois sistemas são diferentes somente no tipo de criostato inserido no banho de ${ }^{4} \mathrm{He}$ e na faixa de temperaturas que podem atingir. A aparência deste tipo pode ser observada na figura 3.8 .

\subsubsection{Criostato de ${ }^{4} \mathrm{He}$}

O Criostato de ${ }^{4} \mathrm{He}$ é o mais simples deste tipo de equipamento para a realização de estudos a baixas temperaturas. O Criostato de ${ }^{4} \mathrm{He}$ é um tipo de VTI que permite atingir uma faixa ampla de temperaturas, indo desde $1,5 \mathrm{~K}$ até a temperatura ambiente, embora 

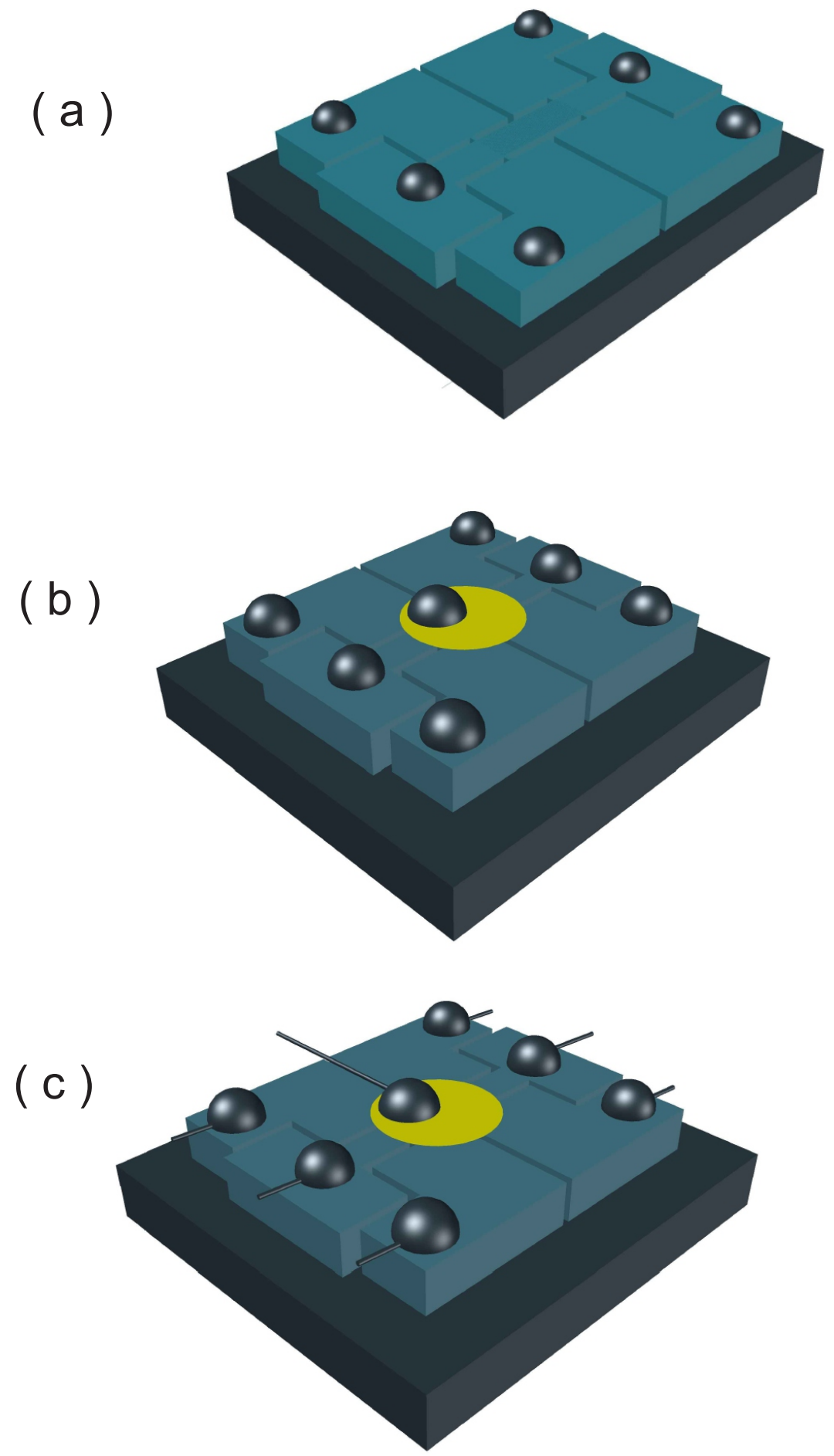

Figura 3.7: Passos na colocação de contatos ôhmicos e porta metálica. (a) colocação do contatos ôhmicos de indio, (b) colocação da porta cobrindo a região da barra Hall e finalmente (c) a coloção do contato ôhmico na porta metálica e a fixação dos contatos. 


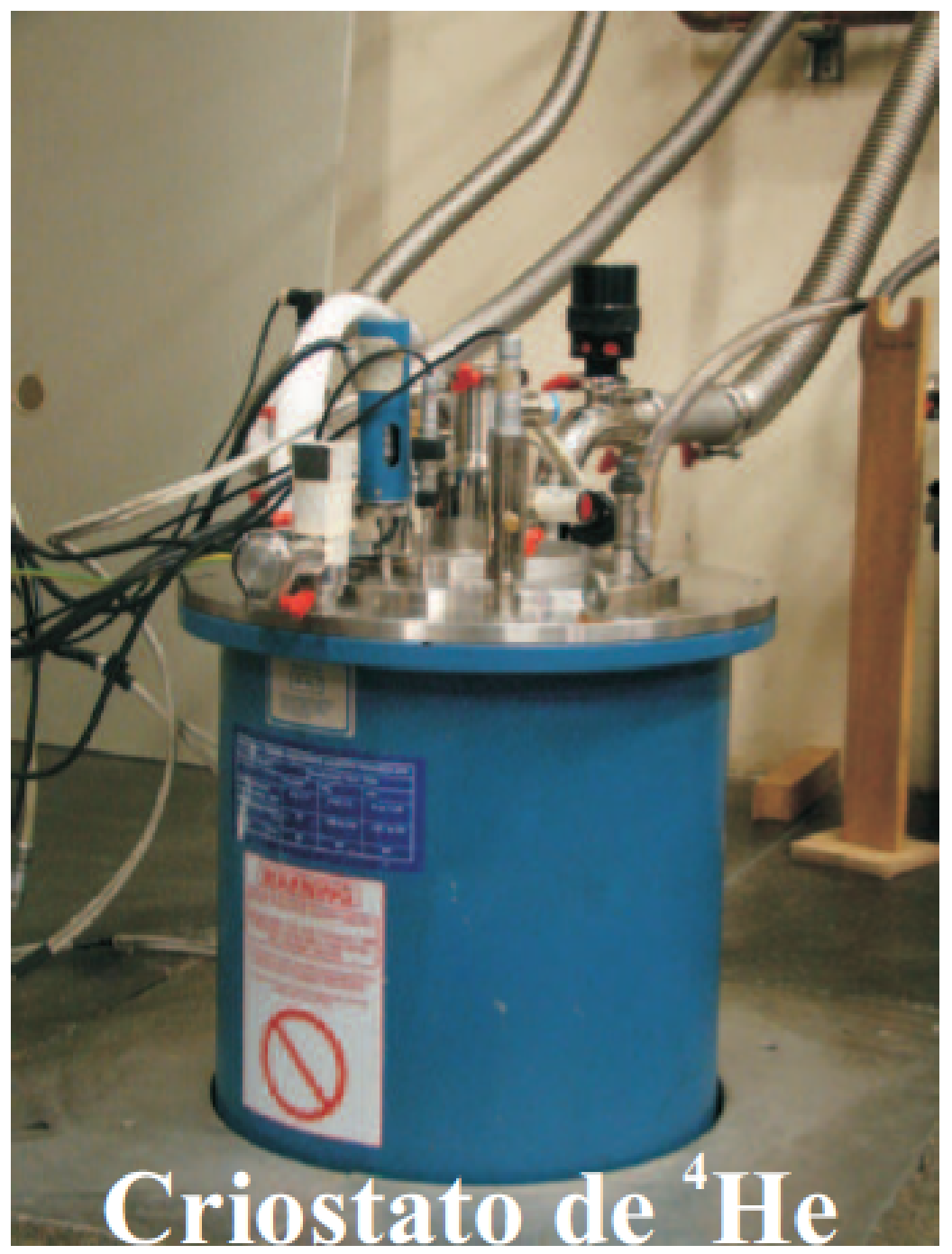

Figura 3.8: Criostato usado para realizar medidas de magnetotransporte. O criostato montado com o sistema apropriado para usar um sistema de refrigeração de ${ }^{4} \mathrm{He}$ o qual funciona como um sistema VTI.

seja possível medir altas temperaturas; para o estudo apresentado nesta dissertação só fora necessário temperaturas ao redor de 1,5 K. a figura 3.9 mostra o esquema básico do princípio de sistema VTI. Este sistema é desenhado para operar a baixas temperaturas usando o ${ }^{4} \mathrm{He}$ como fluido refrigerante. Na temperatura do líquido de ${ }^{4} \mathrm{He}$, a pressão atmosférica é de 4,2 K. Considerando princípios de termodinâmica, diminuindo a pressão do ${ }^{4} \mathrm{He}$ na sua respectiva câmara, a sua temperatura também diminui. Assim é possível atingir temperaturas até de $1,5 \mathrm{~K}$ usando um sistema de bombeamento, mas atingir temperaturas mais baixas se torna mais complicado uma vez que a temperatura de 2,172 $\mathrm{K}$, o ${ }^{4} \mathrm{He}$ se torna super-fluido, tornando pouco eficaz o sistema de bombeamento nessas condições. 


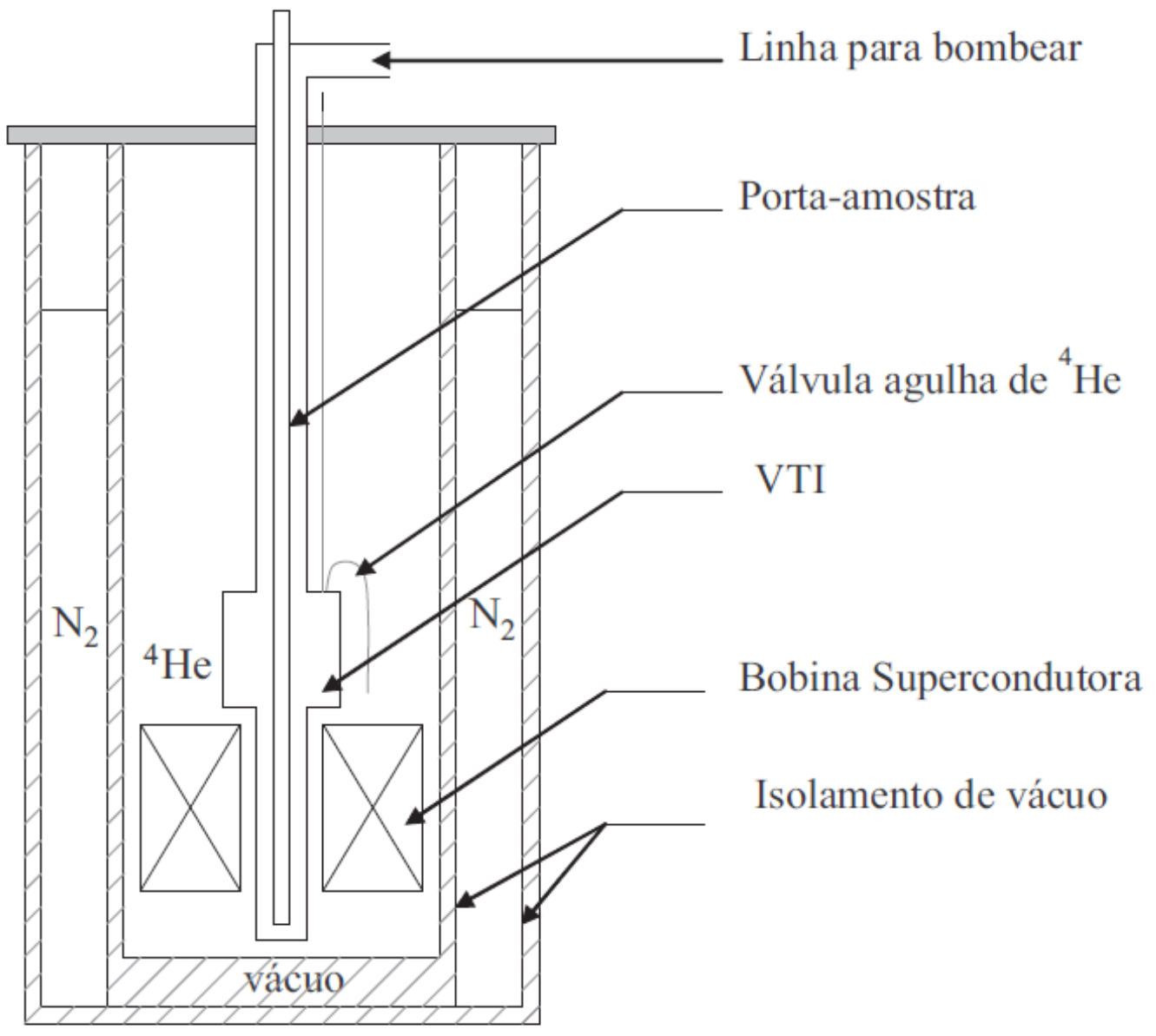

Figura 3.9: Esquema interno básico do criostato com o sistema de refrigeração baseado no ${ }^{4} \mathrm{He}$.

O sistema total basicamente pode ser descrito como a parte superior do criostato, contendo o porta-amostra, que ao mesmo tempo está imerso num banho de ${ }^{4} \mathrm{He}$, onde o porta-amostra está imerso diretamente. Este banho de ${ }^{4} \mathrm{He}$ é conectado ao banho de ${ }^{4} \mathrm{He}$ principal através de uma válvula agulha, a qual é usada para injetar ${ }^{4} \mathrm{He}$ na câmara onde está o porta-amostra. A adequada injeção de ${ }^{4} H e$ na câmara da amostra permite estabilizar a temperatura, sendo a mesma um dos parâmetros críticos. O sistema conta com uma resistência localizada na parte inferior do criostato (a parte que contém o portaamostra), a qual permite aquecer o banho de hélio na câmara que contém a amostra. Este sistema de aquecimento deveria permitir cobrir de modo estavél temperaturas desde $1.5 \mathrm{~K}$ até $300 \mathrm{~K}$. Para atingir diferentes temperaturas inferiores a $4.2 \mathrm{~K}$, não é usada a resistência, mas sim um equilibrio entre o fluxo do ${ }^{4} \mathrm{He}$ bombeado da câmara do portaamostra e o ${ }^{4} \mathrm{He}$ injetado desde o banho principal de ${ }^{4} \mathrm{He}$. Uma vez que a amostra está em contato direto com o banho de ${ }^{4} \mathrm{He}$, atingir uma temperatura estável não é simples, isto é encontrar o fluxo certo do ${ }^{4} H e$ através da válvula agulha e através da chave que controla o fluxo até a bomba. 


\subsubsection{A Bobina Supercondutora}

Para gerar campos magnéticos, são usadas bobinas supercondutoras localizadas na câmara com o banho principal de ${ }^{4} H e$, uma vez que esta câmara está livre de qualquer sistema de bombeamento; a temperatura é de $4.2 \mathrm{~K}$. A supercondutividade permite o fluxo de uma corrente através das bobinas sem a dissipação de energia e é gerado um campo magnético. As bobinas são feitas de fios de nióbio e titânio envoltos numa matriz de cobre. A bobina supercondutora de nosso criostato permite atingir nominalmente até $15 \mathrm{~T}$ com sistema VTI e com a refrigeração normal de ${ }^{4} H e$, embora neste sistema seja possível de atingir até $17 \mathrm{~T}$ usando a técnica do ponto lambda, o qual não foi considerado na descrição dos criostatos. Por razões de segurança, para evitar o quenching e poupar o uso do ${ }^{4} \mathrm{He}$ para a refrigeração, nossas bobinas somente são usadas para gerar campos magnéticos até $12 \mathrm{~T}$.

\subsection{Procedimentos Básicos em Medidas de Transporte}

\subsubsection{Como Fazer as Medidas de Transporte}

As medidas de magnetotransporte foram realizadas variando alguns parâmetros, como a temperatura e a aplicação de potenciais externos através da porta (gate). Para obter resultados no regime linear é necessário aplicar uma corrente suficientemente pequena para evitar os efeitos de aquecimento dos elétrons. O limite menor da corrente é aquele valor em que se permite um acesso bem definido ao sinal procurado, e também que o ruído no sinal de saída seja suficientemente pequeno para ser considerado desprezível. Para evitar o ruido é necessário o uso de cabos apropriados e uma detecção do sinal de saída sincronizada com o sinal de entrada. Com estas condições, é possível obter um sinal livre de ruido.

O esquema básico da configuração dos equipamentos para realizar as medidas de resistência se mostra na figura 3.10. A amostra é colocada no extremo do cano que dá ao porta-amostra. Os contatos são conectados aos diferentes componentes que conformam o sistema de medição através de cabos coaxiais. A voltagem desejada é fornecida pelo lock-ín, o qual é acoplado a uma resistência de determinado valor para atingir a corrente desejada. A frequência dessa voltagem pode ser escolhida uma vez que este mesmo lockin é aplicado para realizar as medidas, essa frequência determina a frequência do sinal medido.

O computador comanda os equipamentos utilizados nas medidas de magnetoresistência. Os principais equipamentos usados em nossas medidas são: um lock-ín (EG\&G5210), um conversor analógico digital (HP34401A), uma fonte de corrente OXFORD IPS 120A-10V. 
Outros dispositivos, como uma fonte de tensão, uma fonte de corrente, alguns multímetros adicionais foram usados para monitorar as medidas e os controladores de temperatura e do nível do ${ }^{4} \mathrm{He}$ e do nitrogênio no criostato. Alguns destes dispositivos são indicados na figura 3.10 .

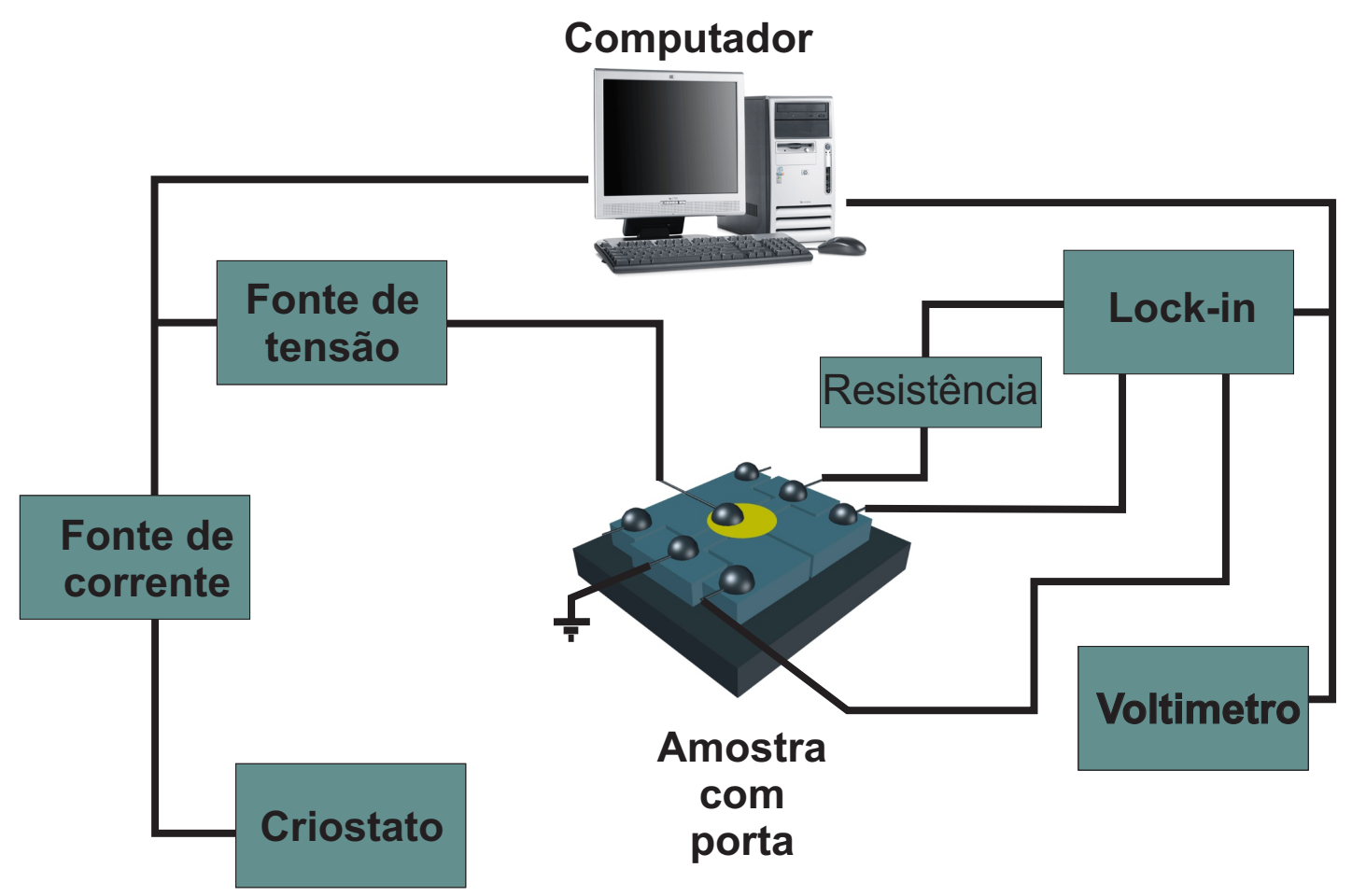

Figura 3.10: Esquema do equipamento usado no LNMS para realizar estudos de magnetotransporte. Aqui como um exemplo é mostrado um esquema básico do método de medição da magnetoresistência longitudinal. Parte do sistema é automatizada usando um programa computacional.

O procedimento para realizar as medidas de transporte é o seguinte: a amostra é imersa em ${ }^{4} \mathrm{He}$ líquido a $1,5 \mathrm{~K}$ em uma região de campo magnético uniforme e perpendicular ao plano de crescimento. O campo magnético é gerado através de uma corrente que é passada por um sistema de bobinas supercondutoras. Uma corrente AC fornecida pelo lock-in é passada através do canal de corrente da barra Hall, ver figura 3.11. Medimos a diferença de potencial paralela ao canal de corrente, o que permite obter a diferença de voltagem longitudinal $\left(V_{x x}\right)$, e a diferença de potencial perpendicular ao canal de corrente da barra Hall, o que permite medir a voltagem transversal $\left(V_{x y}\right)$ que vai fornecer a resistência Hall. Os potenciais em cada ponto são enviados ao lock-in, que realiza a medida propriamente dita. A medida obtida pelo lock-in é enviada ao conversor analógico digital, que envia o sinal ao computador. Todo este sistema é automatizado. Uma fonte de tensão é utilizada para aplicar uma voltagem positiva ou negativa na porta da amostra. O criostato tem 
outros equipamentos adicionais, como controladores do nível de hélio e de nitrogênio e um sensor de temperatura dentro do criostato perto da posição onde se localiza a amostra.

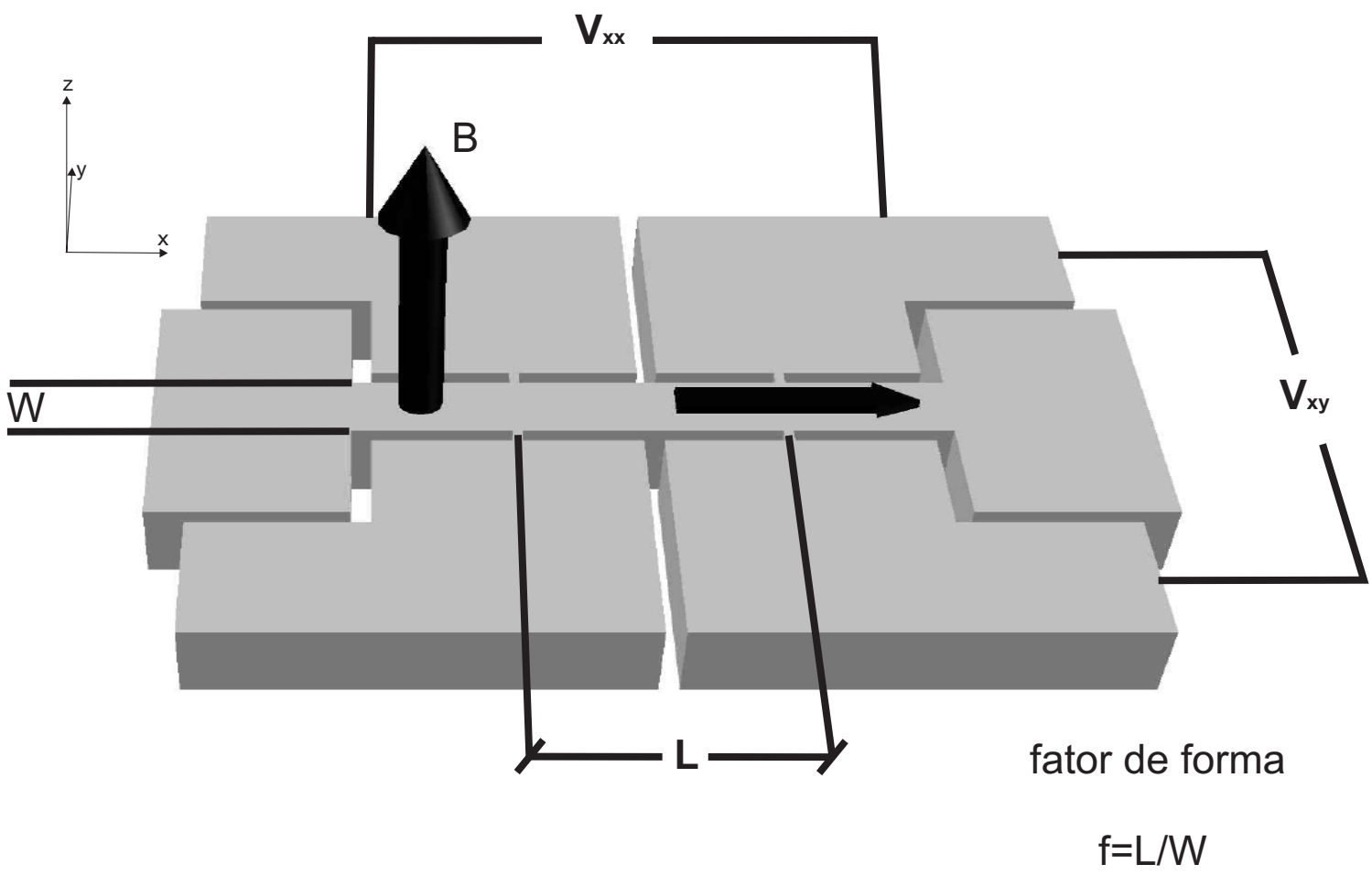

Figura 3.11: Esquema da barra Hall gravada nas amostras de WQWs para os estudos do transporte são indicados o canal de corrente e os respectivos contatos. São indicadas as dimensões da região de interesse largura do canal $200 \mu m$ e o comprimento $500 \mu m$. O fator de forma é dado pela fração do comprimento do canal em relação à largura do canal de corrente, em nossas amostras $f=2,5$.

\subsubsection{Parâmetros Básicos de Transporte}

As resistências longitudinal $R_{x x}$ e transversal $R_{x y}$ são obtidas a partir da lei de Ohm. A resistência longitudinal é dada por:

$$
R_{x x}=\frac{V_{x x}}{I}
$$

está em função do campo magnético uma vez que $V_{x x}$ depende do mesmo. A resistividade é dada por $\rho_{x x}=R_{x x} / f$ onde $f=L / W$ é o fator de forma geométrico da barra Hall, ver figura 3.11. As unidades da resistência longitudinais são as mesmas.

A resistência Hall $R_{x y}$ é equivalente à resistividade $\rho_{x y}$, e é dada por: 


$$
R_{x y}=\frac{V_{x y}}{I}
$$

A densidade eletrônica total é obtida das medidas da resistência Hall $R_{x y}$ usando a relação $\rho_{x y}=-B / e n_{s}$. Quando a curva $R_{x y}(B)$ não tem influência da quantização (platôs), se obtém a inclinação $\alpha$ da curva. Deste modo, a densidade é dada por:

$$
n_{s}=\frac{1}{e \alpha}
$$

Uma vez que $\rho_{x y}$ é dado em [ohms] e B em [T], então $\alpha$ é dado em $\left[m^{2} / C\right]$ e com $e$ em $\left[10^{-19} \mathrm{C}\right]$; a densidade eletrônica é $n_{s}=0,614 / \alpha$ em $\left[10^{15} \mathrm{~cm}^{-2}\right]$.

Outro parâmetro de transporte importante que podemos determinar é a mobilidade de transporte $\mu$, definida como a razão entre a velocidade de arraste e o campo elétrico $v=\mu E$, a qual é obtida usando a relação $1 / \rho_{x x}(0)=n_{s} e \mu$, e é dada por:

$$
\mu=\frac{1}{e R_{x x}(0) n_{s}}
$$

onde $R_{x x}(0)$ é a resistência quando $B=0$. Com $e$ dado em $\left[10^{-19} C\right], R_{x x}(0)$ em [ohms], $n_{s}$ em $\left[10^{11} \mathrm{~cm}^{-2}\right]$ e $f=2.5$; a mobilidade é $\mu=1.56 / R_{x x}(0) n_{s}$ em $\left[10^{8} \mathrm{~cm}^{2} / V s\right]$ 


\section{Capítulo 4}

\section{Resultados Experimentais}

\subsection{Amostras empregadas}

As amostras utilizadas em nosso estudo são heteroestruturas semicondutoras baseadas na junção GaAS/AlGaAS que contém um poço quântico largo (WQW, wide quantum well), as quais foram crescidas usando o método de epitaxia por feixe molecular (molecular beam epitaxy, MBE). As mesmas são usadas para o estudo de magnetotransporte, e estas contêm poços quânticos largos, com uma largura de $45 \mathrm{~nm}$. O poço quântico largo estudado tem um sistema de bicamadas. Na parte superior da amostra foi gravada um padrão de rede de antipontos bidimensionais triangulares com uma periodicidade de rede $a=612$ $\mathrm{nm}$ e o diâmetro do antiponto é $d=100 \mathrm{~nm}$. Acima dessa superfície foi colocada uma porta metálica sob a região de interesse através de um processo de evaporação de camadas de titânio ( $\mathrm{Ti}$ ) e ouro $(\mathrm{Au})$, enchendo os buracos mecânicos feitos pela gravação da rede de antipontos. Aplicando diferentes voltagens de porta faz mudar a magnetoresistência.

\subsection{Magnetotransporte em Bicamadas com Antipontos}

As amostras pesquisadas tem uma alta densidade eletrônica e uma alta mobilidade para o estudo do transporte. Uma ferramenta muito importante para o estudo de transporte é a magnetoresistência, porque reflete as mudanças que os estados eletrônicos quantizados impõem ao transporte. A densidade eletrônica total desta amostra é $n=8,6 \times 10^{11} \mathrm{~cm}^{-2} \mathrm{e}$ a mobilidade é $\mu=1,5 \times 10^{6} \mathrm{~cm}^{2} / V s$. Nosso sistema forma uma configuração de bicamadas devido à redistribuição da carga, quando duas camadas de elétrons perto das interfaces são separadas por uma barreira de potencial eletrostática. A forma do poço é mostrado dentro da figura 4.2 (Wiedmann et al., 2011).

Os mínimos mostrados na figura 4.1 , indicados por $\Delta_{S A S}, \Delta_{Z}$, e $\hbar \omega_{c}$ correspondem ao desdobramento entre as sub-bandas ocupadas, o desdobramento do spin e o gap do 


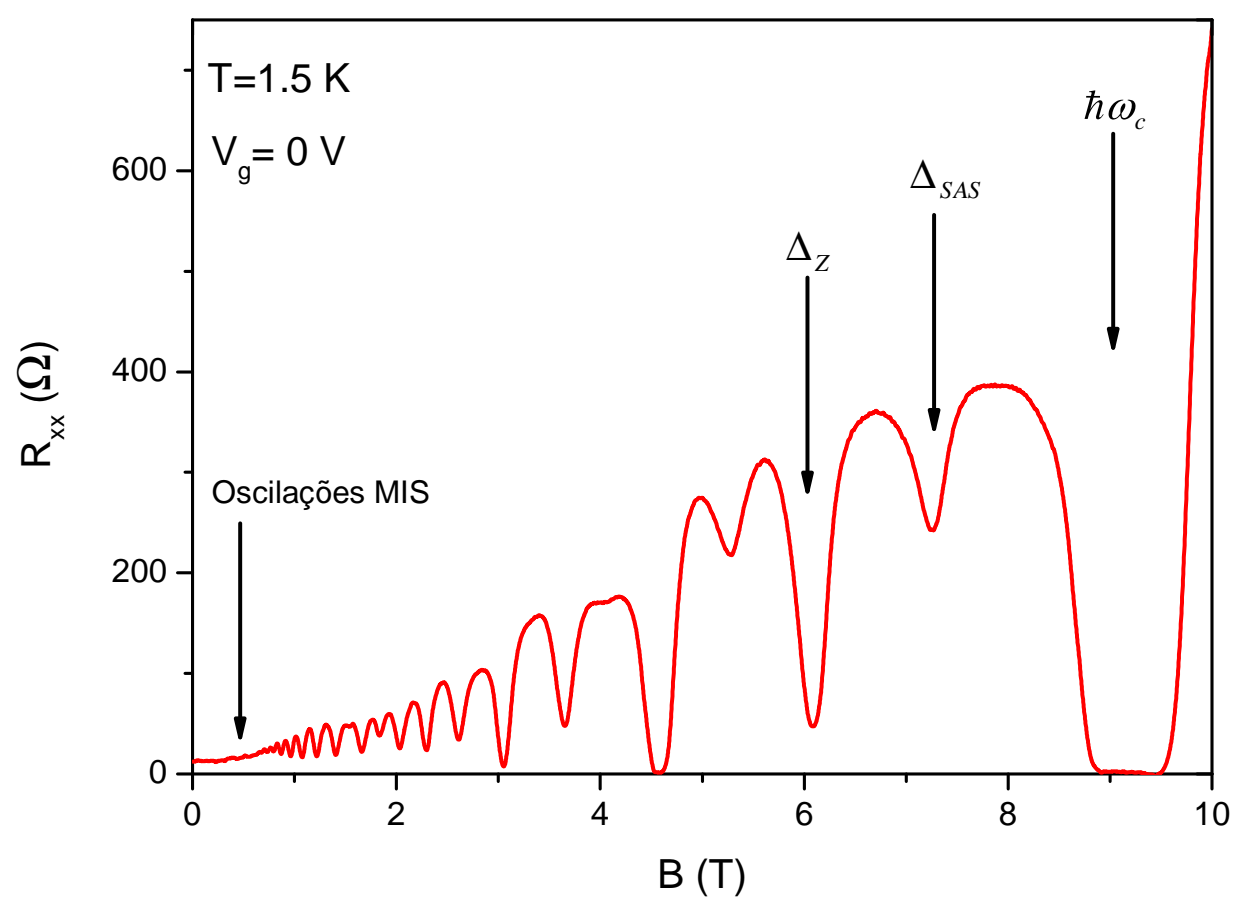

Figura 4.1: Magnetoresistência $R_{x x}$ como uma função do campo magnético perpendicular

cíclotron respectivamente. Esta medida foi realizada na presença de altos campos magnéticos: de $0 T$ até $10 T$. Neste espectro experimental, $\Delta_{S A S}, \Delta_{Z}$, e $\hbar \omega_{c}$ são determinadas pela característica principal das oscilações $R_{x x}$ e $R_{x y}$ que é o fator de preenchimento $\nu$. Assim, para valores de $\nu=2(N+1)$, os gaps de spin estão presentes; para valores de $\nu=4(N+1)$, os gaps de cíclotron estão presentes; os valores de $\nu=2 N+1$ correspondem aos gaps de $\Delta_{S A S}, \operatorname{com} N=0,1,2, \ldots$

A figura 4.2 mostra as medidas de magnetoresistência para diferentes voltagens de porta aplicadas sobre a amostra a baixos campos magnéticos e a temperatura $T=1,5 \mathrm{~K}$. Esta figura mostra como a magnetoresistência muda com a voltagem de porta. A diferença da curva de magnetoresistência de um sistema de bicamadas comparado com as oscilações SdH de um único 2DES, é devido a ocupação de duas sub-bandas com diferentes densidades $n_{1}$ e $n_{2}$. As diferentes densidades das sub-bandas fazem mudar as frequências das oscilações SdH (Mamani et al., 2008). Com o aumento do voltagem de porta (em magnitude $\left|V_{g}\right|$ ), as oscilações MIS são substituídas pelas oscilações devido ao de potencial periódico da rede de antipontos. Estas oscilações na magnetoresistência devido ao potencial da rede de antipontos são como uma função envelope que cobre às oscilações MIS, onde aparecem três picos de comensurabilidade na magnetoresistência a baixos campos magnéticos. 


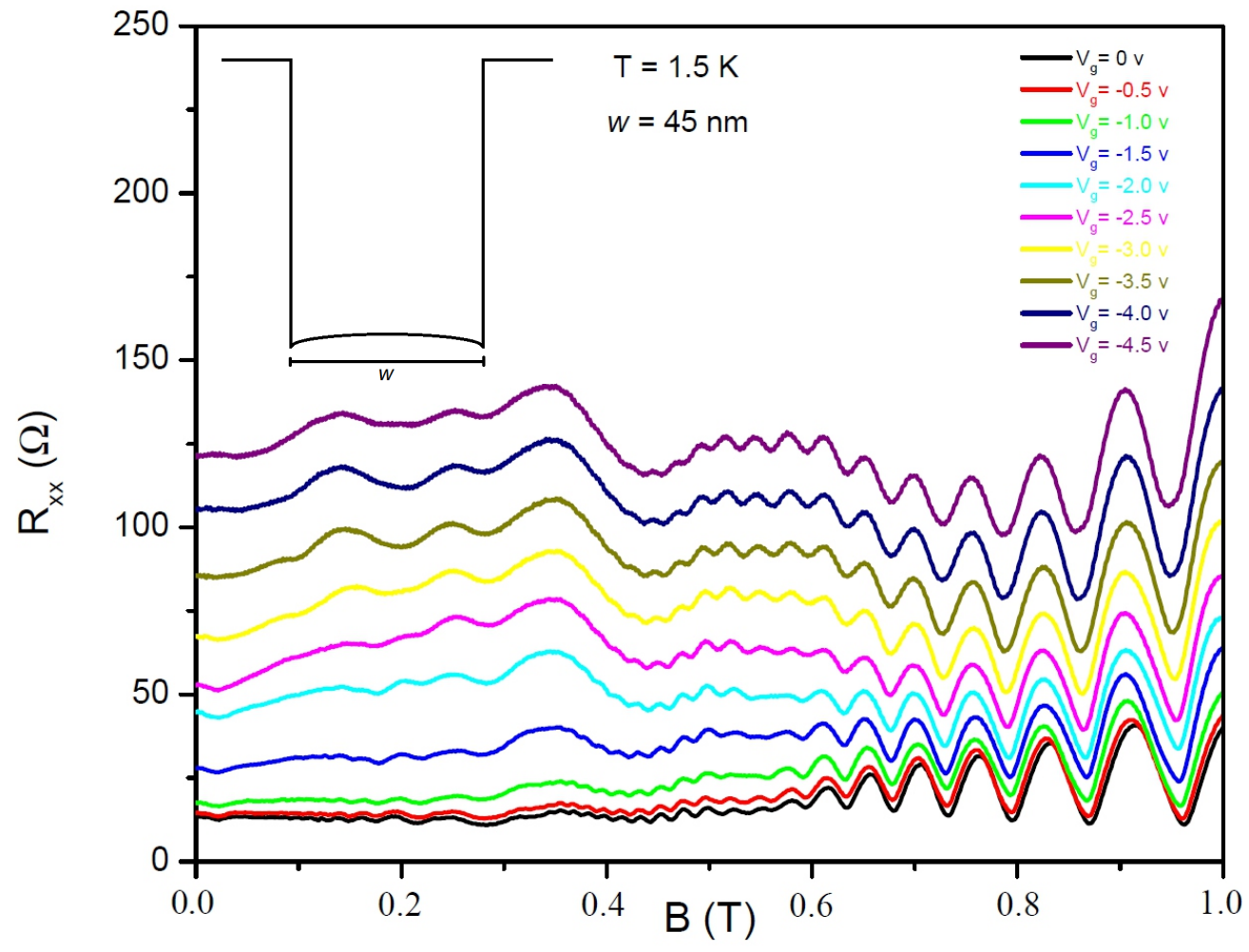

Figura 4.2: Magnetoresistência $R_{x x}$ como uma função do campo magnético perpendicular para diferentes voltagens de porta (desde $0 \mathrm{~V}$ até $-4.5 \mathrm{~V}$ ). A magnetoresistência foi medida a baixos campos magnéticos, a temperatura de $1,5 \mathrm{~K}$. A magnetoresistência aumenta conforme a magnitude da voltagem de porta aumenta (torna-se mais negativo) e o número de oscilaçôes entre os campos magnéticos de 0,1T até 0,4T diminuem. Dentro da figura mostra-se a forma do poço

Para analisar as curvas de magnetoresistência mostradas na figura 4.2 com diferentes voltagens de porta a baixos campos magnéticos usamos a transformada de Fourier rápida (FFT) que é uma importante ferramenta para obter as frequências no analise dos dados experimentais da magnetoresistência (Armas, 2009; Sander et al., 1998), e é apresentada na figura 4.3. Ao realizar o análise FFT dos dados das oscilações SdH, podem-se distinguir claramente dois picos juntos as quais correspondem as sub-bandas, a partir destes picos é possível determinar as densidades das sub-bandas para cada curva de magnetoresistência. Os dois picos agudos são resolvidos e aparecem nas posições indicadas pelas frequências $f_{1}$ e $f_{2}$, correspondentes à primeira e à segunda sub-banda ocupada e também aparece um pico indicado pela frequência $f_{M I S}$ que permanece com a mesma amplitude apesar de variar a voltagem de porta. Observa-se que a amplitude do pico $f_{2}$ diminui com o aumento em magnitude da voltagem de porta. Se sabe que os sistemas de duas subbandas são sensíveis aos campos elétricos transversais induzidos por voltagens de porta externos (Fletcher et al., 2005; Katayama et al., 1995; Mamani et al., 2009), assim como para campos magnéticos (Boebinger et al., 1991; Simmons et al., 1994). Tais campos influenciam consideravelmente a magnetoresistência, desde que a mudança da população 


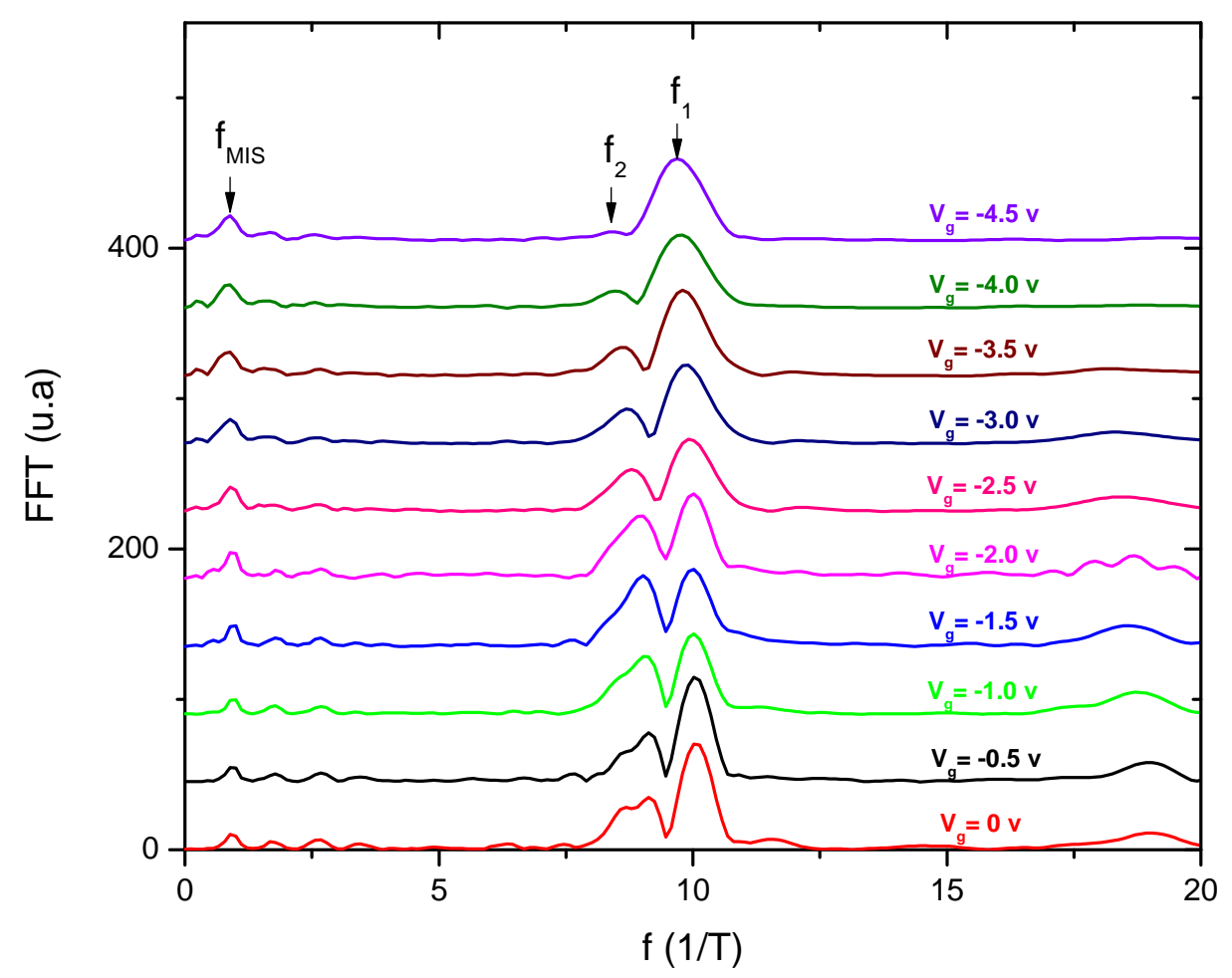

Figura 4.3: FFTs das curvas de magnetoresistência onde $f_{1}$ e $f_{2}$ indicam as frequências da primeira e da segunda sub-banda respectivamente, e também mostra-se a frequência MIS $f_{M I S}$ para as diferentes voltagens de porta.

das sub-bandas e pode levar a uma distorção substancial da superfície de Fermi, incluindo a transição de ocupação da sub-banda dupla a uma única sub-banda. As posições das frequências dos picos $f_{1}$ e $f_{2}$ fornecem diretamente as densidades das sub-bandas individuais $n_{1}$ e $n_{2}$, as quais são obtidas usando as equações:

$$
\begin{aligned}
& n_{1}=2 \times f_{1} \times \frac{h}{e} \\
& n_{2}=2 \times f_{2} \times \frac{h}{e}
\end{aligned}
$$

onde $\left(\frac{h}{e}\right)$ é a degenerescência de cada nível de Landau por unidade de área. O fator dois é incluído para contar a degenerescência de spin. Desde que as oscilações MIS estão relacionadas à condição de alinhamento dos níveis de Landau,

$$
\triangle S A S=k \hbar \omega_{c}
$$


onde $\omega_{c}$ é a frequência do cíclotron, e $k$ é um número inteiro que corresponde a um máximo na magnetoresistência (Raikh e Shahbazyan, 1994).

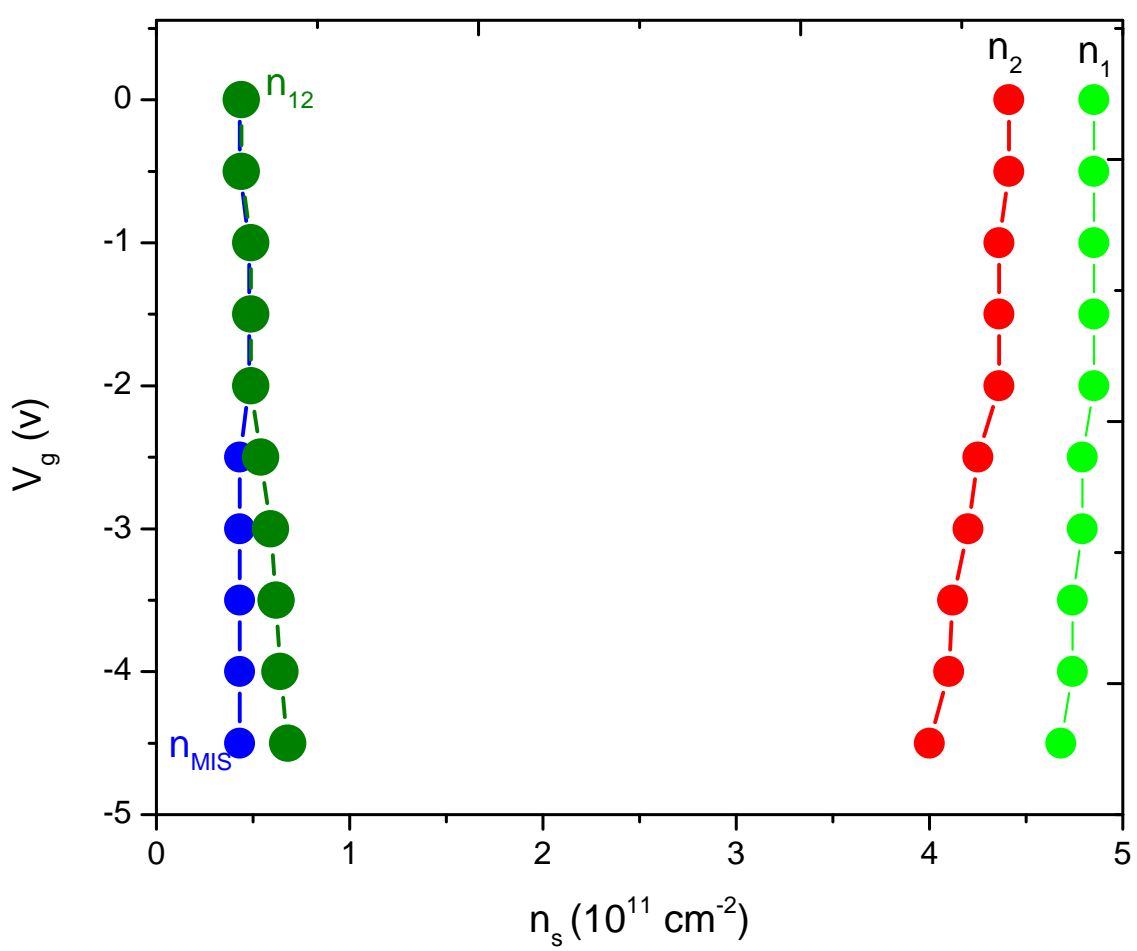

Figura 4.4: Densidades eletrônicas da primeira $n_{1}$ e da segunda $n_{2}$ sub-banda. Também mostrase $n_{M I S}$ que é a freqüência MIS e a diferença entre as densidades das sub-bandas $n_{12}=n_{1}-n_{2}$.

A figura 4.4 mostra as densidades das sub-bandas $n_{1}$ e $n_{2}$ obtidas a partir dos dados obtidos da figura 4.3. Também são apresentadas as quantidades $n_{12}$ que é a diferença entre as densidades $n_{1}$ e $n_{2}$. $n_{M I S}$ é uma quantidade associada à frequência das oscilações MIS. Pode-se observar que para cada voltagem de porta, a densidade eletrônica é quase diferente em cada sub-banda. Isto é devido que as densidades nas sub-bandas dependem da voltagem de porta. A voltagens de porta, $V_{g}$, fazem mudar as densidades das sub-bandas, fazendo-as diminuir conforme aumentamos em magnitude a voltagens de porta. $\mathrm{O}$ valor da frequência MIS, $f_{M I S}$, permanece quase constante dentro dos valores de voltagens de porta medidos, o que indica a simetria do sistema, onde o sistema consiste de um poço quântico largo que é dividido em duas camadas eletrônicas separadas no espaço, devido ao campo elétrico auto-consistente surgido pela presença dos elétrons, criando uma estrutura de bicamadas com uma barreira de potencial auto-consistente. A simetria é uma condição importante para poder observar as oscilações MIS nas oscilações de magnetoresistência, de modo que se a simetria do sistema é alta, maior é a probabilidade de transição intersub-banda. 


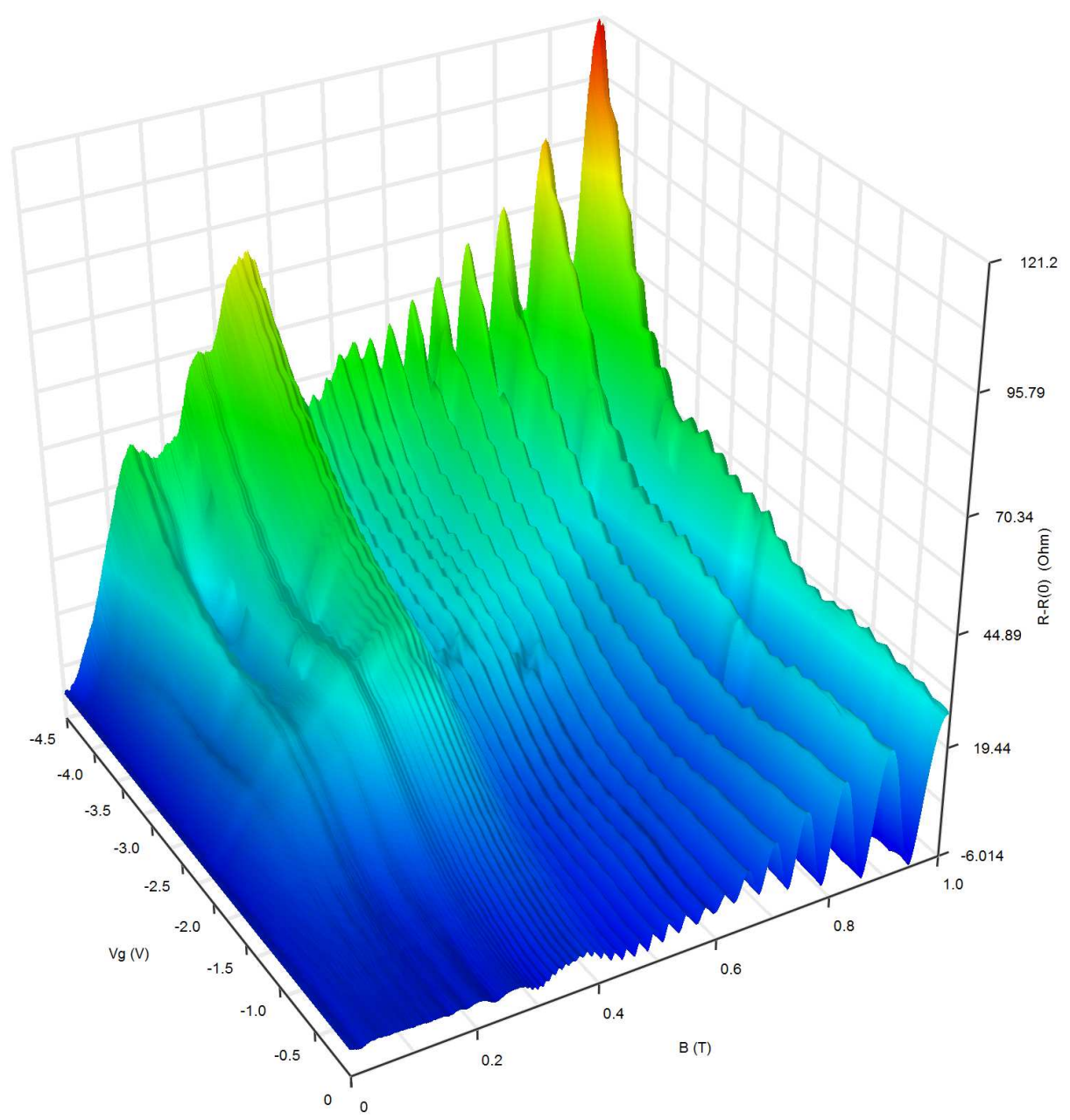

Figura 4.5: Gráfica 3D onde o eixo $X$ indica o campo magnético, o eixo $Y$ indica a voltagem de porta e o eixo $Z$ indica as medidas da diferença $R_{x x}-R_{x x}(0)$ na magnetoresistência. Se observa que quando a voltagem de porta torna-se mais negativo, as oscilações devido al potencial dos antipontos tornam-se mais importantes.

A figura 4.5 mostra uma gráfica 3D da magnetoresistência $R_{x x}$ em função do campo magnético $B$ e da voltagem de porta $V_{g}$, onde o eixo $X$ indica o campo magnético, o eixo $Y$ indica a voltagem de porta e o eixo $Z$ indica as medidas da diferença $R_{x x}-$ $R_{x x}(0)$ na magnetoresistência. Observa-se que a partir de certa voltagem de porta $\left(V_{g} \approx\right.$ $-2.3 \mathrm{~V})$, três picos são relevantes no gráfico para valores de voltagens de porta desde $-4.5 \mathrm{~V}$ até $-2.3 \mathrm{~V}$, e que para as voltagens de porta de $-2.3 \mathrm{~V}$ até $0 \mathrm{~V}$ observa-se que as oscilações MIS predominam. Os três máximos pronunciados que podem-se distinguir entre as voltagens de porta de $-4.5 \mathrm{~V}$ até $-2.3 \mathrm{~V}$, são os picos de comensurabilidade que ocorrem na magnetoresistência quando o diâmetro do cíclotron clássico é comparado com o período da rede de antipontos. 


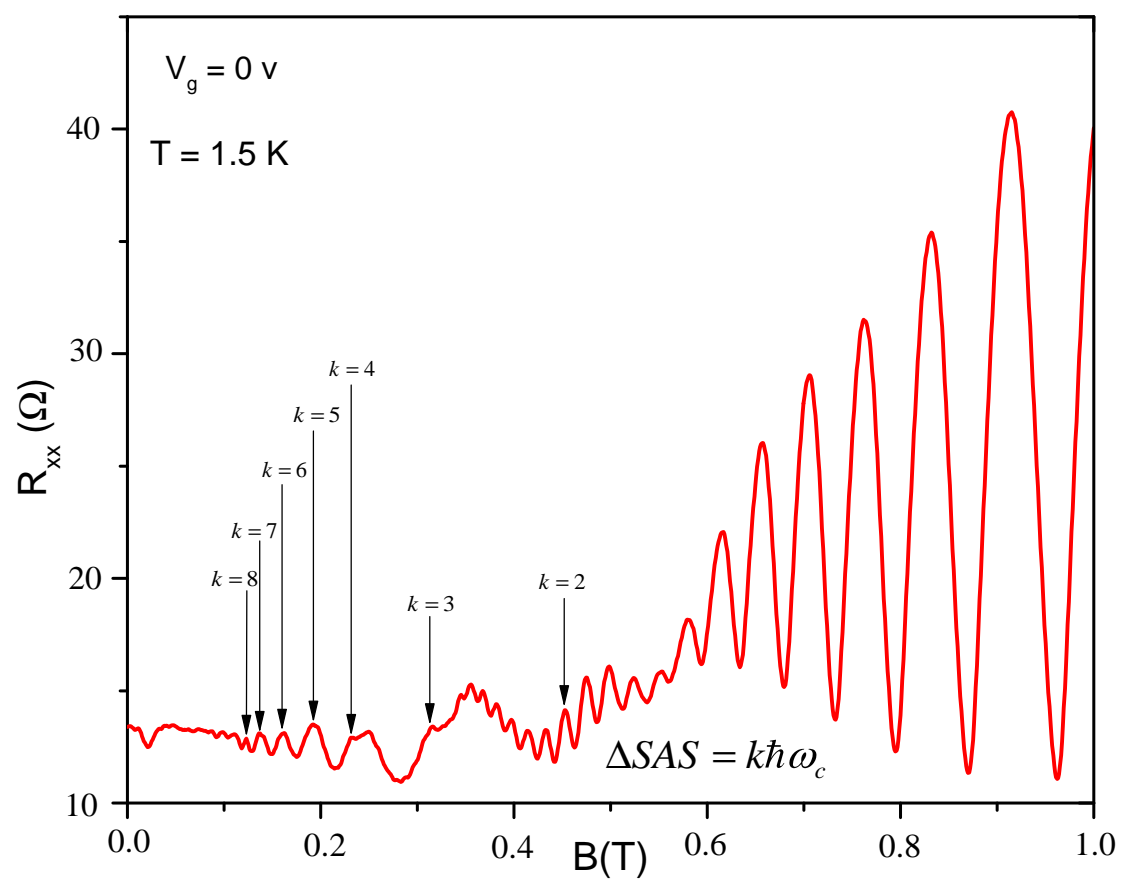

Figura 4.6: Oscilaçôes MIS, $k$ indica os picos correspondentes à condição de ressonância. A curva foi obtida para uma voltagem de porta de $V_{g}=0 \mathrm{~V}$ a $\mathrm{T}=1.5 \mathrm{~K}$.

Foi medida a magnetoresistência para uma voltagem de porta $V_{g}=0 \mathrm{~V}$ a baixos campos magnéticos e a temperatura $T=1.5 \mathrm{~K}$, como se mostra na figura 4.6. Esta figura mostra que as oscilações MIS predominam a para este valor do voltagem de porta, onde os valores de $k$ indicam os picos correspondentes à condição de ressonância. A densidade eletrônica de cada uma das sub-bandas para a voltagem de porta $V_{g}=0 \mathrm{~V}$ é $n_{1}=4,87 \times 10^{11} \mathrm{~cm}^{-2}$ e $n_{1}=4,43 \times 10^{11} \mathrm{~cm}^{-2}$. O valor da energia de Fermi para cada sub-banda é $E_{F 1}=$ $17,4 \mathrm{meV}$ e $E_{F 2}=15,8 \mathrm{meV}$, e o valor de energia de desdobramento entre as sub-bandas é: $\triangle S A S=1.6 m e V$. Nesta gráfica observa-se que os picos para valores de $k>3$ são livres das oscilações SdH, mas para o pico das oscilações MIS com $k=2$ esta modulado pelas oscilações SdH.

A figura 4.7 mostra as oscilações MIS na magnetoresistência para voltagens de porta de $-1,0 \mathrm{~V}$ e $-1,5 \mathrm{~V}$ a campos magnéticos baixos. Assim como a magnitude da voltagem de porta aumenta, observa-se como muda a magnetoresistência e o valor do pico com $k=3$ na figura 4.7 (b) torna-se mais grande que o mostrado na figura 4.7(a) e também é possível ver que os picos desde $k=4$ até $k=5$ vai formar um pico de comensurabilidade como pode se ver na figura 4.5 , assim como os picos desde $k=6$ até $k=8$ formaram outro pico de comensurabilidade, porque os pico das oscilações MIS com aqueles valores 


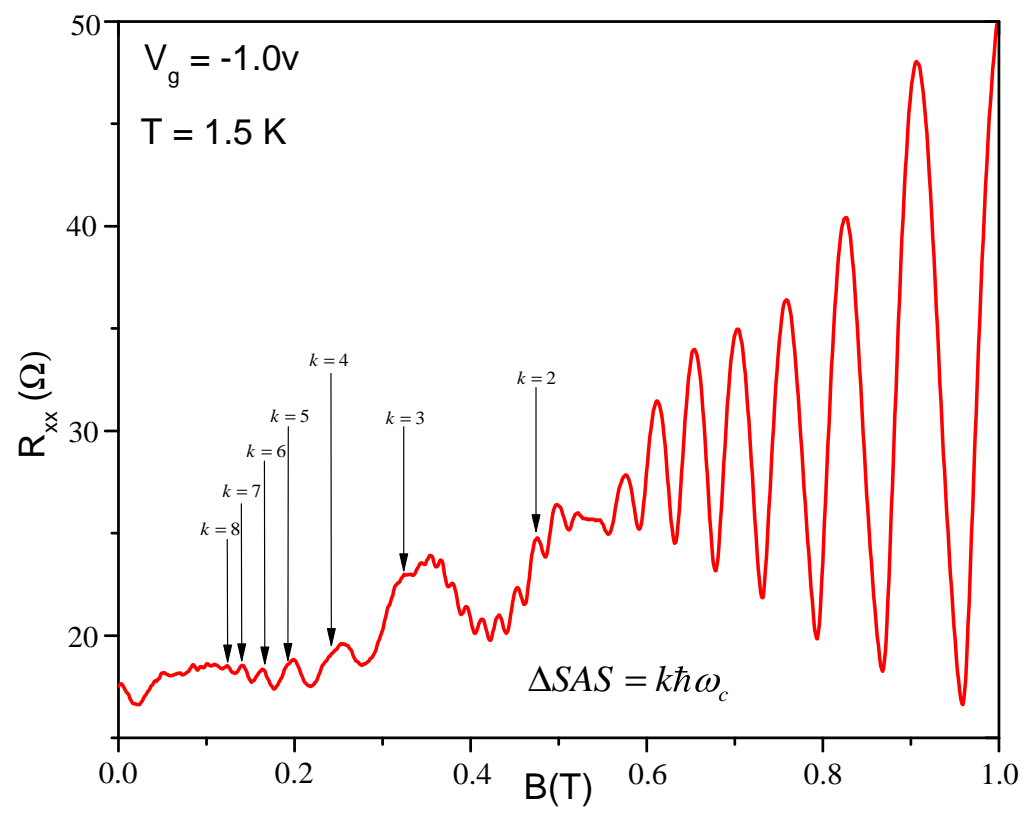

(a)

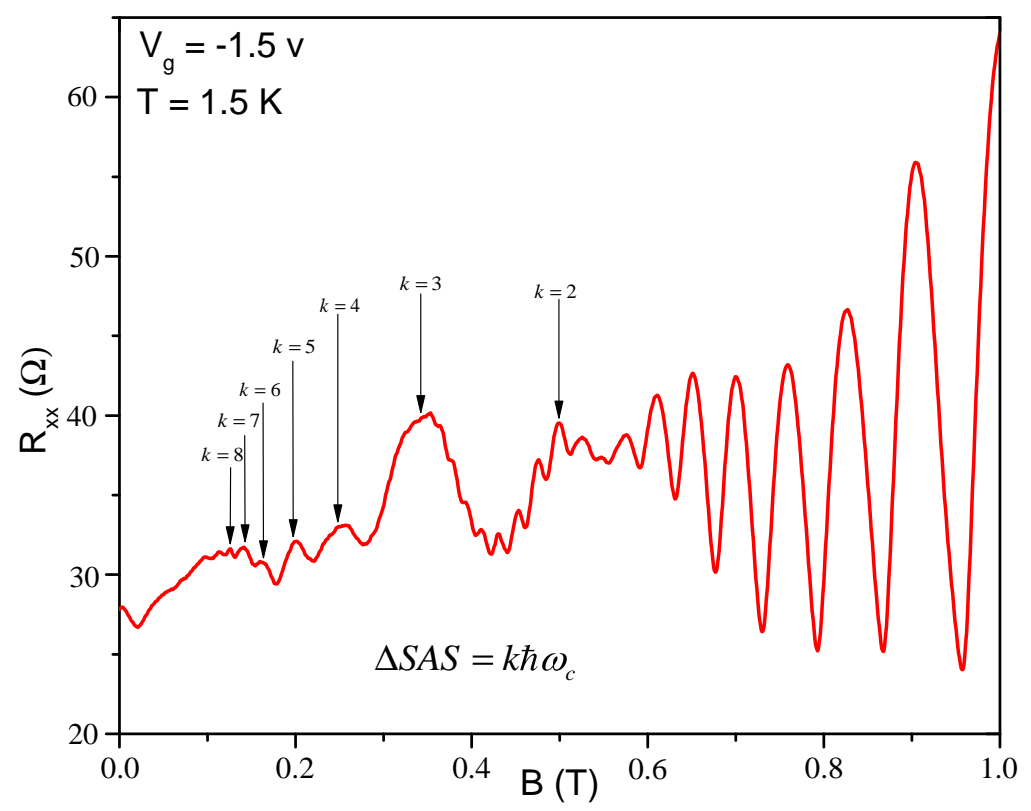

(b)

Figura 4.7: Oscilaçôes MIS para voltagens de porta de (a) $-1.0 \mathrm{~V}$ e de (b) $-1.5 \mathrm{~V}$. $k$ indica os picos que correspondem às condiçôes de ressonância. 
de $k$ vai fazer substituídos pelas oscilações devido ao potencial periódico dos antipontos, como pode-se ver na figura $4.7(\mathrm{a})$.

A magnetoresistência apresenta três picos de comensurabilidade, como mostra-se na figura 4.8. Existem dois modelos que explicam os máximos na magnetoresistência, um deles esta baseada em 2DES de baixa mobilidade com modulações bidimensionais (Fleischmann et al. , 1992; Weiss et al., 1991), onde os picos de comensurabilidade na magnetoresistência são causadas pelas órbitas presas (pinned orbit). O modelo de órbitas presas diz que quando o diâmetro das órbitas ciclotrônicas é comensurável com o período da rede de antipontos, as órbitas serão presas em torno dos antipontos, e não responderão a os campos elétricos, assim que o elétron não terá contribuição com a condutância, mas teremos um aumento na magnetoresistência. O outro modelo esta baseado num 2DES de alta mobilidade (Ando , 1998; Baskin et al., 1992; Gusev et al., 1997; Ishizaka e Ando, 1997b; Ishizaka et al. , 1995), onde as órbitas fugitivas (runaway orbits) dos elétrons deslocalizados contribuem para as oscilações. Quando a condição de comensurabilidade entre o diâmetro das órbitas ciclotrônicas e o período da rede dos antipontos é satisfeita, as órbitas experimentaram muitos espalhamentos, assim que eles estarão pulando ao longo da rede de antipontos, ou seja, estarão pulando de um antiponto ao seu antiponto vizinho, o qual é responsável dos máximos na magnetoresistência assim como na condutância. Dentro da figura 4.8 mostra-se órbitas comensuráveis as quais estão associadas com os picos de comensurabilidade resolvidos na magnetoresistência. Estas órbitas são etiquetadas com os números 1, 2, 3, 5, 6 em nosso sistema de alta mobilidade que tem duas sub-bandas preenchidas, onde cada super-índice indica se a órbita corresponde a primeira (1) ou a segunda (2) subbanda. Os picos de comensurabilidade resolvidos na magnetoresistência ocorrem quando o rádio do cíclotron $R_{c}$ torna-se comensurável com o período $a$ da rede de antipontos, ou seja, cumpre a condição:

$$
2 R_{c}=\gamma a
$$

onde $\gamma$ é uma constante que depende da geometria da rede de antipontos, e $R_{c}=$ $\hbar \sqrt{2 \pi n_{i}} / e B$, onde $n_{i}$ é a densidade de cada sub-banda $(i=1,2)$. A tabela 4.1 mostra a razão $R_{c} / a$

Num arranjo de antipontos, a origem dos picos de comensurabilidade dependem fortemente da razão entre o rádio do cíclotron e o período da rede de antipontos. Para cada valor de de $R_{c} /$ a corresponde a uma órbita de comensurabilidade, a qual rodeia um número fixo de antipontos, como se mostra na tabela 4.1. Para tracejar as órbitas de comensurabilidade, é necessário ter em conta que devido ao esgotamento lateral do 2DEG em torno dos antipontos, o diâmetro eletrônico do antiponto sera maior que 


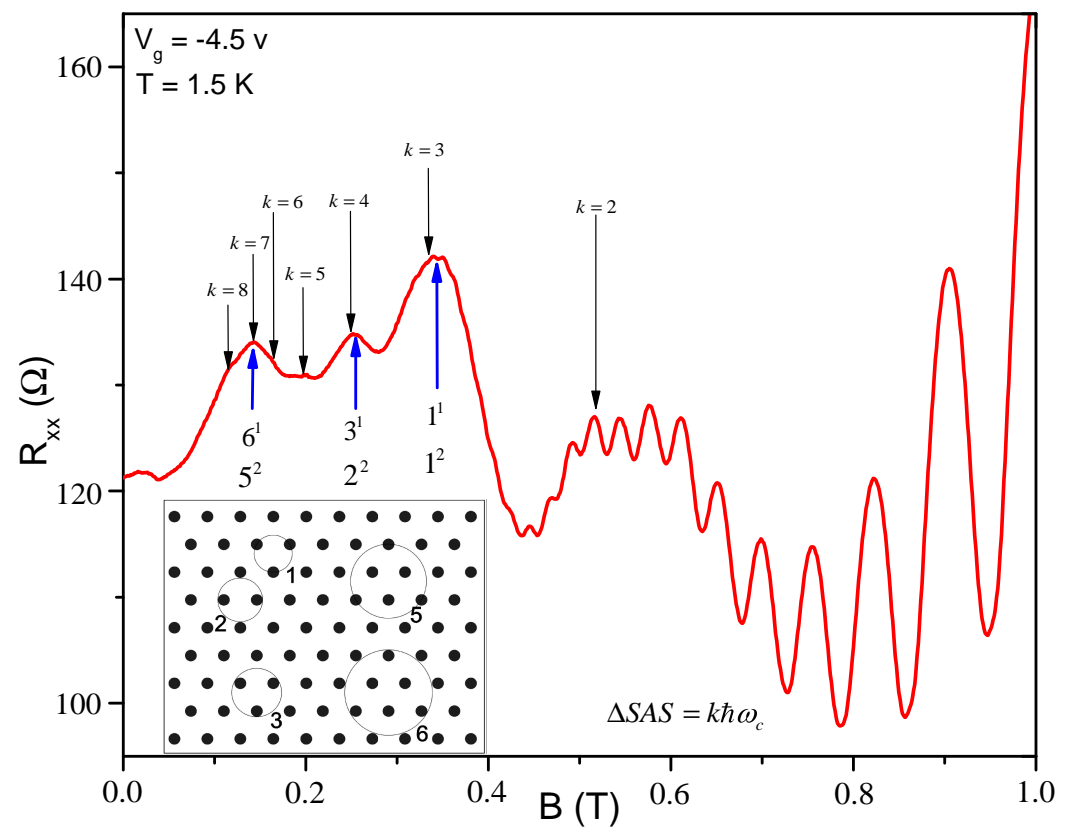

Figura 4.8: Picos de comensurabilidade na magnetoresistência a baixos campos magnéticos e uma voltagens de porta de $-4.5 \mathrm{~V}$ num sistema de bicamadas com uma rede de antipontos triangulares a temperatura $T=1.5 \mathrm{~K}$. Os picos de magnetoresistência + mostrados são $2,3,5$, e 6 e os super-indices indicam se pertencem a primeira o a segunda sub-banda.

o seu diâmetro litográfico. O diâmetro eletrônico pode ser achada das oscilações SdH observadas e obter o comprimento de onda de Fermi no arranjo de antipontos, que é diretamente proporcional ao diâmetro eletrônico. O diâmetro eletrônico $d_{e}$ em nosso sistema é: $d_{e}=219 \mathrm{~nm}$. Um pico de comensurabilidade deve ocorrer para $R_{c} / a=0.5 \mathrm{em}$ uma rede de antipontos triangular segundo a referenda (Yamashiro et al., 1991), mas nosso sistema de bicamadas de alta mobilidade e nos temos que pico mais forte ocorrerá para $R_{c} \sim 0.53$ e 0.5 correspondentes à primeira e à segunda sub-banda respectivamente com uma voltagem de porta de $-4.5 \mathrm{~V}$. Observamos um pequeno aumento de $\sim 6 \%$ na razão de $R_{c} / a$ em nosso sistema, o que significa que os picos maiores na magnetoresistência não corespondem as órbitas presas (Yuan et al., 2006), estas correspondem a órbitas comensuráveis, que dinamicamente experimentam múltiplos espalhamentos, é por isso que a condutividade torna-se maior. O tensor de magnetocondutividade $\sigma_{x x}$ é deduzida dos tensores de magnetoresistência $\left(\sigma_{x x}=\rho_{x x} /\left(\rho_{x x}^{2}+\rho_{x y}^{2}\right)\right)$. No sistema estudado, os picos de comensurabilidade ocorrem quando $\rho_{x y} \gg \rho_{x x}$, e assim $\sigma_{x x}=\rho_{x x} /\left(\rho_{x x}^{2}+\rho_{x y}^{2}\right) \propto \rho_{x y}$, estes estados são responsáveis do máximo no coeficiente de difusão, e consequentemente um máximo na magnetoresistência (se cumpre que $\sigma_{x y}>\sigma_{x x}$ para os campos magnéticos em consideração, e um máximo em $\sigma_{x x}$ corresponde a um máximo em $\rho_{x x}$ ). Portanto, os rádios $R_{c}$ são espalhados sequencialmente por múltiplos antipontos. 


\begin{tabular}{|c|c|c|c|c|}
\hline \multirow{2}{*}{$\begin{array}{l}\text { Voltagem } \\
\text { de porta } \\
\mathrm{V}_{g}(\mathrm{~V})\end{array}$} & \multicolumn{2}{|c|}{ Primeira sub-banda } & \multicolumn{2}{|c|}{ Segunda sub-banda } \\
\hline & $\begin{array}{l}\text { Número de ór- } \\
\text { bita }\end{array}$ & $\frac{\mathbf{R}_{c}}{\mathbf{a}}$ & $\begin{array}{l}\text { Número de ór- } \\
\text { bita }\end{array}$ & $\frac{\mathbf{R}_{c}}{\mathbf{a}}$ \\
\hline \multirow{3}{*}{-4.5} & 1 & 0.54 & 1 & 0.50 \\
\hline & 3 & 0.73 & 2 & 0.68 \\
\hline & 6 & 1.29 & 5 & 1.20 \\
\hline \multirow{3}{*}{-4.0} & 1 & 0.53 & 1 & 0.50 \\
\hline & 3 & 0.73 & 2 & 0.69 \\
\hline & 6 & 1.30 & 5 & 1.21 \\
\hline \multirow{3}{*}{-3.5} & 1 & 0.53 & 1 & 0.50 \\
\hline & 3 & 0.75 & 2 & 0.70 \\
\hline & 6 & 1.30 & 5 & 1.21 \\
\hline \multirow{3}{*}{-3.0} & 1 & 0.53 & 1 & 0.50 \\
\hline & 3 & 0.74 & 2 & 0.70 \\
\hline & 6 & 1.25 & 5 & 1.17 \\
\hline \multirow{3}{*}{-2.5} & 1 & 0.53 & 1 & 0.50 \\
\hline & 3 & 0.73 & 2 & 0.69 \\
\hline & 6 & 1.28 & 5 & 1.21 \\
\hline
\end{tabular}

Tabela 4.1: Razão $R_{c} / a$ para cada uma das sub-bandas para diferentes voltagens de porta. $R_{c} e ́$ o rádio do cíclotron e "a"é o período da rede de antipontos.

A figura 4.9 mostra as oscilações de magnetoresistência para voltagens de porta (a) $-3.5 \mathrm{~V}$ e (b) $-4.0 \mathrm{~V}$, onde os picos de comensurabilidade são bem resolvidos. Ao aplicar a voltagem de porta, as densidades eletrônicas das duas sub-bandas devem mudar e variar a força da modulação do potencial periódico que age sobre os elétrons. Para altos voltagens de porta negativos, correspondem fortes repulsões dos elétrons sob os espaços vazios da amostra, ou seja, uma forte modulação de amplitude, e o aumento desta repulsão conduz a reduzir a densidade eletrônica (Steffens et al., 1998). Aumentado ainda mais em magnitude a voltagem de porta, a estrutura torna-se mais esgotada, fazendo que os rádios dos antipontos possam ser maiores que o seu tamanho geométrico na máscara fotoresistiva (Deruelle et al., 1994). O aumento de $V_{g}$ faz que aumente o comprimento de depleção dos antipontos, e portanto influi sobre os efeitos de comensurabilidade. Portanto, a mudança na energia de Fermi esta intimamente relacionada com uma mudança no potencial de modulação periódico dos antipontos e com a densidade eletrônica. Isto pode ser observado no deslocamento das oscilações $\mathrm{SdH}$, mas a figura 4.2 mostra somente um aumento na magnetoresistência quando diminuímos o valor da voltagem de gate $V_{g}$ e não mostra um deslocamento evidente das oscilações $\mathrm{SdH}$, e portanto a densidade eletrônica não muda. Ainda não temos uma relação teórica entre as oscilações MIS e as oscilações devido ao potencial periódico da rede de antipontos, no qual podamos ver como influem na dinâmica dos elétrons,por isso, não é possível afirmar se a dinâmica dos elétrons são devido às órbitas presas ou fugitivas, ou devido a ambas. 


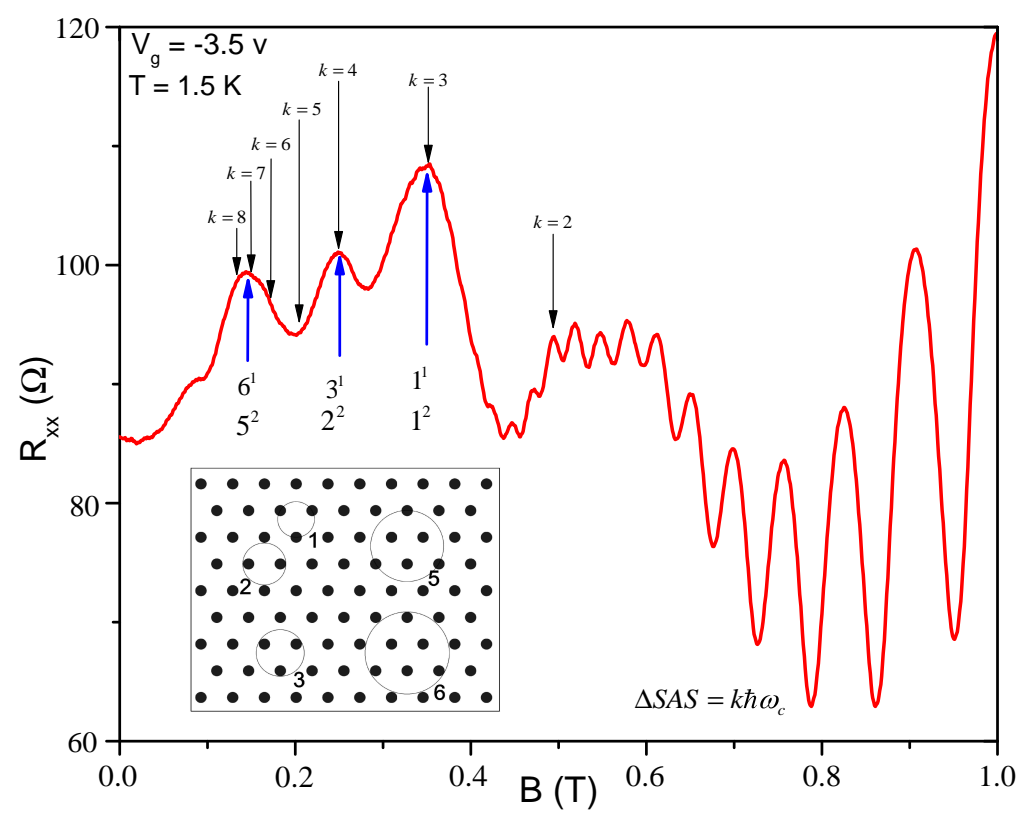

(a)

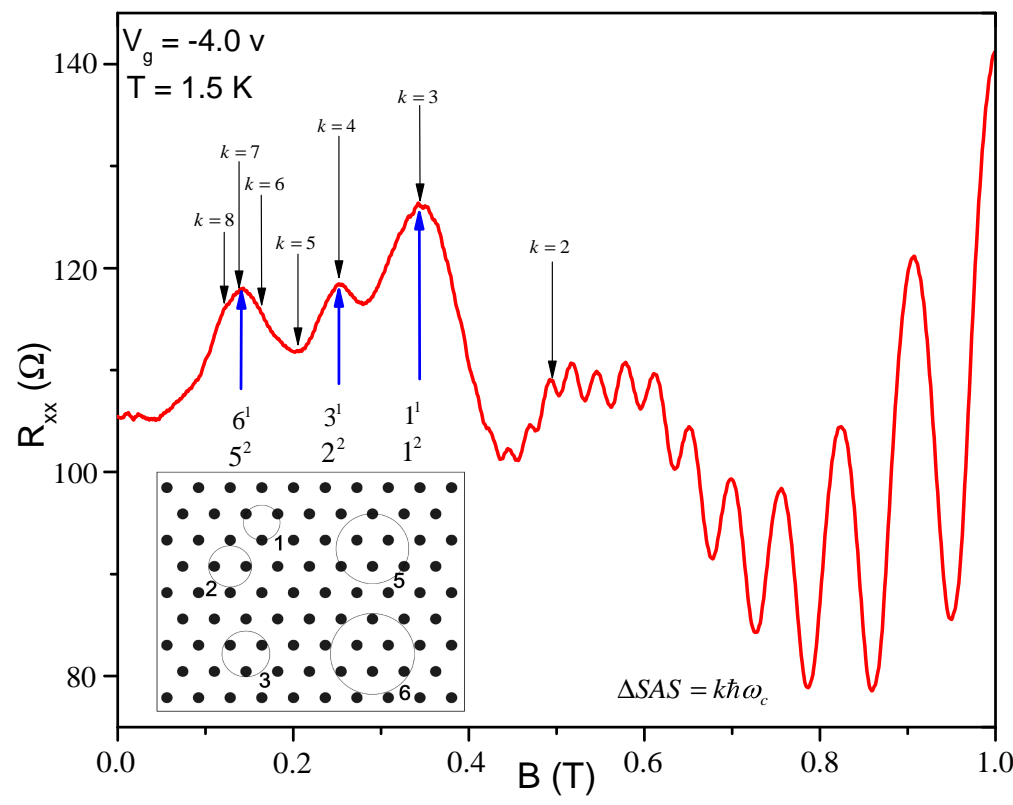

(b)

Figura 4.9: Picos de comensurabilidade da magnetoresistência a baixos campos magnéticos e uma voltagens de porta de (a) $-3,5 \mathrm{~V}$ e (b)-, $0 \mathrm{~V}$ num sistema de bicamadas com uma rede de antipontos triangulares a temperatura $T=1,5 \mathrm{~K}$. Os picos de magnetoresistência mostrados são 2, 3, 5, e 6 e os super-indices indicam se pertencem a primeira o a segunda sub-banda. 


\section{Capítulo 5}

\section{Conclusões}

Nesta tese, relatamos estudos experimentais sobre a magnetoresistência em sistemas de bicamadas de alta mobilidade com antipontos triangulares em um poço quântico largo (WQW). Neste sistema foram observadas experimentalmente as oscilações MIS e as oscilações devido ao potencial de modulação periódico da rede antipontos a baixos campos magnéticos, controladas por uma voltagem de porta aplicada sobre a superfície da amostra.

Foram analisados as oscilações de magnetoresistência a campos baixos $(<1 T)$ usando a transformada de Fourier (FFT), determinando as propriedades eletrônicas do sistema, tais como as densidades eletrônicas de cada sub-banda e a energia de desdobramento entre as mesma $\Delta_{S A S}$. Ao diminuir o valor da voltagem de porta, as amplitudes das oscilações MIS são amortecidas, porque a partir de certo valor de voltagem de porta $(\sim-2.3 \mathrm{~V})$, estas são substituídas pelas oscilações devido ao potencial de modulação periódico da rede de antipontos. Nosso sistema esta baseado em um poço quântico largo de alta mobilidade que forma uma configuração de bicamadas devido a redistribuição de cargas, as camadas próximas às interfaces são separadas por uma barreira de potencial eletrostática. Uma condição para que ocorram as oscilações MIS, é que dependem da simetria do poço; se a simetria do poço é alta, a probabilidade de transições inter-sub-banda é maior e temos um máximo nas oscilações que correspondente à condição quando a energia de desdobramento entre as sub-bandas $\left(\Delta_{S A S}\right)$ é um múltiplo inteiro da energia do cíclotron $\hbar \omega_{c}$.

Nas oscilações devido ao potencial periódico da rede antipontos, os picos de comensurabilidade observados na magnetoresistência dependem da contribuição de cada subbanda, devido a que os rádios das órbitas ciclotrônicas dependem das densidades de cada sub-banda. Aplicando um voltagens de porta muda também a amplitude do potencial periódico da rede de antipontos. 


\subsection{Sugestões para Pesquisas Futuras}

O próximo trabalho a realizar é uma pesquisa experimental e teórica conjunta dos fenômenos de magnetotransporte em poços quânticos duplos e largos contendo uma super-rede de antipontos, para adquirir um novo conhecimento acerca do grau de liberdade quântico devido ao acoplamento de tunelamento nos fenômenos mesoscópicos de magnetotransporte. O plano para próxima pesquisa é fazer um estudo sistemático de transporte em presença de campos magnéticos perpendiculares e paralelos, a aplicação de campos elétricos fracos e fortes, e a radiação de microondas. 


\section{Referências Bibliográficas}

Adachi (1985) S. Adachi. J. Appl. Phys., 58:1058. Citado na pág. 5

Ahlswede (2002) E. Ahlswede. Tese de Doutorado, Max-Planck-Institute, Stuttgart. Citado na pág. 25

Ahoujja et al. (1997) M. Ahoujja, S. Elhamri, R. S. Newrock, D. B. Mast, W. C. Mitchel, I. Lo e A. Faithmullan. J. Appl. Phys., 81:1609. Citado na pág. 19

Altshuler et al. (1981) B. L. Altshuler, A.G. Aronov e B.Z. Spivak. JETP Lett., 33:94. Citado na pág. xvi, $51,52,53$

Ando (1991) T. Ando. Phys. Rev. B, 44:8017. Citado na pág. 51

Ando (1998) T. Ando. Mesoscopic physics and electronic. Springer-Verlag,Berlin. Citado na pág. 79

Ando et al. (1982) T. Ando, A. Fowler e F. Stern. Rev. Mod. Phys., 54:437. Citado na pág. 21

Ando et al. (1997) T. Ando, S. Uryu, S. Ishizaka e T. Nakanishi. Chaos,Solitons \& Fractals, 8:1057. Citado na pág. xv, xvi, 42, 43, 44, 45, 46, 47, 49, 50

Armas (2009) Luis Enrique Gómez Armas. Magnetotransporte em poços-quânticos dupolos e triplos com diferentes valores do fator g de Landé. Tese de Doutorado, Universidade de São Paulo. Citado na pág. 73

Bachmair et al. (2003) H. Bachmair, E. Göbel, G. Hein, J. Melcher, B. Schumacher, J. Schurr, L. Schweitzer e P. Warnecke. Physica E, 20:14. Citado na pág. 20

Baskin et al. (1992) E. M. Baskin, G. M. Gusev, Z. D. Kvon, A. G. Pogosov e M. V. Entin. JETP Lett., 55:678. Citado na pág. 42, 79

Blanchet (1994) J. Blanchet. Transport balistique et effects quantiques dans des nanostructures unidimensionnelles de semi-conducteurs. Tese de Doutorado, Universités Paris-Sud. Citado na pág. 60

Boebinger et al. (1991) G. S. Boebinger, A. Passner, L. N. Pfeiffer e K. W. West. Phys. Rev. B, 43:12 673. Citado na pág. 73

Bosio et al. (1988) C. Bosio, J. L. Staehli, M. Guszzi, G. Burri e R. A. Logan. Phys. Rev. B, 38:3263. Citado na pág. 5

Büttiker (1988) M. Büttiker. Phys. Rev. B, 38:9375. Citado na pág. 24 
Chakraborty e Pietiläinen (1995) T. Chakraborty e P. Pietiläinen. The Quantum Hall Effects: Integral and Fractional. Springer-Verlag, Berlin, 2nd ed. ed. Citado na pág. 21

Chklovskii et al. (1992) D. Chklovskii, B. Shklovskii e L. Glazman. Phys. Rev. B, 46: 4026. Citado na pág. 25

Choque (2002) Nilo Mauricio Sotomayor Choque. Estudo da dinâmica de caos no gás tridimensional de elétrons de alta mobilidade. Tese de Doutorado, Universidade de São Paulo. Citado na pág. 56

Coleridge (1990) P. T. Coleridge. Semicond. Sci. Technol., 5:961. Citado na pág. 32, 33

Debbar e et al. (1989) N. Debbar e et al. Phys. Rev. B, 40:1058. Citado na pág. 5

Deruelle et al. (1994) T. Deruelle, B. Meurer, Y. Guldner, J. P. Vieren, M. Rick, D. Weiss, K. von Klitzing, K. Eberl e K. Ploog. Phys. Rev. B, 49:16 561. Citado na pág. 81

Dingle et al. (1974) R. Dingle, W. Wiegmann e C. H. Henry. Phys. Rev. Lett., 33:827. Citado na pág. 5

Dolan et al. (1986) G.J. Dolan, J.C. Licini e D.J. Bishop. Phys. Rev. Lett., 54:1493. Citado na pág. 51

Ensslin e Petroff (1990) K. Ensslin e P. M. Petroff. Phys. Rev. B, 41:12307. Citado na pág. 37

Esaki e Tsu (1970) L. Esaki e R. Tsu. IBM J. Res. Dev., 14:61. Citado na pág. 2

Ezawa (2000) Z.F. Ezawa. Quantum Hall Effects - Field Theoretical Approach and Related Topics. World Scientific Singapore. Citado na pág. 30

Ferry e Goodnick (1997) David K. Ferry e Stephen M. Goodnick. Transport in Nanostructures. Cambridge University Press, first ed. Citado na pág. 7

Fleischmann et al. (1992) R. Fleischmann, T. Geisel e R. Ketzmerick. Phys. Rev. Lett., 68:1367. Citado na pág. 79

Fleischmann et al. (1994) R. Fleischmann, T. Geisel e R. Ketzmerick. Europhys. Lett., 25:219. Citado na pág. 37

Fletcher et al. (1990) R. Fletcher, E. Zaremba, M. D'Iorio, C. T. Foxon e J. J. Harris. Phys. Rev. B, 41:10649. Citado na pág. 27

Fletcher et al. (2005) R. Fletcher, M. Tsaousidou, T. Smith, P. T. Coleridge, Z. R. Wasilewski e Y. Feng. Phys. Rev. B, 71:155310. Citado na pág. 73

Galperins (2009) Yuri M. Galperins. Introduction to Modern Solid State Physics. Citado na pág. xiv, 11,14

Grosso e Parravicini (2003) Giuseppe Grosso e Giuseppe Pastori Parravicini. Solid State Physics. Academic Press. Citado na pág. 15

Gusev et al. (1991) G. M. Gusev, V. T. Dolgopolov, Z. D. Kvon, A. A. Shashkin, V. M. Kudryashov, L. V. Litvin e Yu. V. Nastaushev. JETP Lett., 54:364. Citado na pág. 38 
Gusev et al. (1992a) G. M. Gusev, Z. D. Kvon, L. V. Litvin, Yu. V. Nastushev, A. K. Kalagin e A. I. Toropov. J. Phys. Condens. Matter, 4:L269. Citado na pág. 38

Gusev et al. (1992b) G. M. Gusev, Z. D. Kvon, L. V. Litvin, Yu. V. Nataushev, A. K. Kalagin e A. I. Toropov. JETP Lett., 56:170. Citado na pág. xxii, 38

Gusev et al. (1993) G. M. Gusev, P. Basmaji, D. I. Lubyshev, L. V. Litvin, Yu. V. Nastaushev e V. V. Preobrazhenskii. Phys. Rev. B, 47:9928. Citado na pág. xxii

Gusev et al. (1997) G. M. Gusev, Z. D. Kvon, A. G. Pogosov e M. M. Voronin. JETP Lett., 65:248. Citado na pág. 79

Gusev et al. (1994) G.M. Gusev, P. Basmaji, Z.D. Kvon, L.V. Litvin, Yu.V. Nastaushev e A.I. Toropov. J. Phys., Condens. Matter, 6:73. Citado na pág. 51

Gusev et al. (1992c) M. Gusev, Z. D. Kvon, L. V. Litvin, Yu. V. Nastausshev, A. K. Kalagin e A. I. Toropov. JETP Lett., 55:123. Citado na pág. 38, 51

Halperin (1982) B. Halperin. Phys. Rev. B, 25:2185. Citado na pág. 24

Hamaguchi (2010) Chihiro Hamaguchi. Basic Semiconductor Physics. Springer, second ed. Citado na pág. 4, 10

Harris et al. (1987) J. J. Harris, D. E. Lacklinson, C.T. Foxon, F. M. Selten, A. M. Suckling, R. J. Nicholas e K. W. J. Barnham. Semicond. Sci. Technol., 2:783. Citado na pág. 32

Haug et al. (1988) R.J. Haug, A.H. MacDonald, P. Streda e K. von Klitzing. Phys. Rev. Lett., 61:2797. Citado na pág. 25

Heller (1984) E. Heller. Phys. Rev. Lett., 53:1515. Citado na pág. 37

Ishizaka e Ando (1997a) S. Ishizaka e T. Ando. Phys. Rev. B, 55:16331. Citado na pág. xvi, $43,46,48$

Ishizaka e Ando (1998) S. Ishizaka e T. Ando. Solid State Electron., 42:1147. Citado na pág. 48

Ishizaka e Ando (1997b) S. Ishizaka e T. Ando. Phys. Rev. B, 56:15195. Citado na pág. 43,79

Ishizaka et al. (1995) S. Ishizaka, F. Nihey, K Nakamura, J. Sone e T. Ando. Phys. Rev. B, 51:9881. Citado na pág. 43, 79

Isihara e Smrc?ka (1986) A. Isihara e L. Smrc?ka. J. Phys. C, 19:6777. Citado na pág. 32

Janßen et al. (1994) M. Janßen, O. Viehweger, U. Fastenrath e J. Hajdu. Introduction to the Theory of the Integer Quantum Hall Effect. VCH, Weinheim Heidelberg. Citado na pág. 21

Katayama et al. (1995) Y. Katayama, D. C. Tsui, H. C. Manoharan, S. Parihar e M. Shayegan. Phys. Rev. B, 52:14 817. Citado na pág. 73

Kroemer et al. (1980) H. Kroemer, Wu-Yi Chien, J. S. Harris e D. D. Edwall. Appl. Phys. Lett., 33:295. Citado na pág. 5 
Kubo et al. (1965) R. Kubo, S.J. Miyake e Vol. 17 N. Hashitsume. Solid State Physics. New York: Academic Press. Citado na pág. 43, 44

L. et al. (1982) Störmer H. L., Gossard A. C. e Wiegmann W. Solid State Commun., 41:707. Citado na pág. 27, 32

Leadley et al. (1992) D. R. Leadley, R. Fletcher, R. J. Nicholas, F. Tao, C. T. Foxon e J. J. Harris. Phys. Rev. B, 46:12 439. Citado na pág. 32, 33, 34

llani et al. (2004) S. llani, J. Martina, E. Teitelbaum, J.H. Smet, D. Mahalu, V. Umansky e A. Yacoby. Nature (London), 427:328. Citado na pág. 25

Lorke et al. (1991) A. Lorke, J. P. Kotthaus e K. Ploog. Superlattices Microstuct., 9: 103. Citado na pág. 38

Lundstrom (2000) Mark Lundstrom. Fundamental and Carrier Transport. Cambridge University Press. Citado na pág. 10

Mamani et al. (2008) N. C. Mamani, G. M. Gusev, T. E. Lamas, A. K. Bakarov e O. E. Raichev. Phys. Rev. B, 77:205327. Citado na pág. 35, 72

Mamani et al. (2009) N. C. Mamani, G. M. Gusev, E. C. F. da Silva, O. E. Raichev, A. A. Quivy e A. K. Bakarov. Phys. Rev. B, 80:085304. Citado na pág. 73

Mamani (2009) Niko Churata Mamani. Magnetotransporte em Poços Quânticos de AlGaAs/GaAs com diferentes formas de potencial. Tese de Doutorado, Universidade de São Paulo. Citado na pág. 35

Müller (1992) G. Müller. Tese de Doutorado, Max-Planck-Institute, Stuttgart. Citado na pág. 25

Müller et al. (1990) G. Müller, D. Weiss, S. Koch, K. von Klitzing, H. Nickel, W. Schlapp e R. Lösch. Phys. Rev. B, 42:7633. Citado na pág. 25

Müller et al. (1992) G. Müller, D. Weiss, A.V. Khaetskii, K. von Klitzing, S. Koch, H. Nickel, W. Schlapp e R. Lösch. Phys. Rev. B, 45:3932. Citado na pág. 25

Nakamura et al. (1994) K. Nakamura, S. Ishizaka e F. Nihey. Physica B, 197:144. Citado na pág. 51,53

Nakanishi e Ando (1996a) T. Nakanishi e T. Ando. Phys. Rev. B, 54:8021. Citado na pág. xvi, 51, 52, 53

Nakanishi e Ando (1996b) T. Nakanishi e T. Ando. Physica B, 227:127. Citado na pág. 51

Nihey et al. (1995) F. Nihey, S. W. Hwang e K. Nakamura. Phys. Rev. B, 51:4649. Citado na pág. xvi, $38,51,52,53$

Patterson e Bailey (2007) James D. Patterson e Bernard C. Bailey. Solid State. Springer. Citado na pág. 16

Prange (1981) R. E. Prange. Phys. Rev. B, 23:4802. Citado na pág. 21 
Raikh e Shahbazyan (1993) M. E. Raikh e T. V. Shahbazyan. Phys. Rev. B, 47:1522. Citado na pág. 18

Raikh e Shahbazyan (1994) M. E. Raikh e T. V. Shahbazyan. Phys. Rev. B, 49:5531. Citado na pág. $32,33,75$

Sander et al. (1996) T. H. Sander, S. N. Holmes, J. J. Harris, D. K. Maude e J. C. Portal. Surf. Sci., 361/362:564. Citado na pág. 32

Sander et al. (1998) T. H. Sander, S. N. Holmes, J. J. Harris, D. K. Maude e J. C. Protal. Phys. Rev. B, 58:13856. Citado na pág. 33, 73

Sarma e Pinczuk (1996) S. Das Sarma e A. Pinczuk. Perspectives on Quantum Hall Effects. Wiley, New York. Citado na pág. 21

Schuster et al. (1993) R. Schuster, K. Ensslin, J. P. Kotthaus, M. Hollland e C. Stanley. Phys. Rev. B, 47:6843. Citado na pág. xxii, 38

Schuster et al. (1994a) R. Schuster, K. Ensslin, D. Wharam, S. Kühn, J.P. Kotthaus, W. Klein G. Bühm, G. Tränkle e G. Weimann. Phys. Rev. B, 49:8510. Citado na pág. 38

Schuster et al. (1994b) R. Schuster, G. Ernst, K. Ensslin, M. Entin, M. Holland, G. Böhm e W. Klein. Phys. Rev. B, 50:8090. Citado na pág. 43

Sharvin e Sharvin (1981) D.Yu. Sharvin e Yu.V. Sharvin. JETP Lett., 34:272. Citado na pág. 51

Shubnikov e de Haas (1930) L. Shubnikov e W. J. de Haas. Leiden Commun., 207:3. Citado na pág. 17

Siddiki e Gerhardts (2003) A. Siddiki e R.R. Gerhardts. Phys. Rev. B, 68:125315. Citado na pág. 25

Simmons et al. (1994) J.A. Simmons, S.K. Lyo, N. E. Harff e J.F. Klem. Phys. Rev. Lett., 73:2256. Citado na pág. 73

Sinai e Chernov (1987) Y. G. Sinai e Nni Chernov. Russian Mayhematical Surveys, 42:181. Citado na pág. 37

Smith et al. (1988) T. P. Smith, F. F. Fang, U. Meirav e M. Heiblum. Phys. Rev. B, 38:12744. Citado na pág. 27

Steffens et al. (1998) O. Steffens, T. Schlosser, P. Rotter, K. Ensslinx, M. Suhrke, J. P. Kotthausz, U. Rossler e M. Hollandk. J. Phys.: Condens. Matter, 10:3859. Citado na pág. 81

Taylor (1989) B. N. Taylor. IEEE Trans. Instrum. Meas., 38:164. Citado na pág. 20

Tsui et al. (1982) D. C. Tsui, B. Meurer, H. L. Stormer e A. C. Gossard. Phys. Rev. Lett., 49:1559. Citado na pág. xxi

Tsukagoshi et al. (1996a) K. Tsukagoshi, M. Haraguchi, S. Takaoka e K. Murase. J. Phys. Soc. Jpn., 65:811. Citado na pág. 42 
Tsukagoshi et al. (1996b) K. Tsukagoshi, T. Nagao, M. Haraguchi, S. Takaoka, K. Murase e K. Gano. J. Phys. Soc. Jpn., 65:1914. Citado na pág. 43

v. Klitzing (1986) K. v. Klitzing. Rev. Mod. Phys., 58:519. Citado na pág. 20

v. Klitzing et al. (1980) K. v. Klitzing, G. Dorda e M. Pepper. Phys. Rev. Lett., 45: 494. Citado na pág. xxi, 20

van Houten et al. (1988) H. van Houten, J. G. Williamson, M. E. I. Brooekaat, C. T. Foxon e J. J. Harris. Phys. Rev. B, 37:2756. Citado na pág. 27

van Wees et al. (1989) B.J. van Wees, and C.W.J. Beenakker E.M.M. Willems, and C.J.P.M. Harmans, H. van Houten, and C.T. Foxon J.G. Williamson e J.J. Harris. Phys. Rev. Lett., 62:1181. Citado na pág. 25

Washburn et al. (1988) S. Washburn, A.B. Fowler, H. Schmid e D. Kern. Phys. Rev. Lett., 61:2801. Citado na pág. 25

Weiss et al. (1991) D. Weiss, M. L. Roukes, A. Mensching, P. Grambow, K. von Klitzing e G. Weimann. Phys. Rev. Lett., 66:2790. Citado na pág. xv, xxii, 38, 40, 41, 42, 59, 79

Weiss et al. (1993) D. Weiss, K. Richter, A. Mensching, R. Bergmann, H. Schweizer, K. von Klitzing e G. Weimann. Phys. Rev. Lett., 70:4118. Citado na pág. 38

Wiedmann et al. (2011) S. Wiedmann, G. M. Gusev, O. E. Raichev, A. K. Bakarov e J. C. Portal. Journal of Physics: Conference Series, 334:012014. Citado na pág. 71

Willett et al. (1987) R. Willett, J. P. Eisenstein, H. L. St“ormer, D. C. Tsui, A. C. Gossard e J. H. English. Phys. Rev. Lett., 59:1776. Citado na pág. xv, 25, 27

Y. W. Suen (1991) et al. Y. W. Suen. Phys. Rev. B, 44:5947. Citado na pág. 28

Yamashiro et al. (1991) T. Yamashiro, J. Takahara, Y. Takagaki, K. Gamo, S. Namba, S. Takaoka e K. Murase. Solid State Commun., 79:885. Citado na pág. xxii, 38, 80

Yuan et al. (2006) Z. Q. Yuan, C. L. Yang, R. R. Du, L. N. Pfeiffer e K. W. West. Phys. Rev. B, 74:075313. Citado na pág. 80

Zaremba (1986) E. Zaremba. Phys. Rev. B, 45:14143. Citado na pág. 18 